US Army Corps of Engineers ${ }_{\circledast}$

Engineer Research and

Development Center

\title{
Hydraulic Modeling of Extreme Flows for the White Sands Missile Range Using Adaptive Hydraulics (AdH)
}

Gary L. Bell, Jeremy A. Sharp, James W. Lewis, Gaurav Savant,

December 2018 and Jennifer N. McAlpin

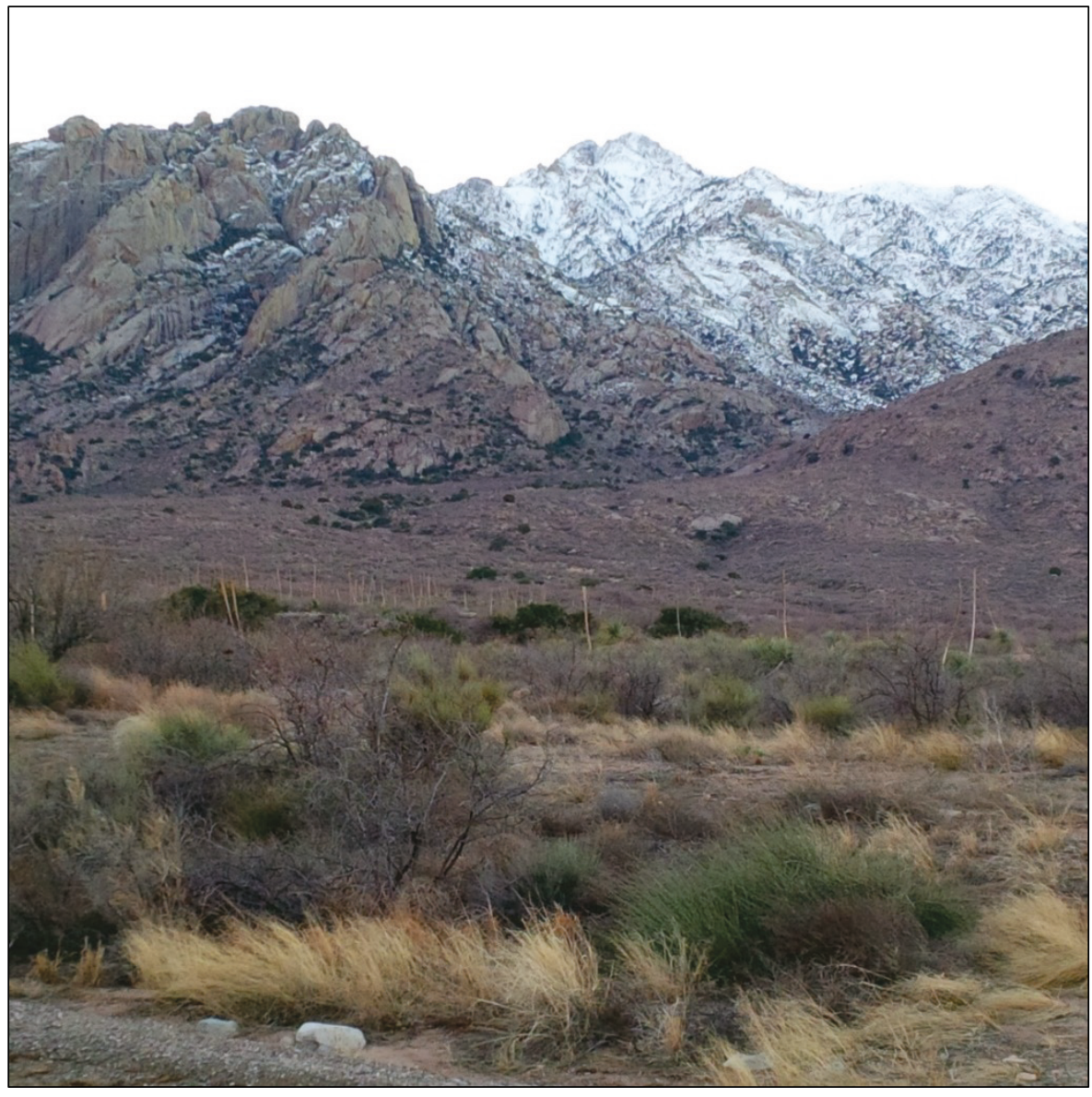


The U.S. Army Engineer Research and Development Center (ERDC) solves the nation's toughest engineering and environmental challenges. ERDC develops innovative solutions in civil and military engineering, geospatial sciences, water resources, and environmental sciences for the Army, the Department of Defense, civilian agencies, and our nation's public good. Find out more at www.erdc.usace.army.mil.

To search for other technical reports published by ERDC, visit the ERDC online library at http://acwc.sdp.sirsi.net/client/default. 


\section{Hydraulic Modeling of Extreme Flows for the White Sands Missile Range Using Adaptive Hydraulics (AdH)}

Gary L. Bell, Jeremy A. Sharp, James W. Lewis, Gaurav Savant, and Jennifer N. McAlpin

Coastal and Hydraulics Laboratory

U.S. Army Engineer Research and Development Center 3909 Halls Ferry Road

Vicksburg, MS 39180-6199

Final report

Approved for public release; distribution is unlimited.

Prepared for U.S. Army, White Sands Missile Range

White Sands, NM 88002-5070

Under Project No. 10754978, “White Sands Missile Range-A Storm Water Model” 


\section{Abstract}

The River Engineering Branch of the U.S. Army Engineer Research and Development Center, Coastal and Hydraulics Laboratory, conducted a two-dimensional numerical model investigation of the White Sands Missile Range located approximately 24.1 kilometers east of Las Cruces, NM. The range has experienced flooding within the installation during past large rainstorm events. The floodwater flowing easterly from the Organ Mountains overtops the levee that protects the installation for extreme events in some locations. The installation becomes more flooded with increasing values of storm return period (e.g., 100-year, 500-year). Plans consist of raising the levee elevation in critical locations as well as extending the levee in other areas. Numerical calculations indicated that raising the existing levee by approximately 0.5 meter and adding an extension on the northern portion of the installation as well as a standalone levee south of the installation eliminated flooding from 100-year events.

DISCLAIMER: The contents of this report are not to be used for advertising, publication, or promotional purposes. Citation of trade names does not constitute an official endorsement or approval of the use of such commercial products. All product names and trademarks cited are the property of their respective owners. The findings of this report are not to be construed as an official Department of the Army position unless so designated by other authorized documents. 


\section{Contents}

Abstract.................................................................................................................................. if

Contents............................................................................................................................... iii

Figures and Tables...............................................................................................iv

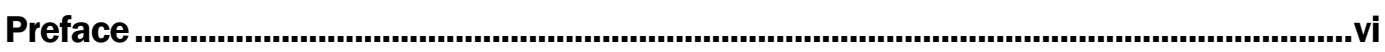

Unit Conversion Factors........................................................................................vii

1 Introduction .................................................................................................................... 1

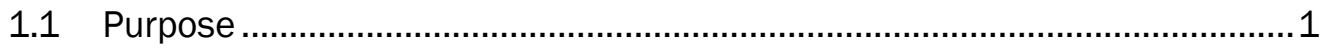

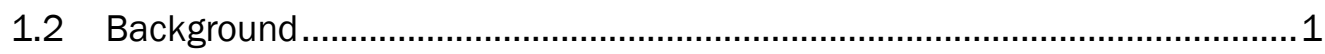

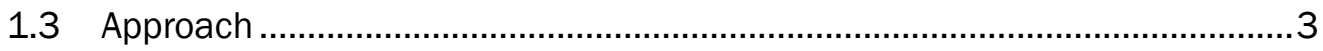

2 Model Approach ................................................................................................ 4

3 Model Development.................................................................................................... 5

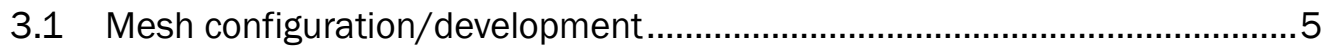

3.2 Boundary conditions and hydrograph development ................................ 9

4 Existing Conditions .............................................................................................11

5 Alternative Simulations .........................................................................................13

5.1 Alternatives ................................................................................. 13

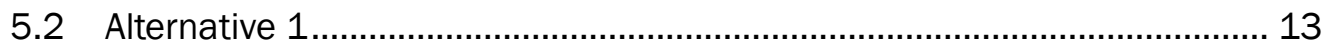

5.3 Alternative 2 A.................................................................................... 14

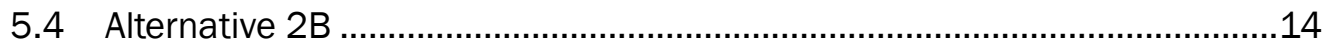

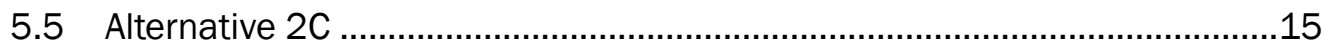

6 Results and Discussion ..........................................................................................17

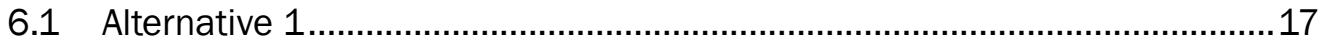

6.2 Alternative 2 A................................................................................... 19

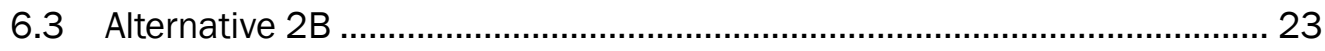

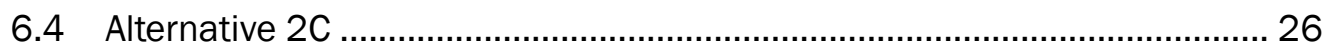

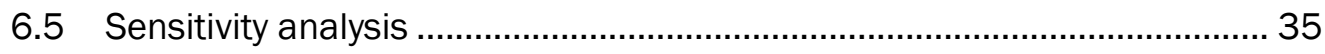

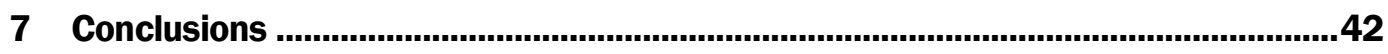

References...................................................................................................................44

Report Documentation Page 


\section{Figures and Tables}

\section{Figures}

Figure 1. Location map of White Sands installation at WSMR............................................. 2

Figure 2. Main flood control features for White Sands installation. ..................................... 3

Figure 3. Base-model domain limits and key features. .................................................... 6

Figure 4. Material locations in the base-model domain........................................................ 7

Figure 5. Topographic elevations of domain ( 25 m elevation contours).............................. 9

Figure 6. Watershed delineation and identifiers for the head waters west of WSMR.

Figure 7. Hydrograph of the combined runoff of all watersheds for the three return events tested $(\mathrm{cms}=$ cubic meters per second) .........................................................10

Figure 8. Maximum water depth (meter) for the existing-conditions 100-year event.

Figure 9. Maximum water depth (meter) for the existing-conditions 500-year event.

Figure 10. Maximum water depth (meter) for the existing-conditions 1978-year

event.

Figure 11. Alternative 1 levee boundary location

Figure 12. Alternative $2 \mathrm{~A}$ boundary levee location.

Figure 13. Alternative 2B boundary levee location.............................................................

Figure 14. Alternative $2 \mathrm{C}$ boundary levee location. ............................................................16

Figure 15. Alternative 1; 100-year event results. .............................................................17

Figure 16. Alternative 1; 500-year event results. .............................................................18

Figure 17. Alternative 1; 1978-year event..................................................................18

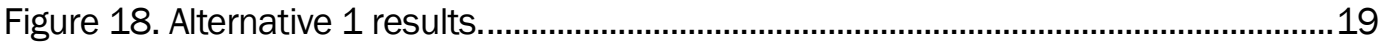

Figure 19. Alternative 2A; 100-year event.....................................................................20

Figure 20. Alternative 2A; 500-year event.......................................................................21

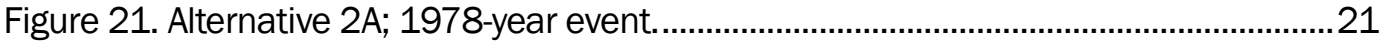

Figure 22. Alternative $2 A$ results for the existing levee. ....................................................22

Figure 23. Alternative $2 A$ results for the new proposed north levee. .................................22

Figure 24. Alternative 2B; 100-year event...........................................................................23

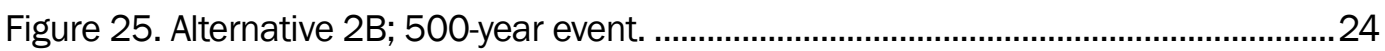

Figure 26. Alternative 2B; 1978-year event. ......................................................................... 24

Figure 27. Alternative 2B results for the existing levee.....................................................25

Figure 28. Alternative $2 \mathrm{~B}$ results for the new proposed north levee.................................25

Figure 29. Alternatives 2B and 2A simulations at Owen Road. ..........................................26

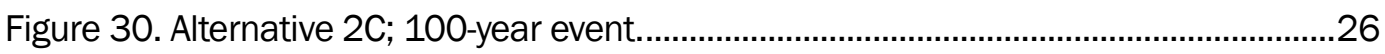

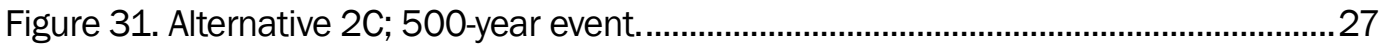

Figure 32. Alternative 2C; 1978-year event. ........................................................................2 
Figure 33. Alternative $2 \mathrm{C}$ results for the existing levee. ..................................................28

Figure 34. Alternative $2 \mathrm{C}$ results for the new proposed south levee....................................28

Figure 35. Alternative 2C; 100-year event results at 1 hour, 10 minutes...........................29

Figure 36. Alternative 2C; 100-year event results at 1 hour, 20 minutes...........................30

Figure 37. Alternative 2C; 100-year event results at 1 hour, 30 minutes.........................30

Figure 38. Alternative 2C; 100-year event results at 1 hour, 40 minutes...........................31

Figure 39. Alternative 2C; 100-year event results at 1 hour, 50 minutes...........................31

Figure 40. Alternative 2C; 100-year event results at 2 hours............................................32

Figure 41. Alternative 2C; 100-year event results at 2 hours, 10 minutes........................32

Figure 42. Alternative 2C; 100-year event results at 2 hours, 20 minutes. ........................33

Figure 43. Alternative 2C; 100-year event results at 2 hours, 30 minutes. ........................33

Figure 44. Alternative 2C; 100-year event results at 2 hours, 40 minutes. .......................34

Figure 45. Alternative 2C; 100-year event results at 2 hours, 50 minutes. ......................34

Figure 46. Alternative 2C; 100-year event results at 3 hours..........................................35

Figure 47. Sensitivity $B(n=0.025)$ results, 100-year event...............................................36

Figure 48. Sensitivity A $(n=0.035)$ results, 100-year event. ..............................................36

Figure 49. Alternative 1 - Sensitivity B difference plot, 100-year event..............................37

Figure 50. Sensitivity A - Alternative 1 difference plot, 100-year event. ..............................37

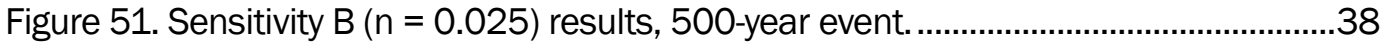

Figure 52. Sensitivity $A(n=0.035)$ results, 500-year event. ............................................38

Figure 53. Alternative 1 - Sensitivity B difference plot, 500-year event.............................39

Figure 54. Sensitivity A - Alternative 1 difference plot, 500-year event..............................39

Figure 55. Sensitivity $B(n=0.025)$ results, 1978-year event.............................................40

Figure 56. Sensitivity A $(n=0.035)$ results, 1978-year event............................................40

Figure 57. Alternative 1 - Sensitivity B difference plot, 1978-year event. ............................41

Figure 58. Sensitivity A - Alternative 1 difference plot, 1978-year event............................41

\section{Tables}

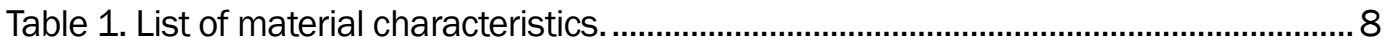

Table 2. Summary of approximate levee adjustments needed based on

Alternative 1 results.

Table 3. Specifics of each alternative. 


\section{Preface}

This study was conducted for the White Sands Missile Range under Project No. 10754978, "White Sands Missile Range-A Storm Water Model." The technical monitor was Ms. Kelly Norwood.

The work was performed by the River Engineering Branch (CEERDHFR) of the Flood and Storm Protection Division (CEERD-HF), U.S. Army Engineer Research and Development Center, Coastal and Hydraulics Laboratory (ERDC-CHL). At the time of publication of this report, Mr. Keith W. Flowers was Branch Chief, CEERD-HF-R; Dr. Cary A. Talbot was Division Chief, CEERD-HF. The Deputy Director of ERDC-CHL was Mr. Jeffrey R. Eckstein, and the Director was Dr. Ty V. Wamsley.

COL Ivan P. Beckman was the Commander of ERDC, and Dr. David W. Pittman was the Director. 


\section{Unit Conversion Factors}

\begin{tabular}{|l|c|l|}
\hline Multiply & \multicolumn{1}{l|}{ By } & To Obtain \\
\hline acres & $4,046.873$ & square meters \\
\hline acre-feet & $1,233.5$ & cubic meters \\
\hline cubic feet & 0.02831685 & cubic meters \\
\hline cubic yards & 0.7645549 & cubic meters \\
\hline degrees (angle) & 0.01745329 & radians \\
\hline degrees Fahrenheit & (F-32)/1.8 & degrees Celsius \\
\hline feet & 0.3048 & meters \\
\hline inches & 0.0254 & meters \\
\hline miles (U.S. statute) & $1,609.347$ & meters \\
\hline square feet & 0.09290304 & square meters \\
\hline yards & 0.9144 & meters \\
\hline
\end{tabular}




\section{Introduction}

\subsection{Purpose}

The U.S. Army Engineer Research and Development Center (ERDC), Coastal and Hydraulics Laboratory (CHL), performed a numerical hydraulic model study for White Sands Missile Range (WSMR) to examine the extent of inundation within the installation and determine best-case alternatives to prevent this from occurring in the future.

\subsection{Background}

The WSMR is an army testing site located in Southern New Mexico south of Albuquerque and approximately 24.1 kilometers $(\mathrm{km})$ east of Las Cruces, NM (Figure 1). The installation is susceptible to heavy runoff produced from rainfall events over the Organ Mountains, which are located west and southwest of the installation. During rainfall events, runoff flows easterly and is diverted around the installation via the North and South Arroyos. Currently, there is a levee and diversion channel system surrounding the installation that diverts moderate flows (sub-100year events, though it is unclear what exact return interval could be completely discharged) (Figure 2). The diversion channel runs parallel to the levee. The channel coupled with the North and South Arroyos is designed to guide the runoff to detention ponds located northeast and southeast of the installation. 
Figure 1. Location map of White Sands installation at WSMR.

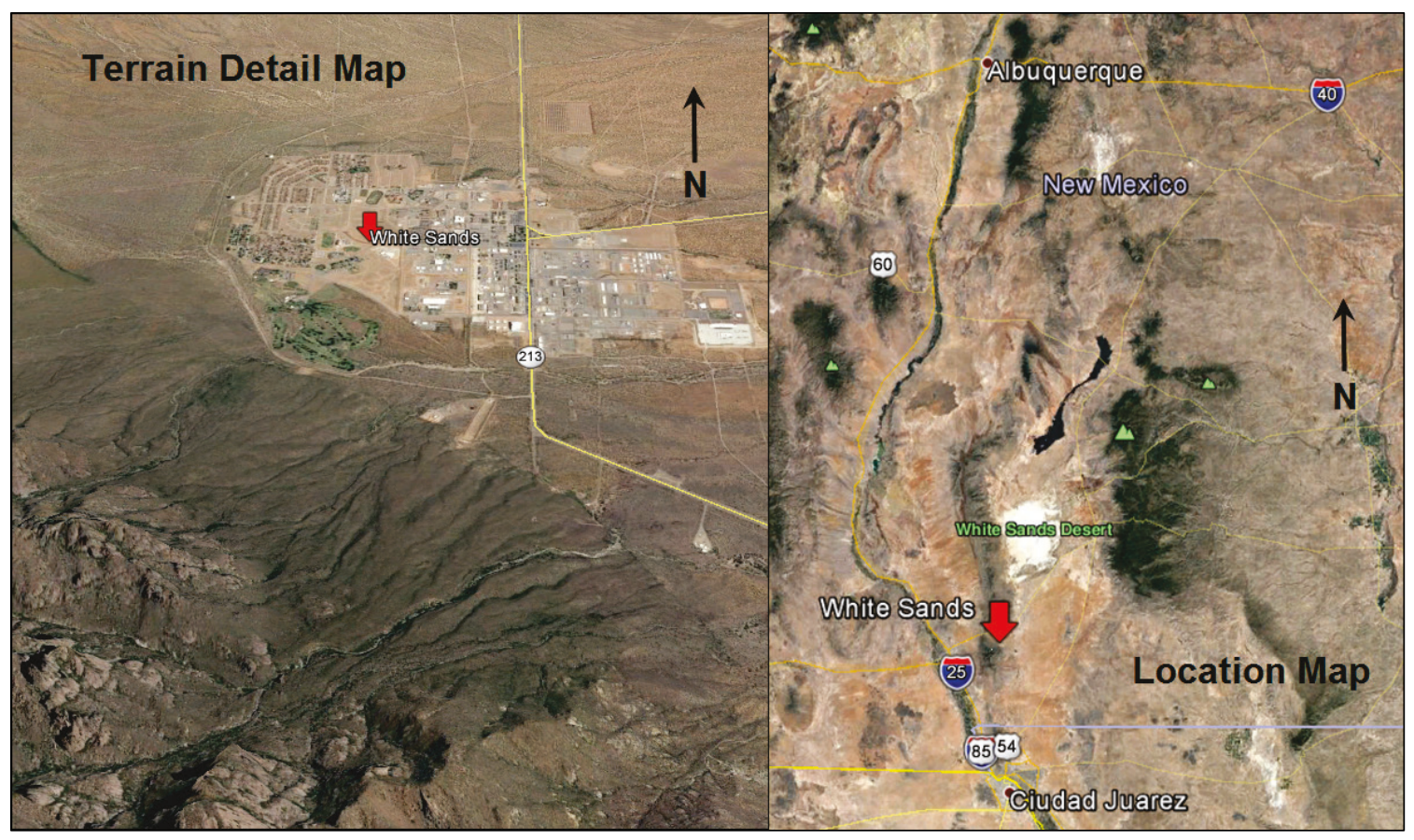

WSMR personnel requested the assistance of the ERDC-CHL to evaluate flood mitigation alternatives to increase the flood protection of the installation (design event for this study is a 100-year event). A twodimensional (2D) Shallow Water (SW2) depth-averaged numerical model, Adaptive Hydraulics (AdH) Version 4.5, was used for analysis to evaluate the flooding conditions and proposed alternatives. The model initially simulated existing conditions to determine the areas that would experience inundation during rainfall events. The existing conditions were then compared to the alternatives. Flood mitigation alternatives were derived from the joint input from WSMR and ERDC-CHL. These inputs were then formulated into general flood control changes/alterations implemented into the existing AdH model. 
Figure 2. Main flood control features for White Sands installation.

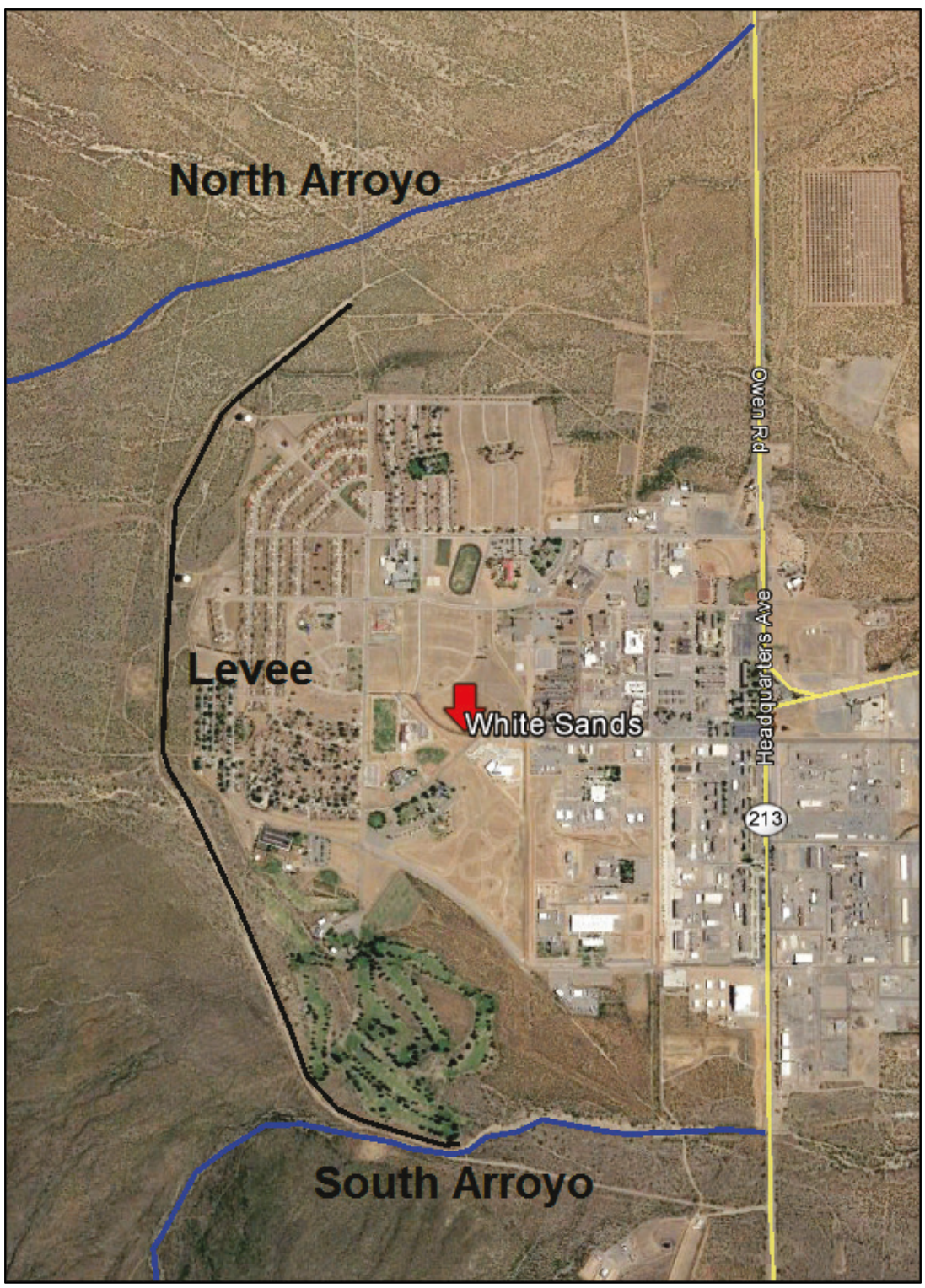

\subsection{Approach}

The approach is presented in Chapter 2 Model Approach. 


\section{Model Approach}

The investigation was performed using the SW2-AdH code to construct a model of the project area (USACE 2015). AdH was used to evaluate extreme flooding events under existing conditions and under varying alternatives intended to reduce flooding at WSMR. Five sets of modeling conditions were built, which included existing conditions and four flood mitigation alternatives. These five base simulations were tested at three different flow conditions to determine the associated impact. Thus, a total of 15 simulations was conducted.

The first base-model geometry represents the existing conditions that were in place in 2015. The first base-model of existing elevation data was established with flown lidar survey data provided by WSMR. Additionally, modifications to the levee, made in 2016, were also added in the existing conditions configuration. Once the existing conditions were established, a sensitivity analysis (explained later in this report) was performed to select the surface roughness parameters that would define the model domain. The surface roughness, Manning's roughness coefficient, was varied from 0.025 to 0.035 for a low to high range. Results of this sensitivity analysis are shown later in this report; for all other model simulations, a Manning's roughness value of 0.03 was used.

The existing-conditions model was adjusted to represent the proposed alternatives for the remaining four base models. These additional base models were built using the existing conditions mesh. Modifications were then made to the existing-conditions mesh to incorporate the proposed design alternatives. The alternative models required modified topography in the mesh as well as increased mesh resolution to appropriately represent key features. The alternatives were then compared to the existing conditions to determine the effectiveness of flood mitigation. 


\section{Model Development}

Model development is the construction of the numerical domain and its key features. The model was developed from several sources of data. Most of the data were provided by WSMR, including bathymetry, topography, aerial imagery, and key feature locations. With the absence of flow data, a HEC-HMS model was used for the delineation of the watersheds and runoff hydrographs (Jacobs et al. 2009). Additionally, a site visit was conducted by team members to evaluate field conditions.

All data were applied and reported in metric units. For model input, the horizontal geo-referenced projection was World Geodetic System (WGS) 1984 Universal Transverse Mercator Zone 13, and the vertical datum was North American Vertical Datum of 1988, meters.

\subsection{Mesh configuration/development}

The existing-conditions mesh is comprised of $1,106,800$ nodes and $2,212,454$ elements that encompass an area of approximately $205,678,545 \mathrm{~m}^{2}$. The mesh boundary highlighted in green is shown in Figure 3. Twenty-three different material types were assigned to the model (Figure 4) to represent the various materials of the flood plains, channels, levee, installation, etc. Table 1 lists each material, assigned attributes of surface roughness, eddy viscosity parameters, and fraction card (FRC) parameters. The FRCs are denoted by percentages within the boundary condition file. The model will take into account how much of an element is wet from the simulation and either include it or remove it from the calculations (Sharp et al. 2012). The order of the values in the "Eddy Viscosity" column are tensor values for EVxx, EVyy, and EVxy (USACE 2015).

The topographic data provided by WSMR are shown interpolated to the mesh in Figure 5. Note that from the west boundary to the east boundary of the model there is a difference of approximately 230 meters $(\mathrm{m})$ of elevation change over approximately $14.3 \mathrm{~km}$ of length. Note that infiltration was not considered within the AdH models. The HEC-HMS model (Jacobs et al. 2009) accounted for infiltration when the delineation of the watersheds and runoff hydrographs was created. Additionally, it was assumed that the WSMR interior drainage network can effectively handle runoff from within the installation and does not contribute to any inundation. 
Figure 3. Base-model domain limits and key features.

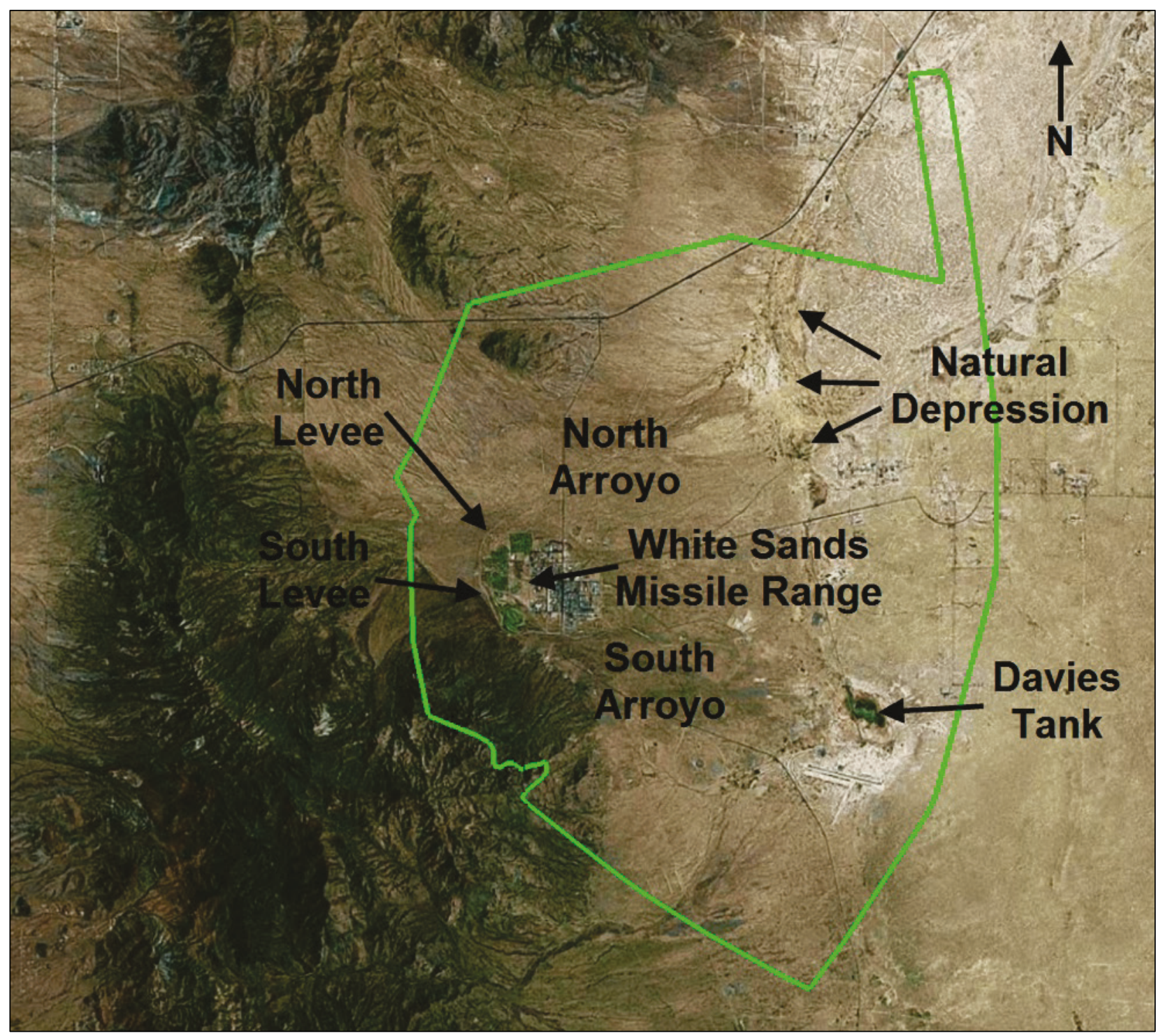


Figure 4. Material locations in the base-model domain.

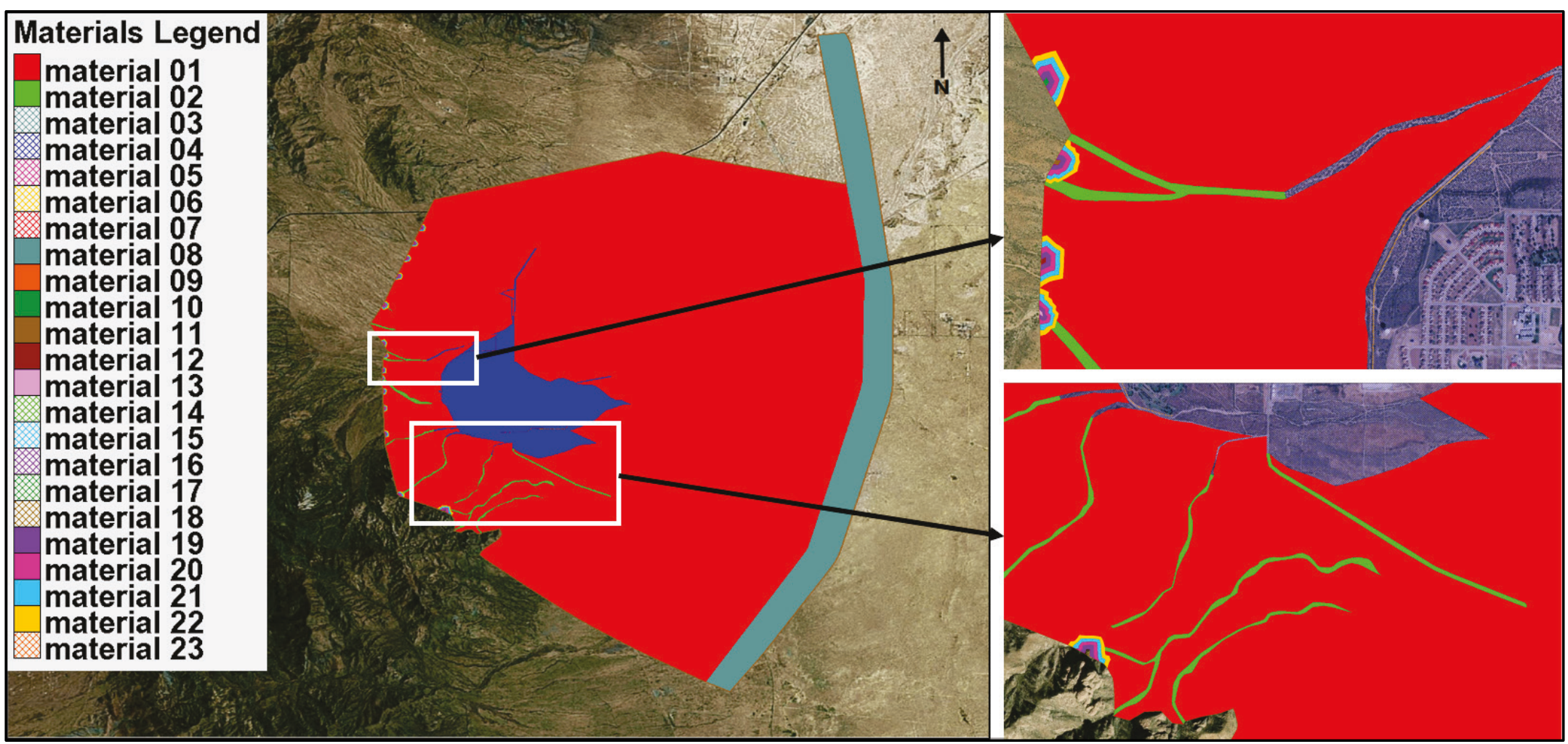


Table 1. List of material characteristics.

\begin{tabular}{|l|l|l|l|}
\hline Material & Surface Roughness & Eddy Viscosity & FRC \\
\hline 1. Main Flood Plain & 0.03 & $10,10,10$ & 0.3 \\
\hline 2. Mountain Flow Paths & 0.03 & $2,2,2$ & 0.25 \\
\hline 3. Downstream Boundary & 0.03 & $2,2,2$ & 0.25 \\
\hline 4. WSMR Area & 0.03 & $5,5,5$ & 0.28 \\
\hline 5. A8 & 0.03 & $5,5,5$ & 0.001 \\
\hline 6. A7 & 0.03 & $5,5,5$ & 0.001 \\
\hline 7. A6 & 0.03 & $5,5,5$ & 0.001 \\
\hline 8. A5 & 0.03 & $5,5,5$ & 0.001 \\
\hline 9. A4 & 0.03 & $5,5,5$ & 0.001 \\
\hline 10. A3 & 0.03 & $5,5,5$ & 0.001 \\
\hline 11. A2 & 0.03 & $5,5,5$ & 0.001 \\
\hline 12. A1 & 0.03 & $5,5,5$ & 0.001 \\
\hline 13. B1 & 0.03 & $5,5,5$ & 0.001 \\
\hline 14. B2 & 0.03 & $5,5,5$ & 0.001 \\
\hline 15. B3 & 0.03 & $5,5,5$ & 0.001 \\
\hline 16. B4 & 0.03 & $5,5,5$ & 0.001 \\
\hline 17. B5 & 0.03 & $5,5,5$ & 0.001 \\
\hline 18. B6 & 0.03 & $5,5,5$ & 0.001 \\
\hline 19. First FRC Layer & 0.03 & $5,5,5$ & 0.15 \\
\hline 20. Second FRC Layer & 0.03 & $5,5,5$ & 0.2 \\
\hline 21. Third FRC Layer & 0.03 & $5,5,5$ & 0.25 \\
\hline 22. Fourth FRC Layer & 0.03 & $5,5,5$ & 0.275 \\
\hline 23. Proposed Levee(s) & 0.03 & $5,5,5$ & 0.28 \\
\hline & & & \\
\hline
\end{tabular}


Figure 5. Topographic elevations of domain ( $25 \mathrm{~m}$ elevation contours).

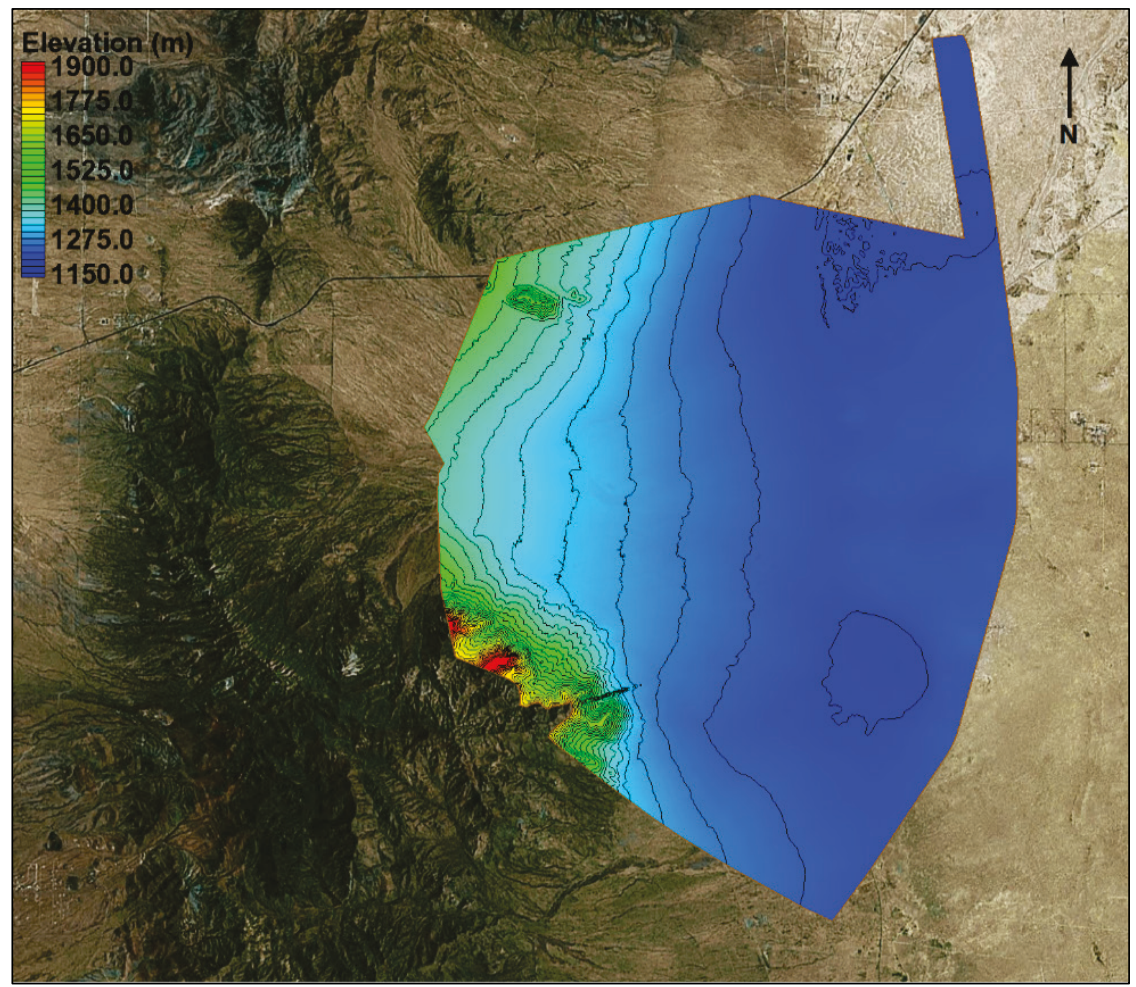

\subsection{Boundary conditions and hydrograph development}

The WSMR receives most of its precipitation during the late summer/early fall months (July to September). With steep headwater streams originating in the Organ Mountains, flood conveyance occurs rapidly. In other words, runoff from precipitation quickly reaches the North and South Arroyos.

The boundary conditions for the model are driven by hydrologic data acquired from the watersheds west of the installation (Figure 6). The National Hydrography Dataset flowlines (shown in black) are for representation of flow direction, and the blue/red shaded areas represent the individual watersheds for the North/South Arroyos, respectively. The watershed delineations are from the HEC-HMS hydrologic model (Jacobs et al. 2009), which was used to generate hydrographs. The three different storm events that were simulated in the HEC-HMS numerical model were the storm frequencies of 100 and 500 years with corresponding precipitation depths of 7.24 and 9.4 centimeters, and the 19 August 1978 storm event, which allegedly produced 10 in. of rainfall. Actual precipitation amounts were not recorded, but news articles of the event report over 10 in. falling in a 4- to 5-hour period (White 1978, 1979). Each simulation was modeled with a duration of 6 hours. The combined watershed runoff hydrographs for each event are shown in Figure 7. 
Figure 6. Watershed delineation and identifiers for the head waters west of WSMR.

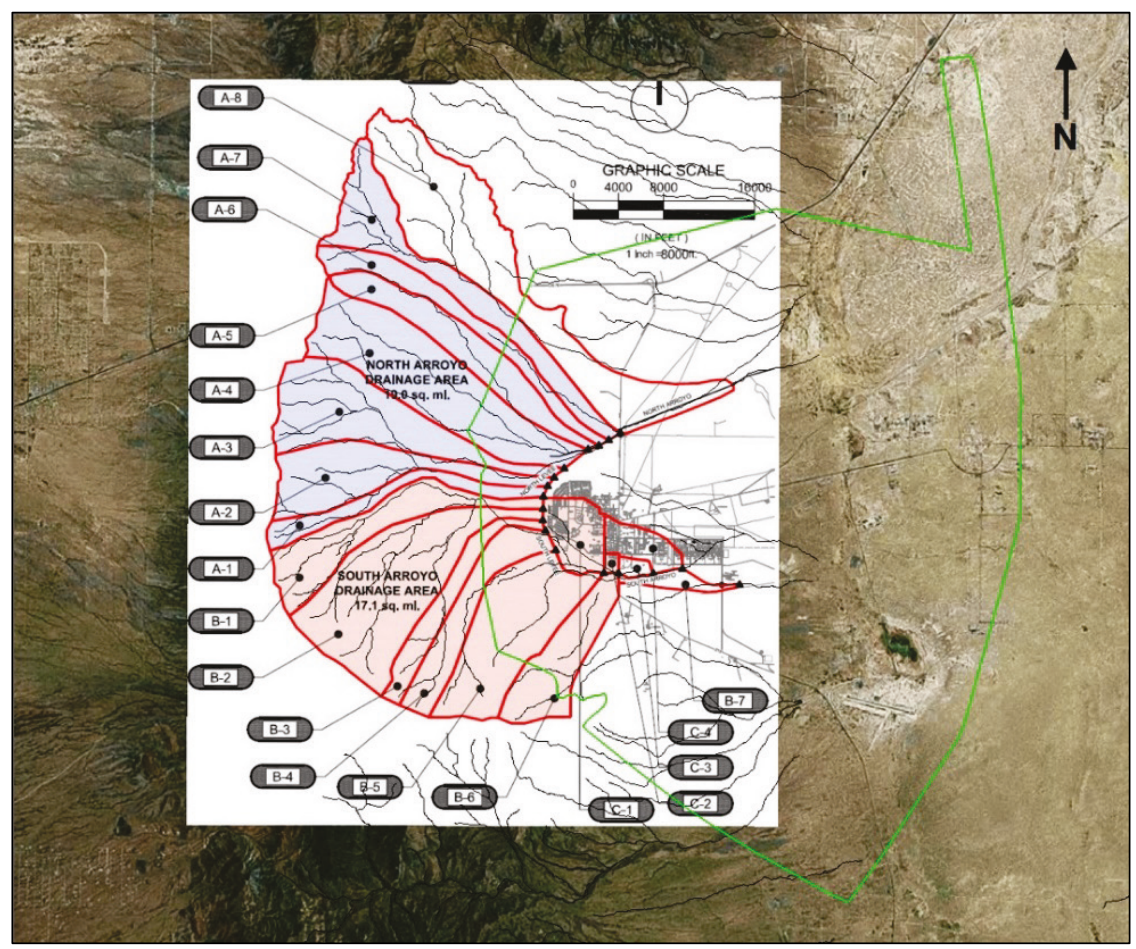

Figure 7. Hydrograph of the combined runoff of all watersheds for the three return events tested (cms = cubic meters per second).

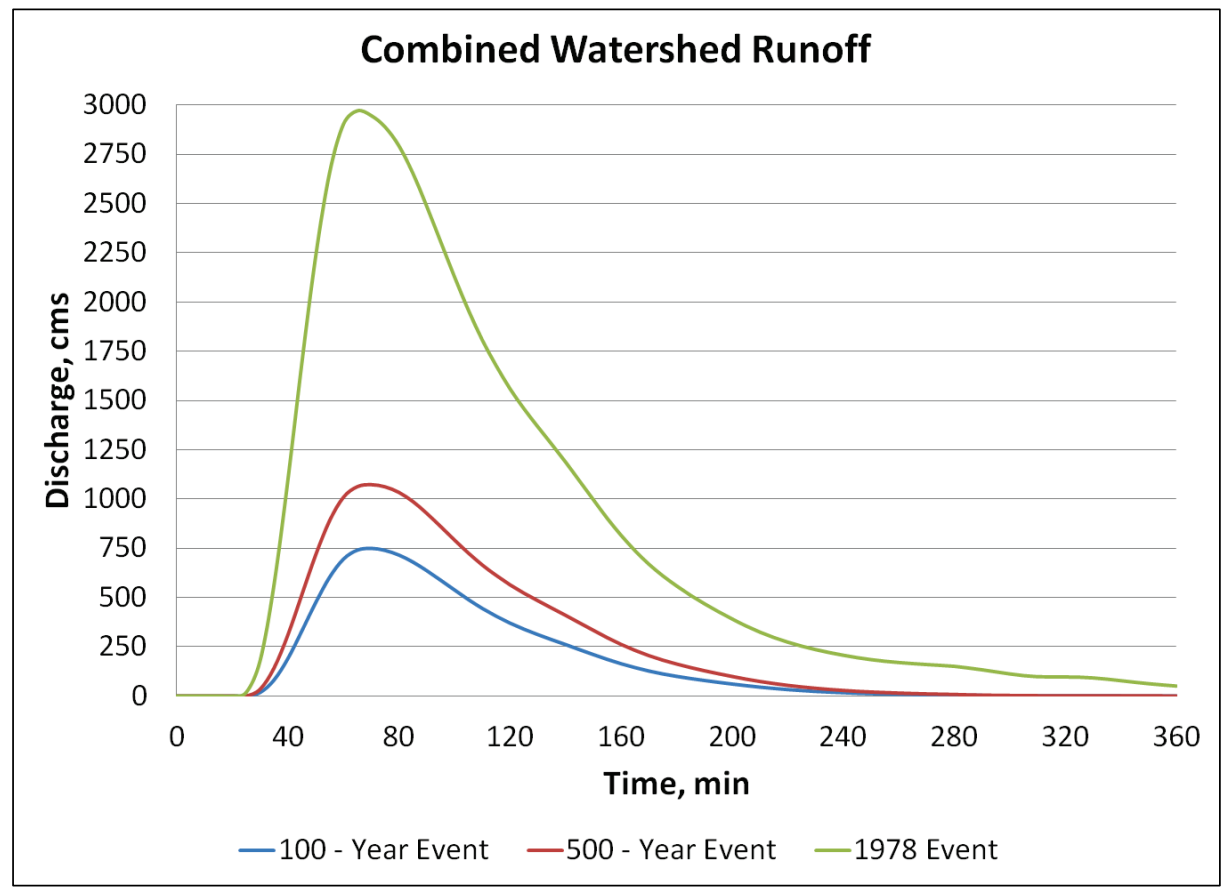




\section{Existing Conditions}

The existing conditions for WSMR were modeled for the 100-year, 500-year, and 1978-year flood events. This was performed to obtain an understanding of the maximum amount of inundation the installation would face under varying flow conditions. In Figure 8 - Figure 10, the maximum water depth is plotted for any time during the model simulation. Blue colors represent deeper depths while red colors represent shallower depths. For the sake of visual clarity, the contour maps are in the 0.0-1.0 m range with all depths greater than $1.0 \mathrm{~m}$ shown in blue.

Figure 8. Maximum water depth (meter) for the existing-conditions 100-year event.

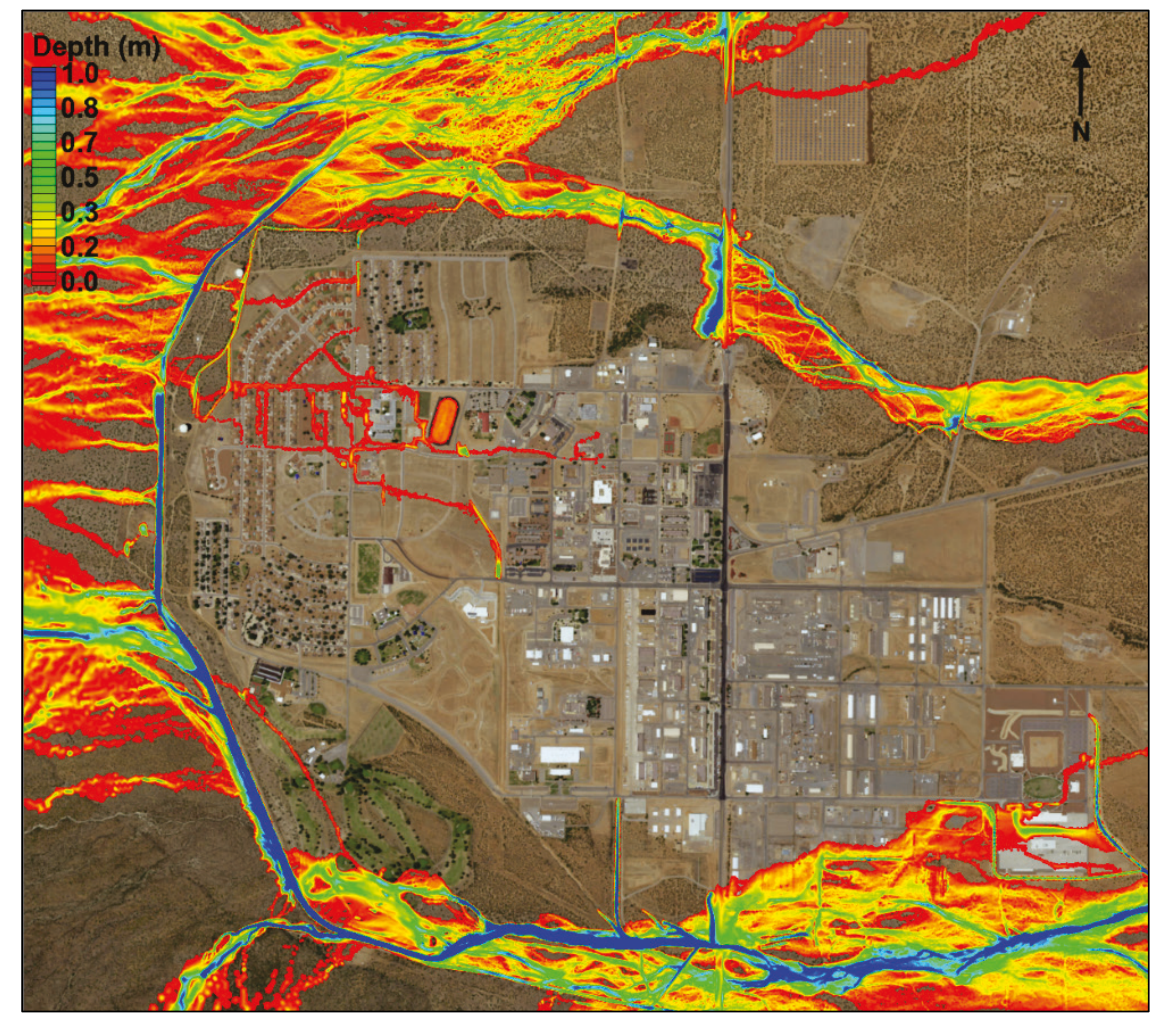


Figure 9. Maximum water depth (meter) for the existing-conditions 500-year event.

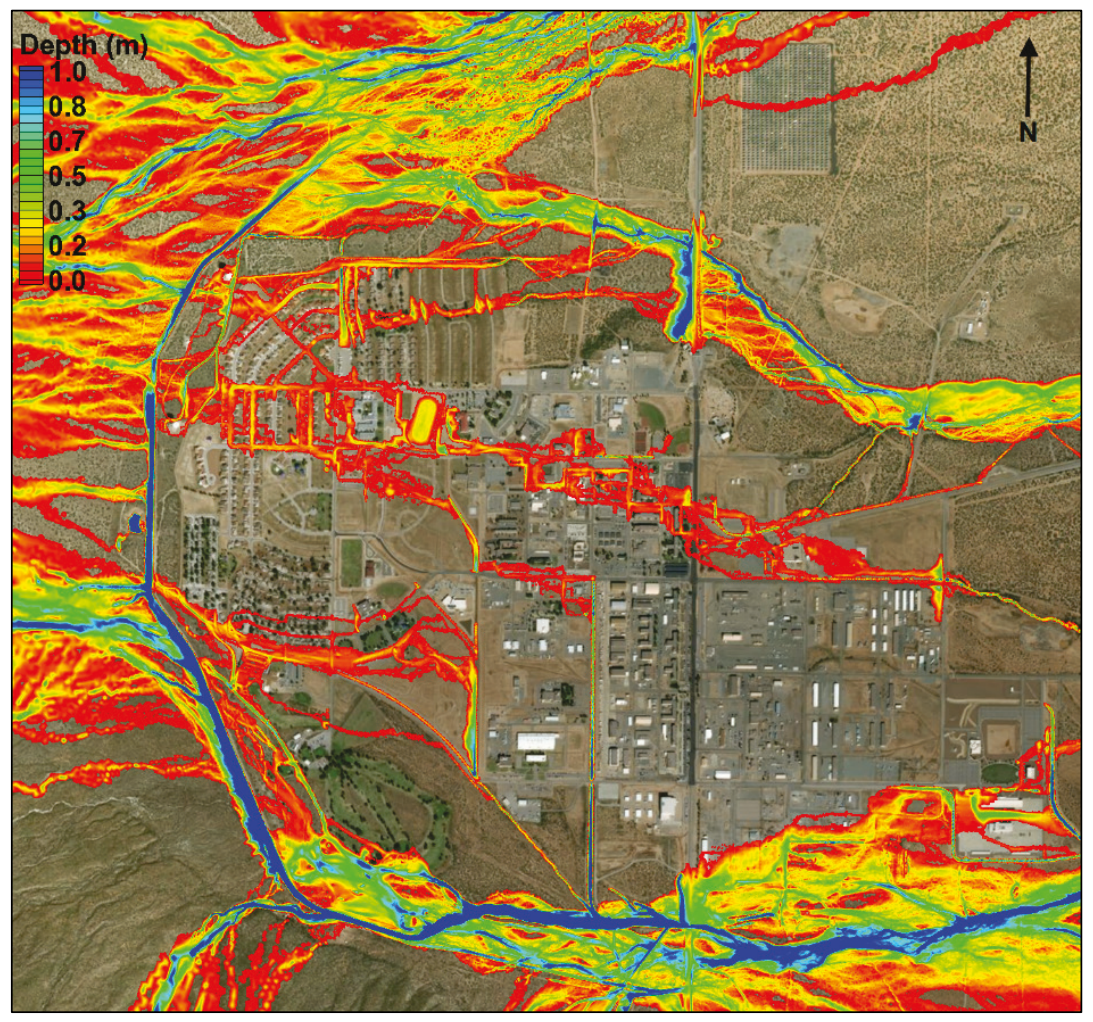

Figure 10. Maximum water depth (meter) for the existing-conditions 1978-year event.

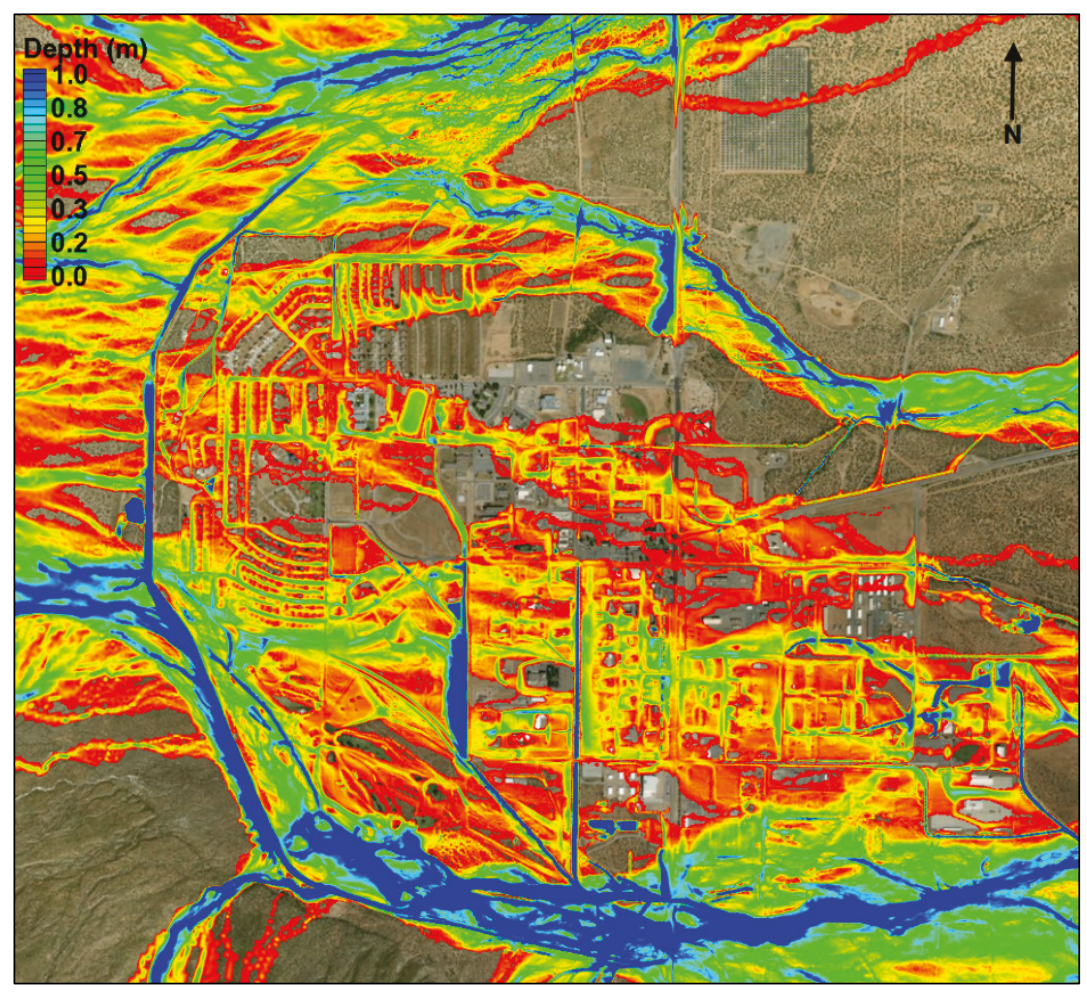




\section{Alternative Simulations}

\subsection{Alternatives}

A total of four alternative numerical model simulations were performed to evaluate flood mitigation possibilities at White Sands Missile Range.

\subsection{Alternative 1}

Alternative 1 was modeled to determine the maximum depth of water that would overtop the levee during each of the three storm events. This was accomplished by first establishing a boundary in the model that would assess the water depth at the crest of the existing levee. A material type was created to represent this levee profile and thus allowed for the material to be turned off (blue line shown in Figure 11). Alternative 1 is not actually an "alternative" in the sense that it will not be implemented in the field. It was simulated to give estimates as to where the existing levee would overtop for the three storm events.

Figure 11. Alternative 1 levee boundary location.

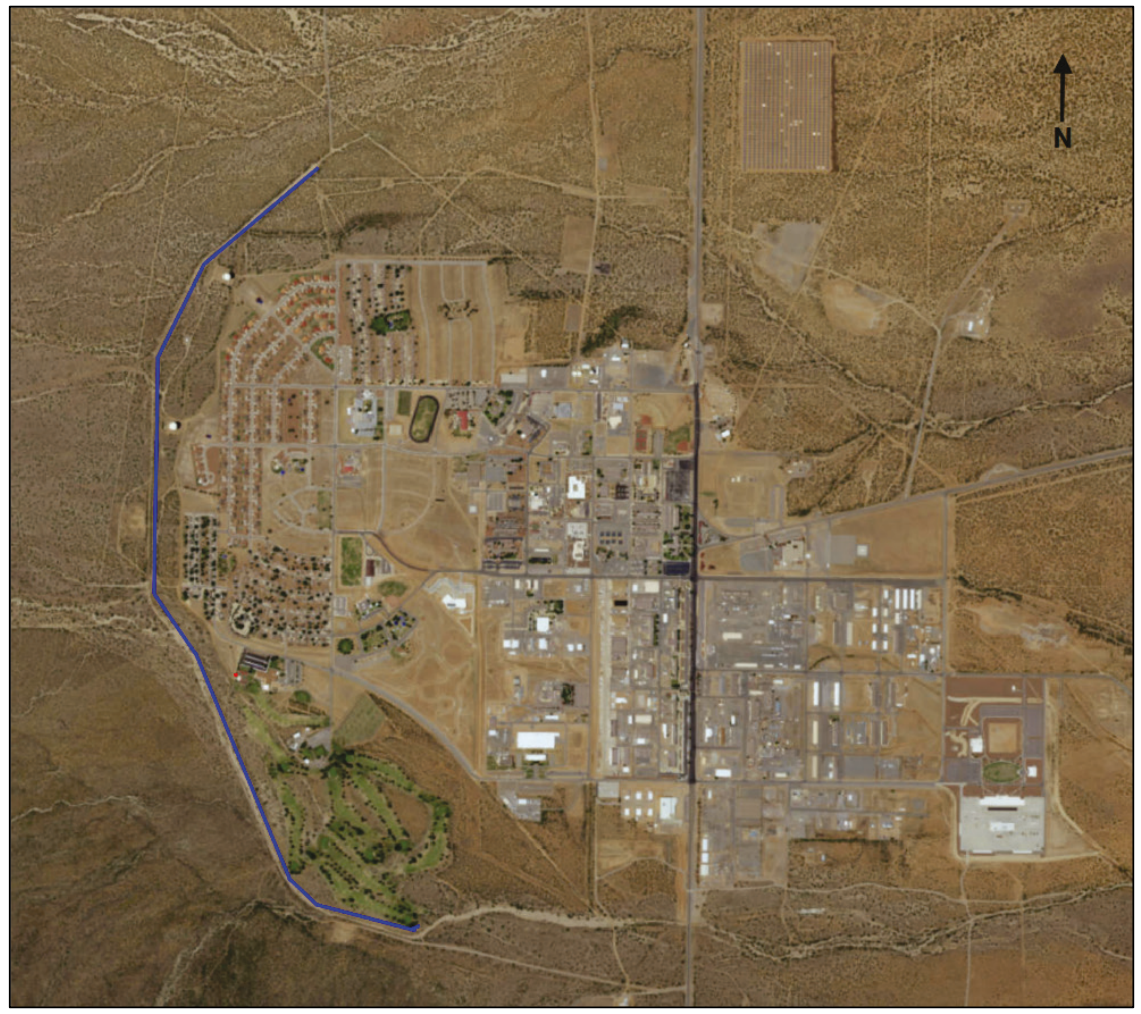




\subsection{Alternative 2A}

Alternative 2A was modeled to determine the maximum depth of water that would overtop the levee during each of the three storm events as well but incorporated some changes to the existing levee. Alternative 2A was an extension of Alternative 1 in that the same levee boundary was kept in position. There was an additional section of levee that was also distinguished as a boundary levee and did not allow water to overtop (Figure 12; denoted by the red line). The intention was to route the North Arroyo flood flow farther northeast of the WSRM.

Figure 12. Alternative 2A boundary levee location.

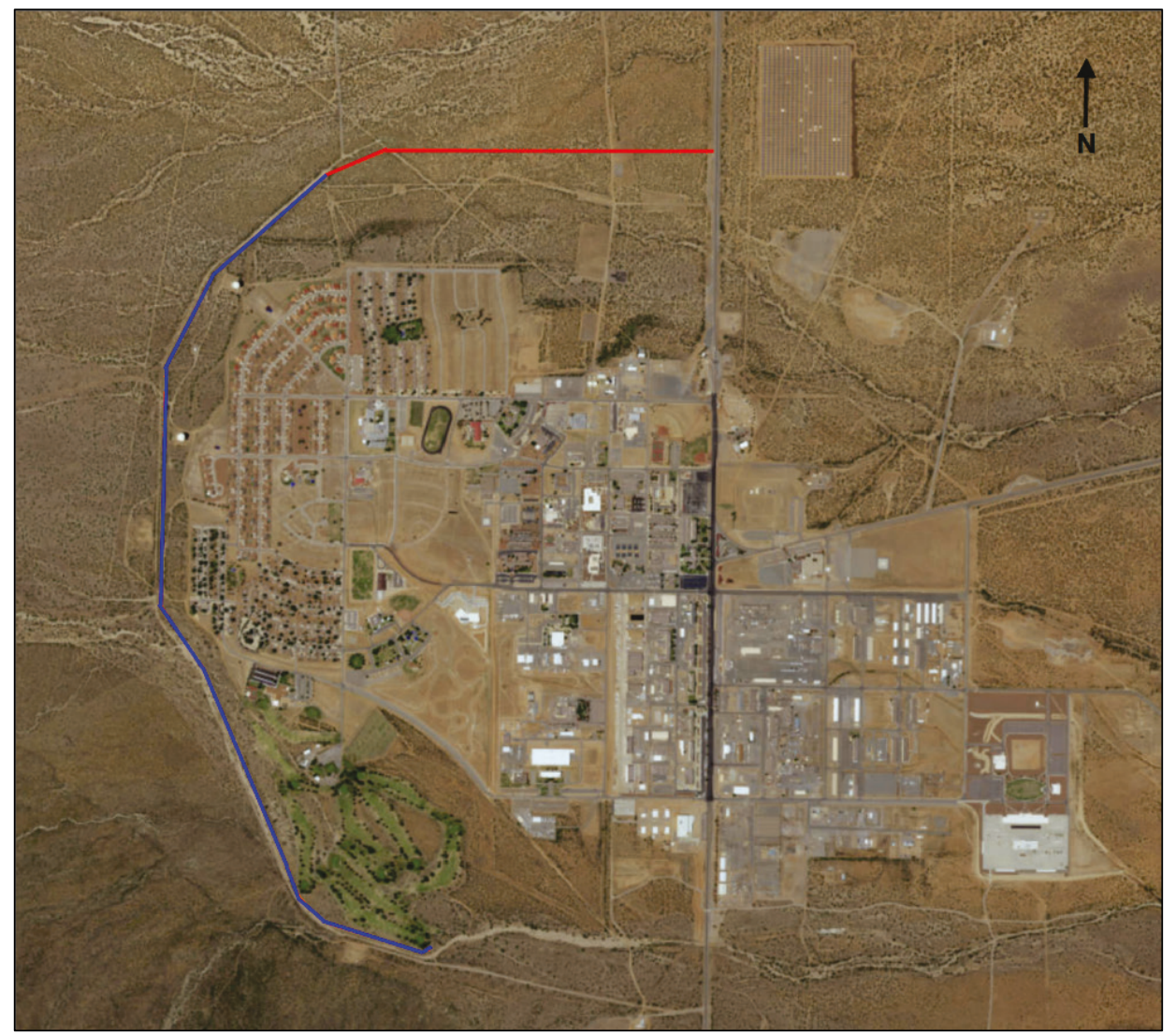

\subsection{Alternative 2B}

Alternative 2B included further levee modifications (denoted by the red line in Figure 13). Based on the results from Alternative 2A, a lengthy portion of the levee $(\sim 490 \mathrm{~m})$ was not necessary because the water diverts in a northeast direction naturally due to the topography, leaving that portion of the levee dry during the simulation. Alternative $2 \mathrm{~B}$ was proposed to account for this as well as test the concept of a small detention 
area. The idea was to keep water from building up at Owen Road where the culverts at this location are relatively small and severely restrict flow during most storm events forcing the floodwaters to overtop the road (Jacobs et al. 2009). Like the previous simulations, the elements located on the design levee location were turned off to determine the needed levee design height.

Figure 13. Alternative 2B boundary levee location.

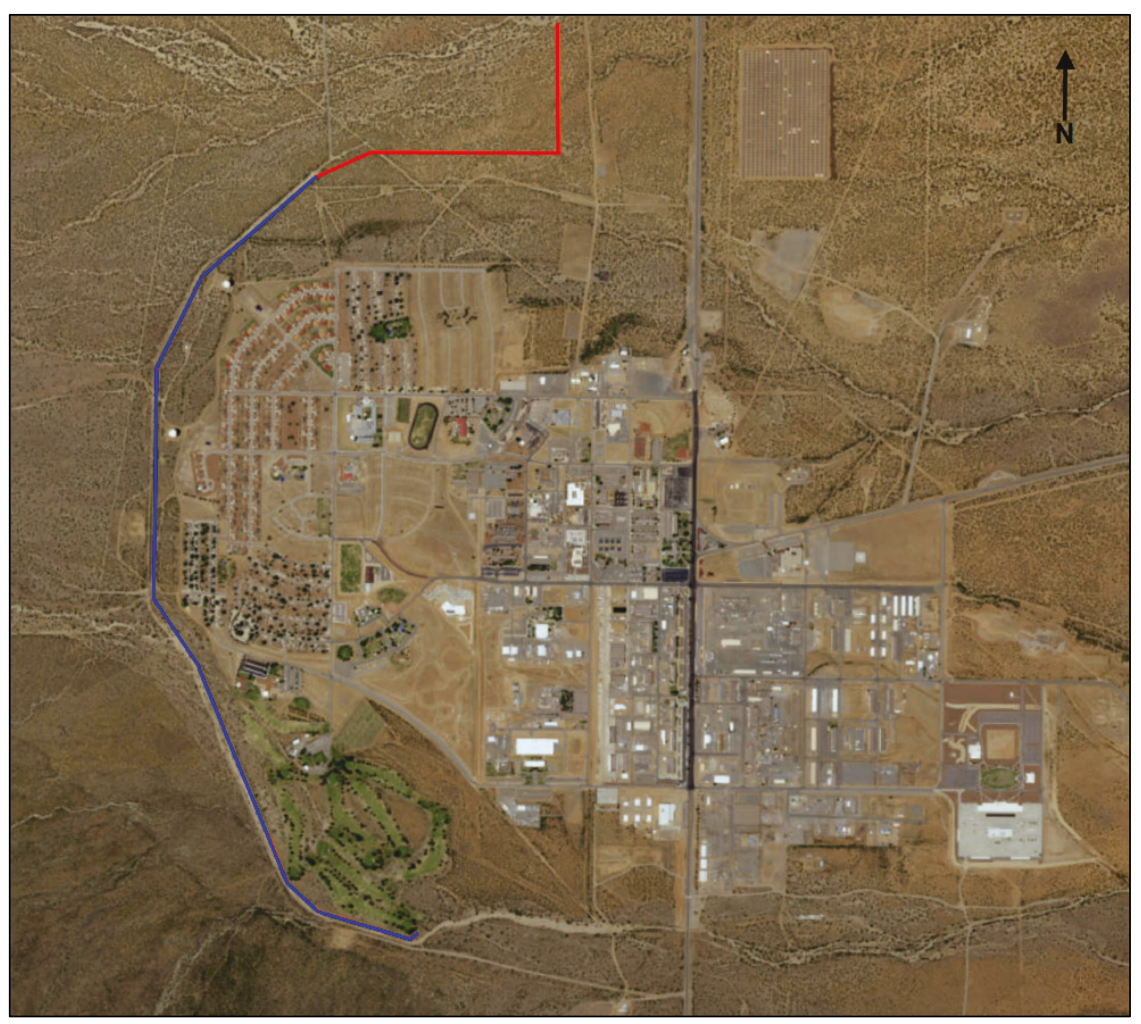

\subsection{Alternative 2C}

Alternative $2 \mathrm{C}$ incorporated even further levee modifications (denoted by the red line in Figure 14). This standalone southern-based new levee was designed to protect the WSMR from floodwaters coming from the South Arroyo/Headquarters Avenue intersection. The culverts at this location are also severely underdesigned for these sizes of flood events and thus cause major backup issues and increase the amount of water that is stored in the area. The same extension from Alternative 2B was included with this simulation. Like the previous simulations, the elements located on the design levee location were turned off to determine the needed levee design height. 
Figure 14. Alternative $2 \mathrm{C}$ boundary levee location.

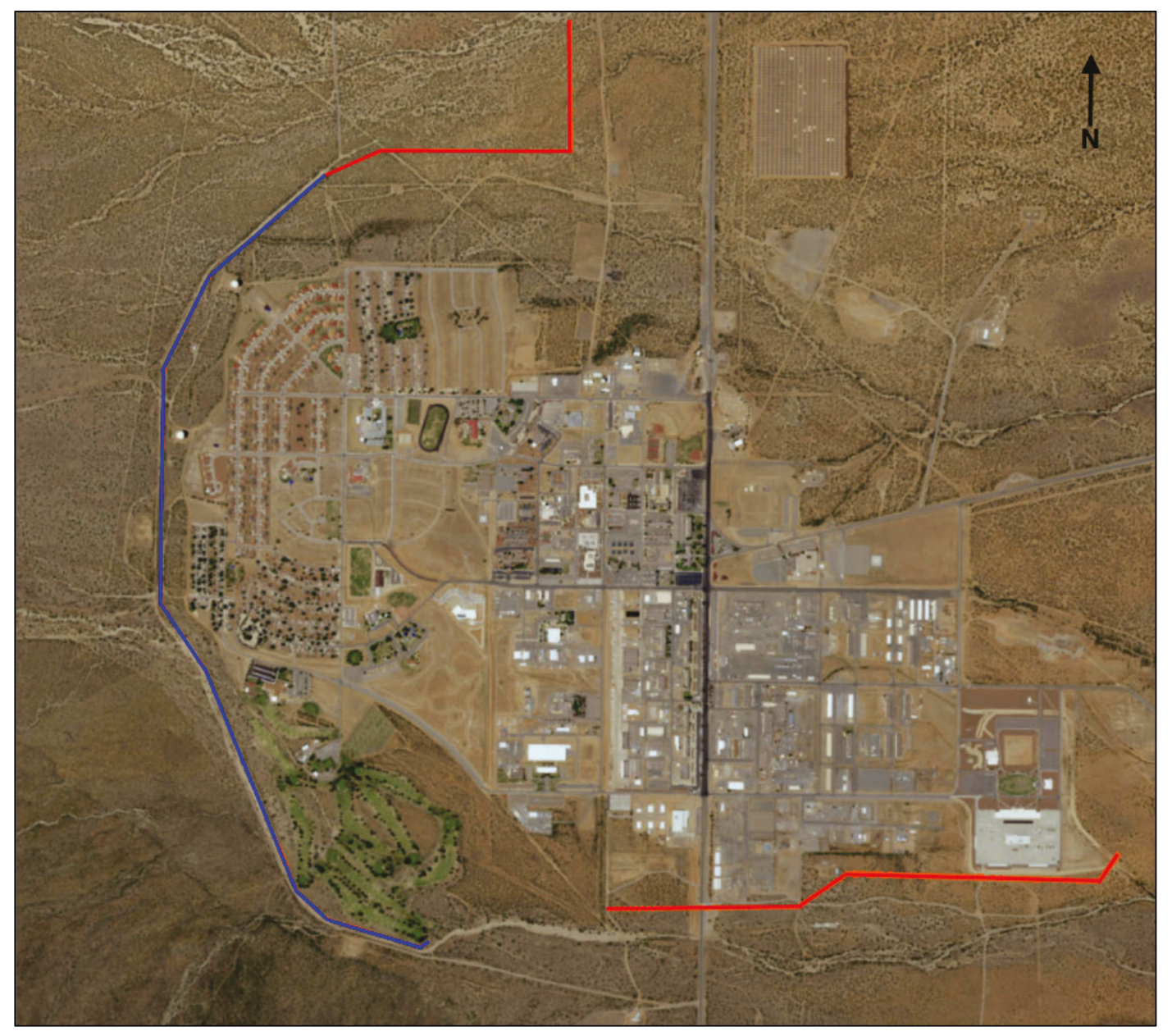




\section{Results and Discussion}

\subsection{Alternative 1}

The boundary shown in Figure 11 numerically allows for the water to reach the boundary and rise/fall based on the conditions present. Following the completion of the simulation, a MATLAB code was utilized to filter the model results. The main purpose of this data filtration process was to obtain the maximum water depth at each node during any point in time during the simulation to be extracted and plotted (Figure 15 - Figure 17). A profile view of the maximum levee elevation and the maximum depth during the simulation is plotted in Figure 18.

Figure 15. Alternative 1; 100-year event results.

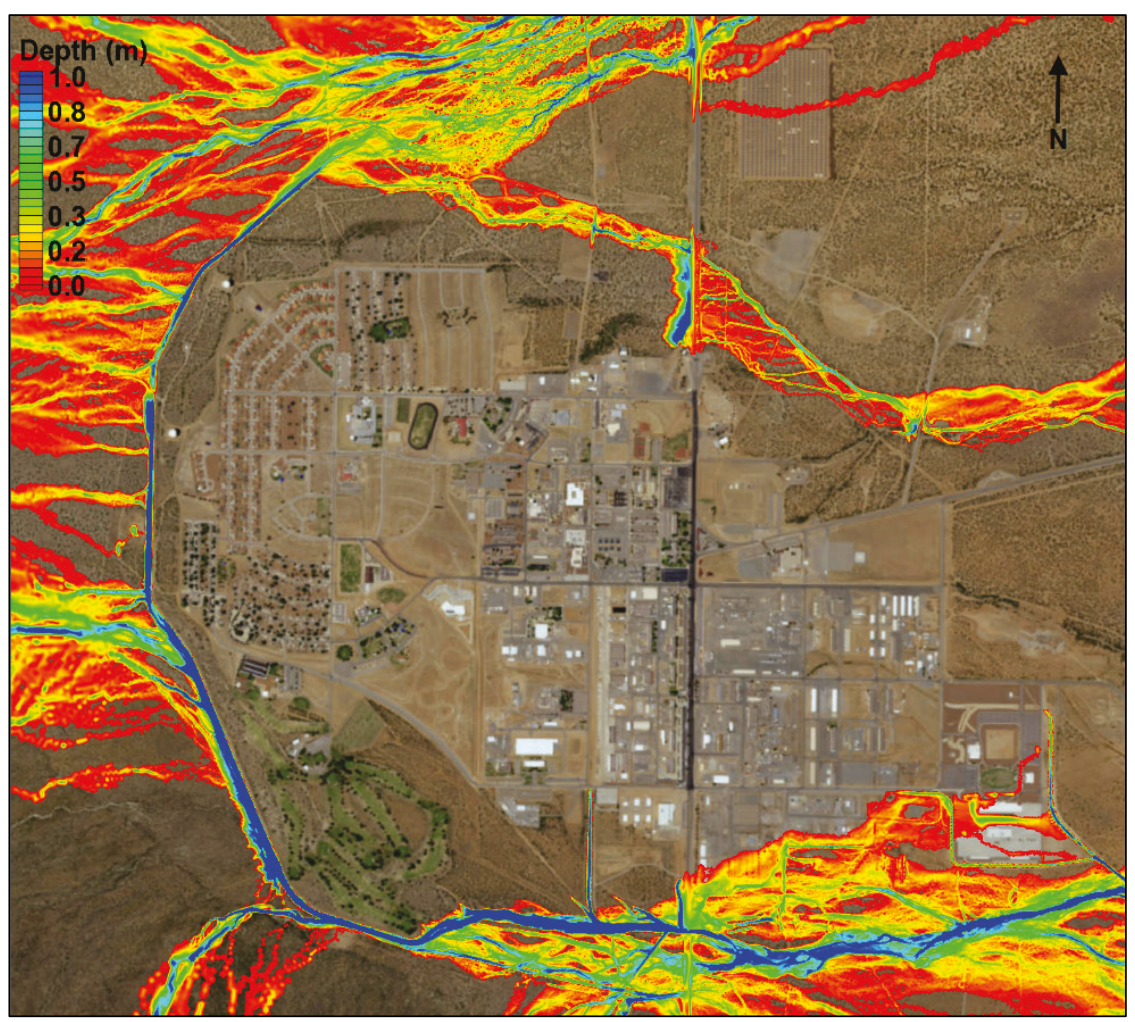


Figure 16. Alternative 1; 500-year event results.

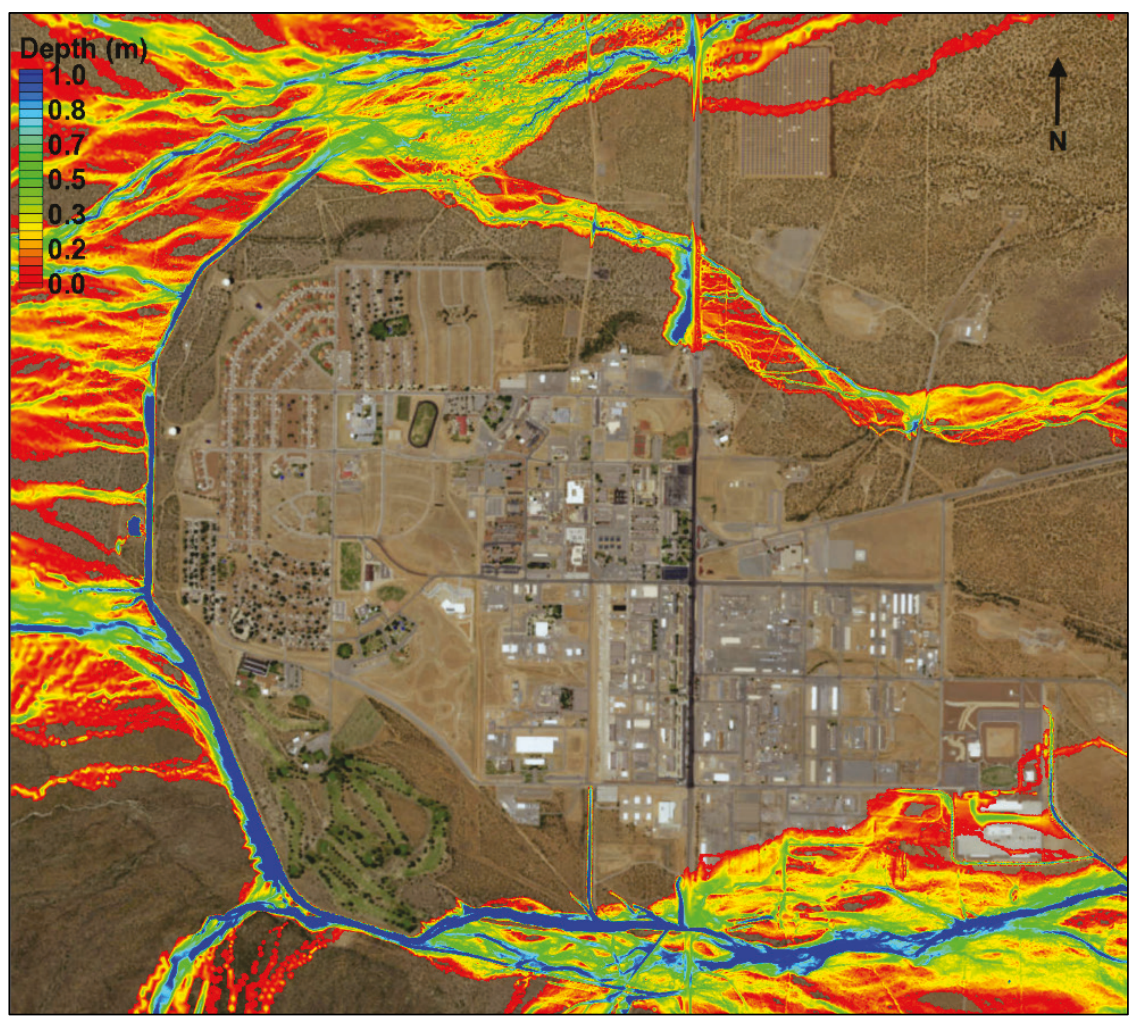

Figure 17. Alternative 1; 1978-year event.

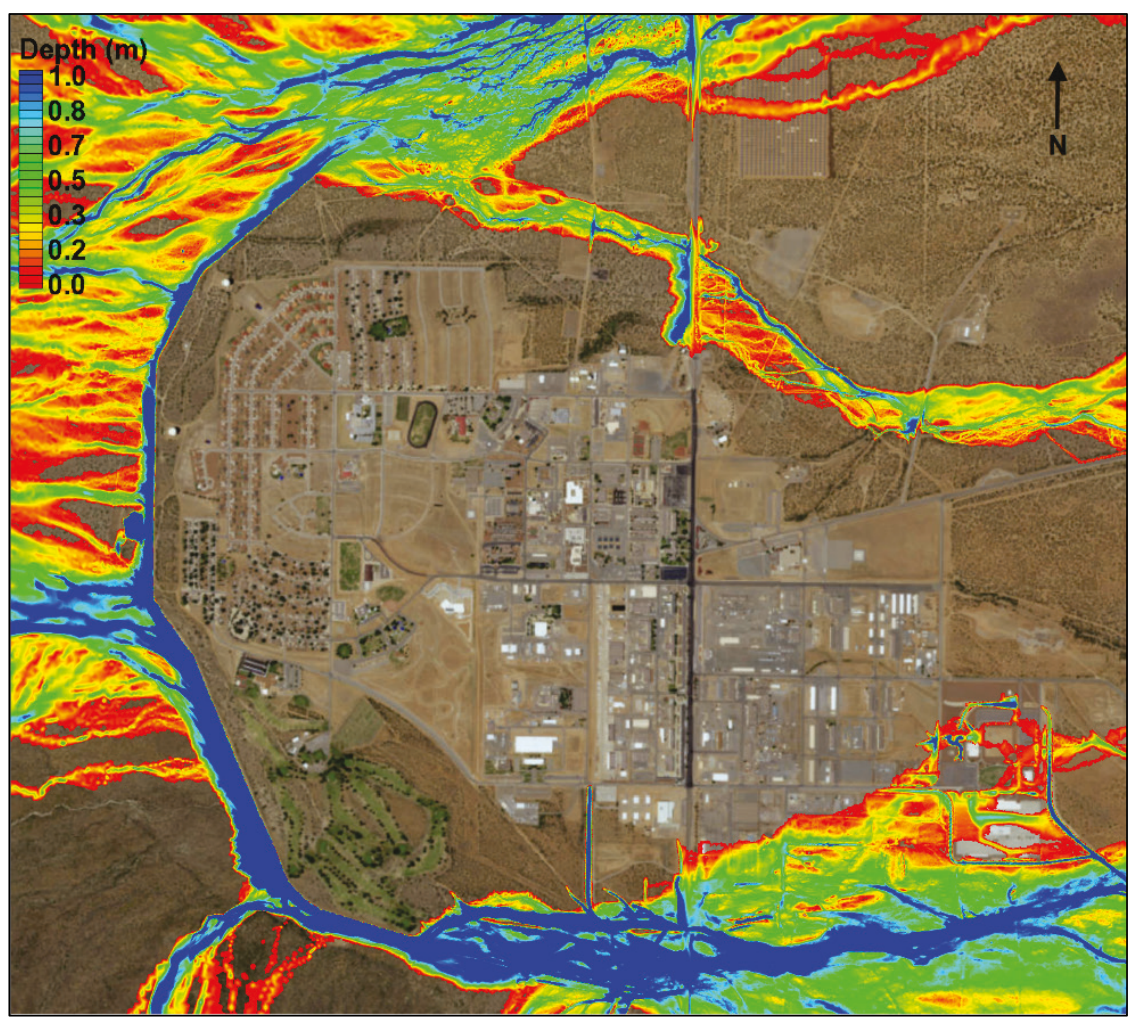


Figure 18. Alternative 1 results.

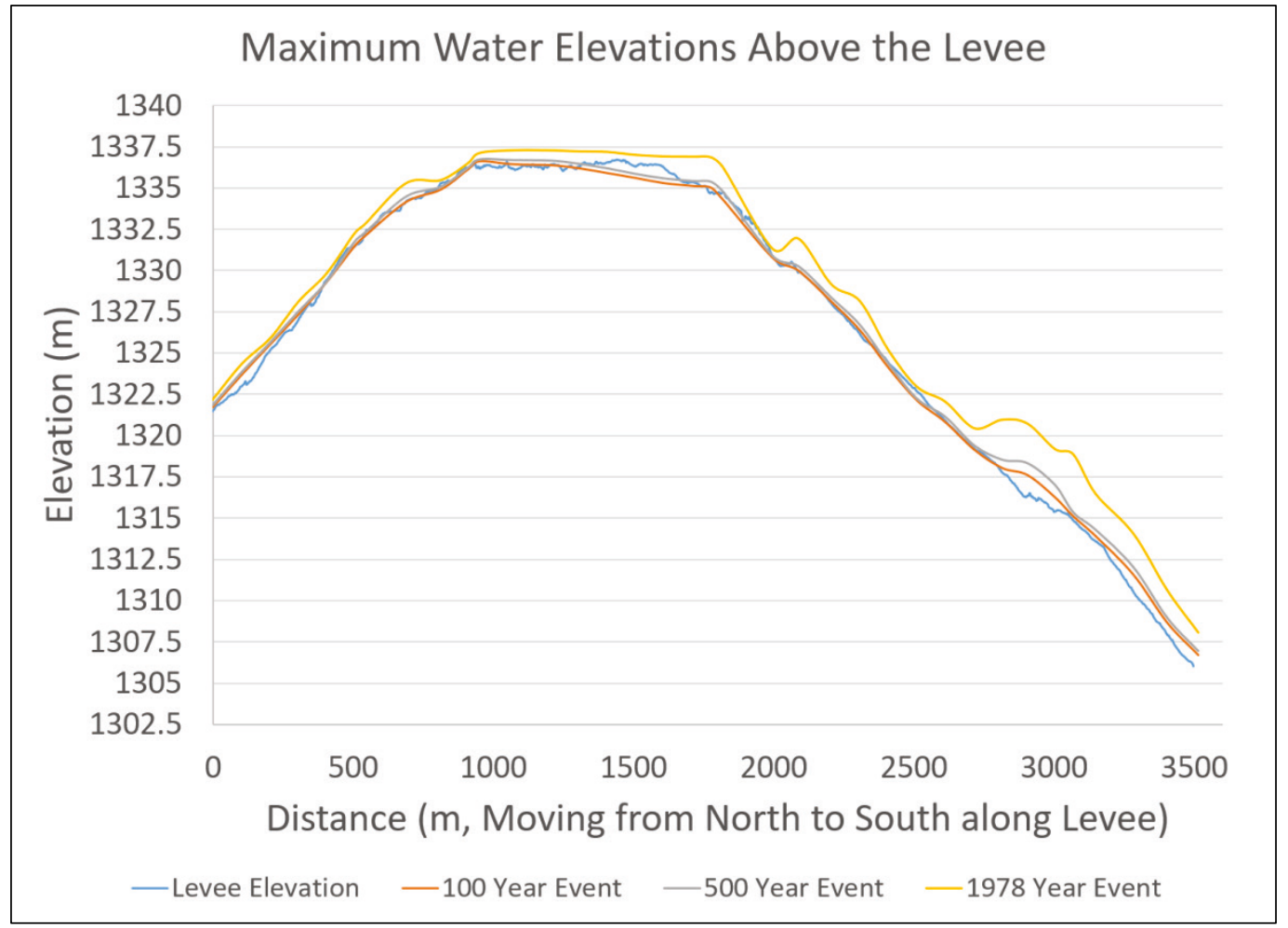

In general, Alternative 1 produced the following results in regards to necessary levee adjustments to prevent overtopping. Note that the average is an approximation across the entire existing levee and that not every location on the levee needed to be raised (Table 2).

Table 2. Summary of approximate levee adjustments needed based on Alternative 1 results.

\begin{tabular}{|l|l|l|}
\hline Event & $\begin{array}{l}\text { Average Levee Height } \\
\text { Adjustment Needed }\end{array}$ & $\begin{array}{l}\text { Maximum Levee Height } \\
\text { Adjustment Needed }\end{array}$ \\
\hline 100-year event & $0.5 \mathrm{~m}$ & $1.5 \mathrm{~m}$ \\
\hline 500-year event & $0.75 \mathrm{~m}$ & $2 \mathrm{~m}$ \\
\hline 1978-year event & $1 \mathrm{~m}$ & $3 \mathrm{~m}$ \\
\hline
\end{tabular}

\subsection{Alternative 2A}

The extended portion of the levee added to the Alternative 1 design can be seen in Figure 12. The maximum water depth at each node during any point in time during the simulation was extracted and plotted (Figure $19-$ Figure 21). A profile view of the maximum existing levee elevation and the maximum water surface elevation at that location during the simulation is plotted in Figure 22. Figure 23 is a plot of the results located at the 
proposed new north levee. Note that the flow does not go all the way to the end of the levee extension thus reducing the necessary length of that particular levee design.

Figure 19. Alternative 2A; 100-year event.

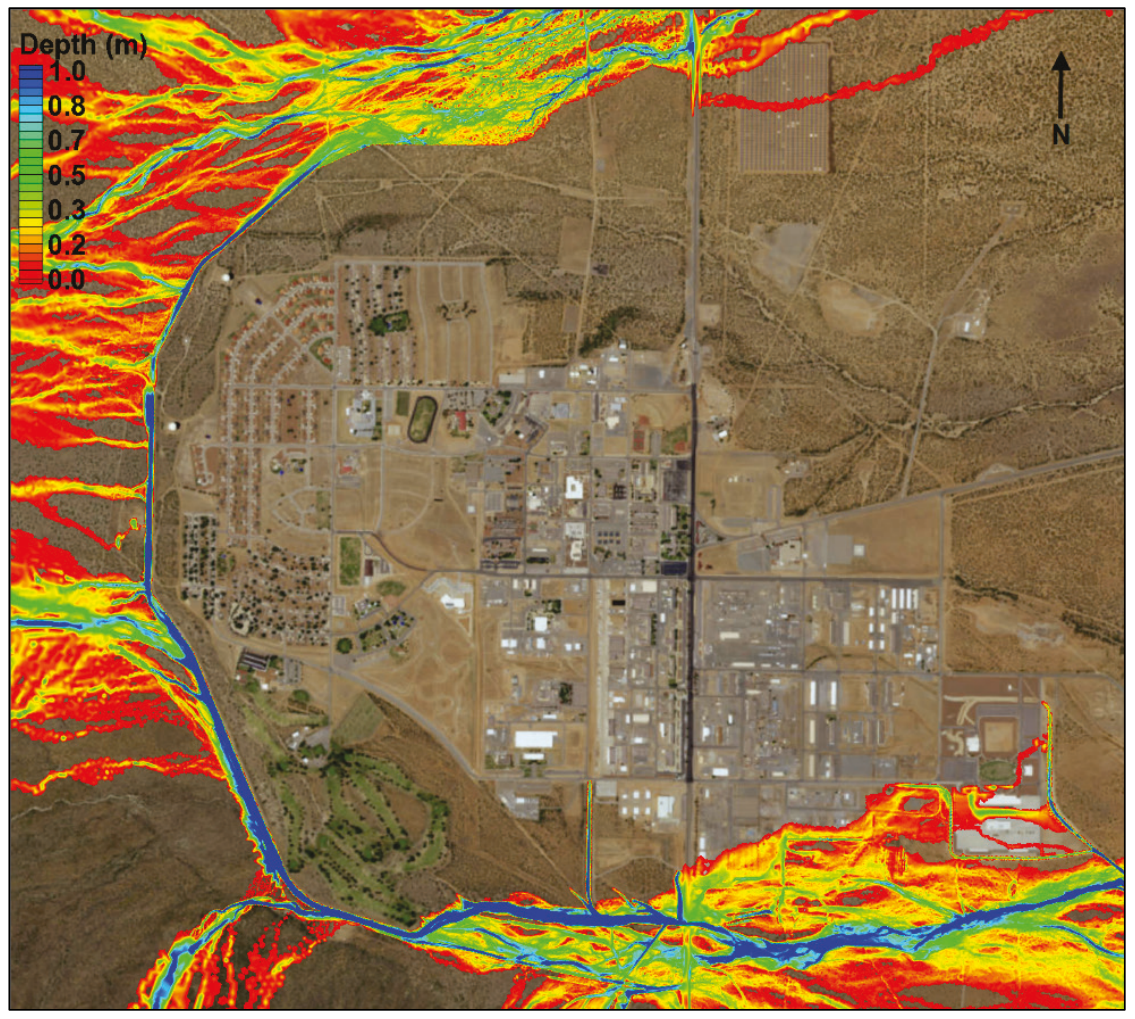


Figure 20. Alternative 2A; 500-year event.

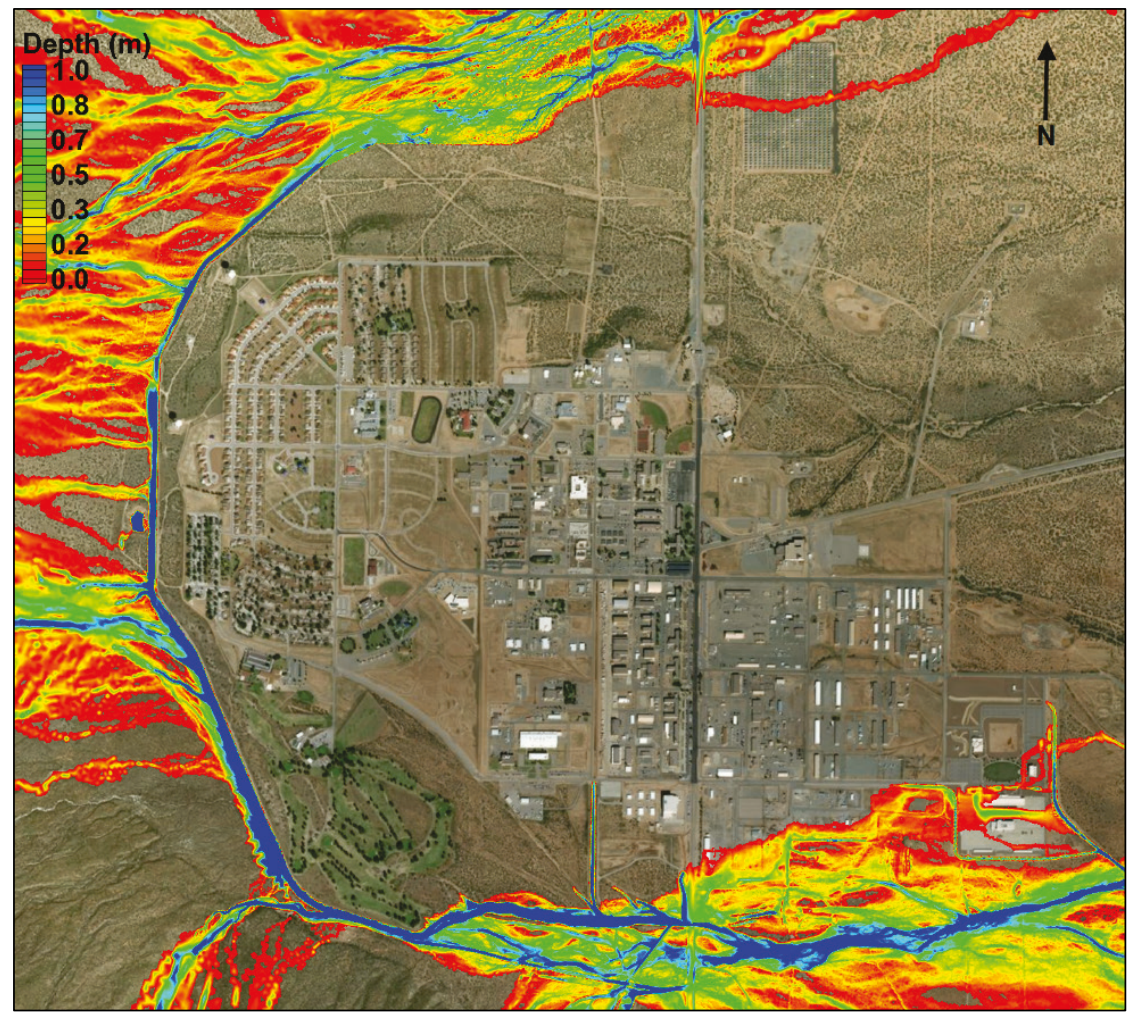

Figure 21. Alternative 2A; 1978-year event.

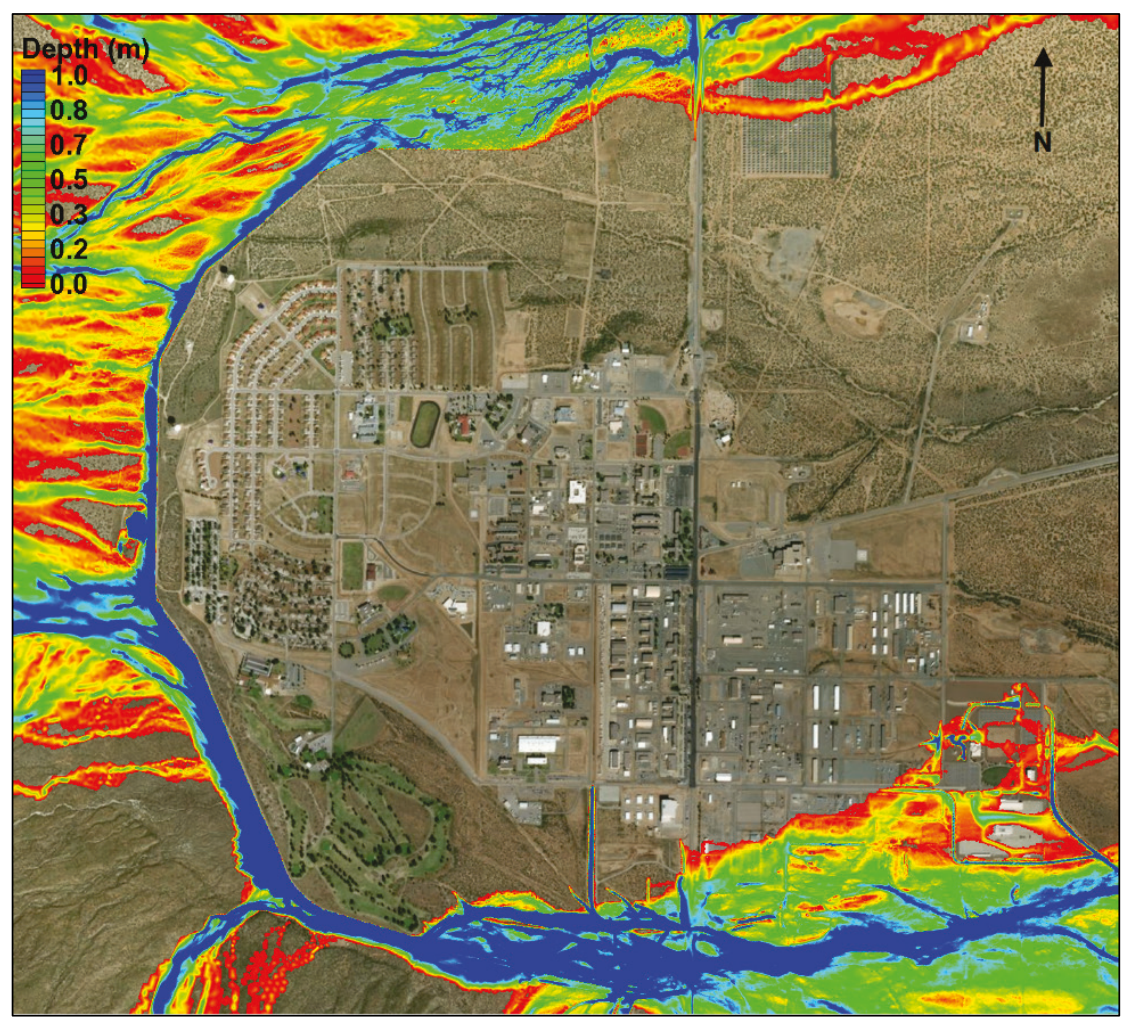


Figure 22. Alternative 2A results for the existing levee.

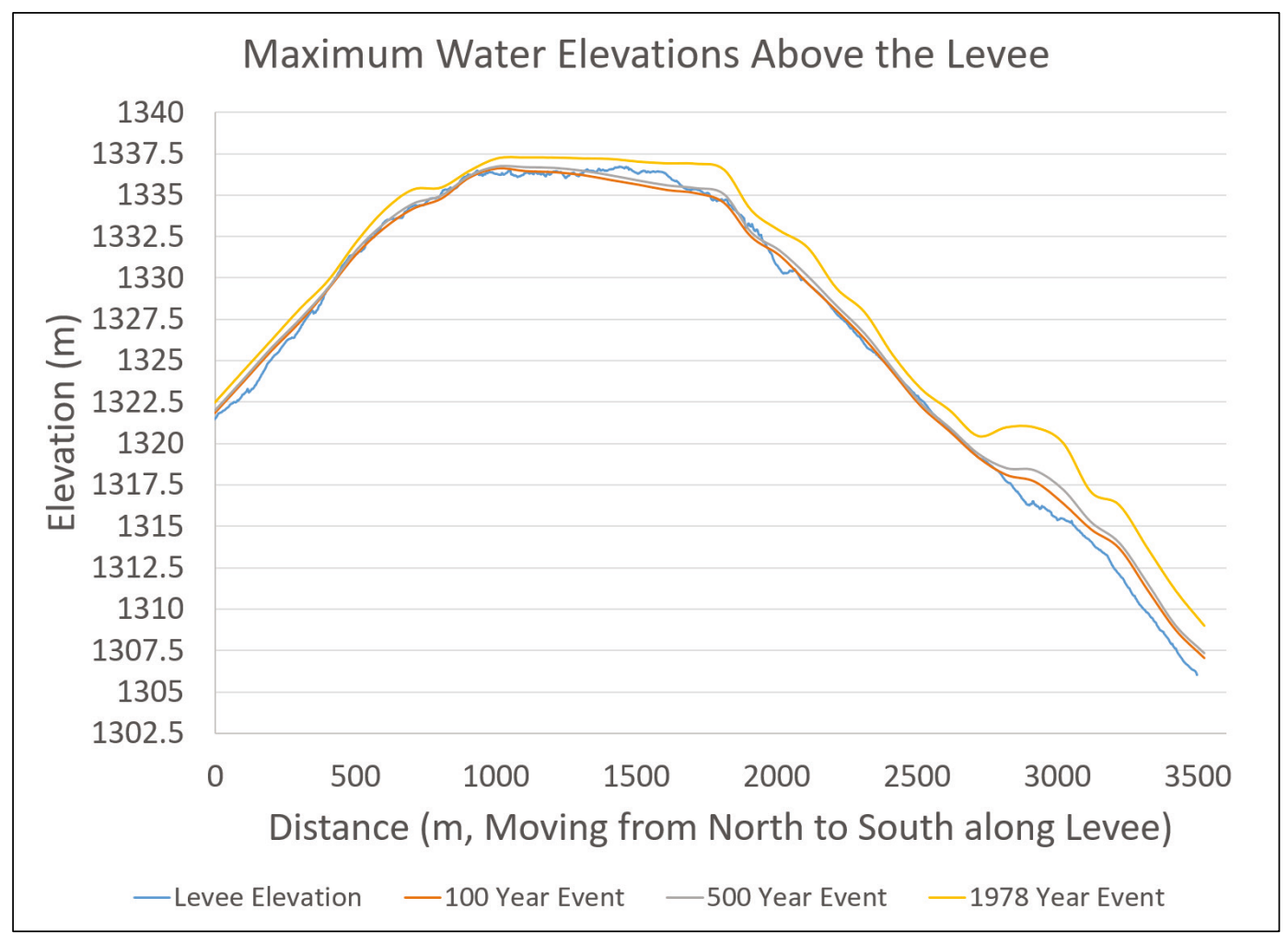

Figure 23. Alternative $2 \mathrm{~A}$ results for the new proposed north levee.

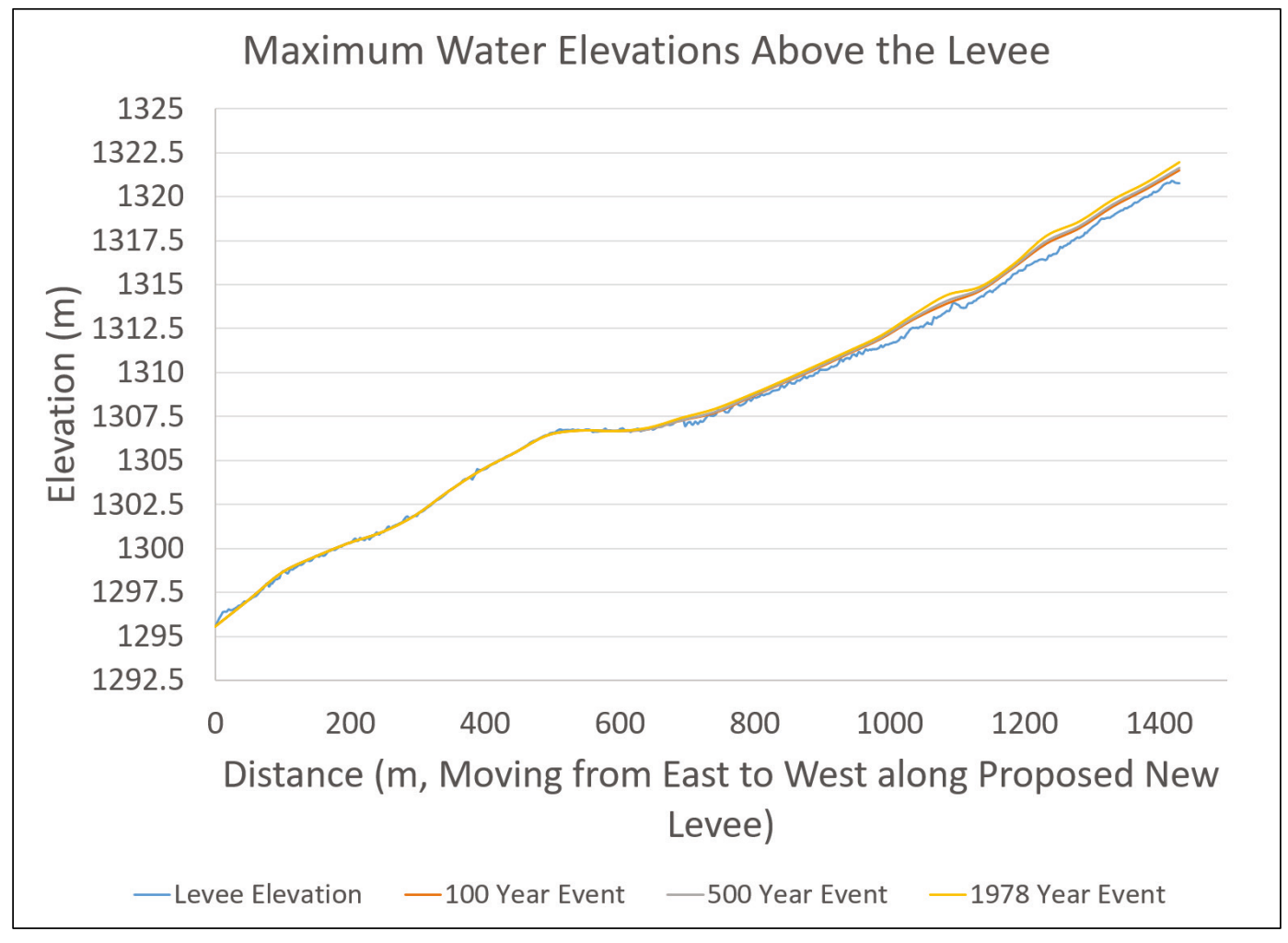




\subsection{Alternative 2B}

Further modifications were made to the proposed levee (Figure 13) and were simulated in this alternative. The maximum water depth at each node during any point in time during the simulation was extracted and plotted (Figure 24 - Figure 26). A profile view of the maximum existing levee elevation and the maximum depth during the simulation is plotted in Figure 27. Figure 28 plots the proposed north levee elevation and corresponding model results. Note that Alternative $2 \mathrm{~B}$ did reduce the water level at Owen Road (see Figure 29 for comparison with Alternative 2A).

Figure 24. Alternative 2B; 100-year event.

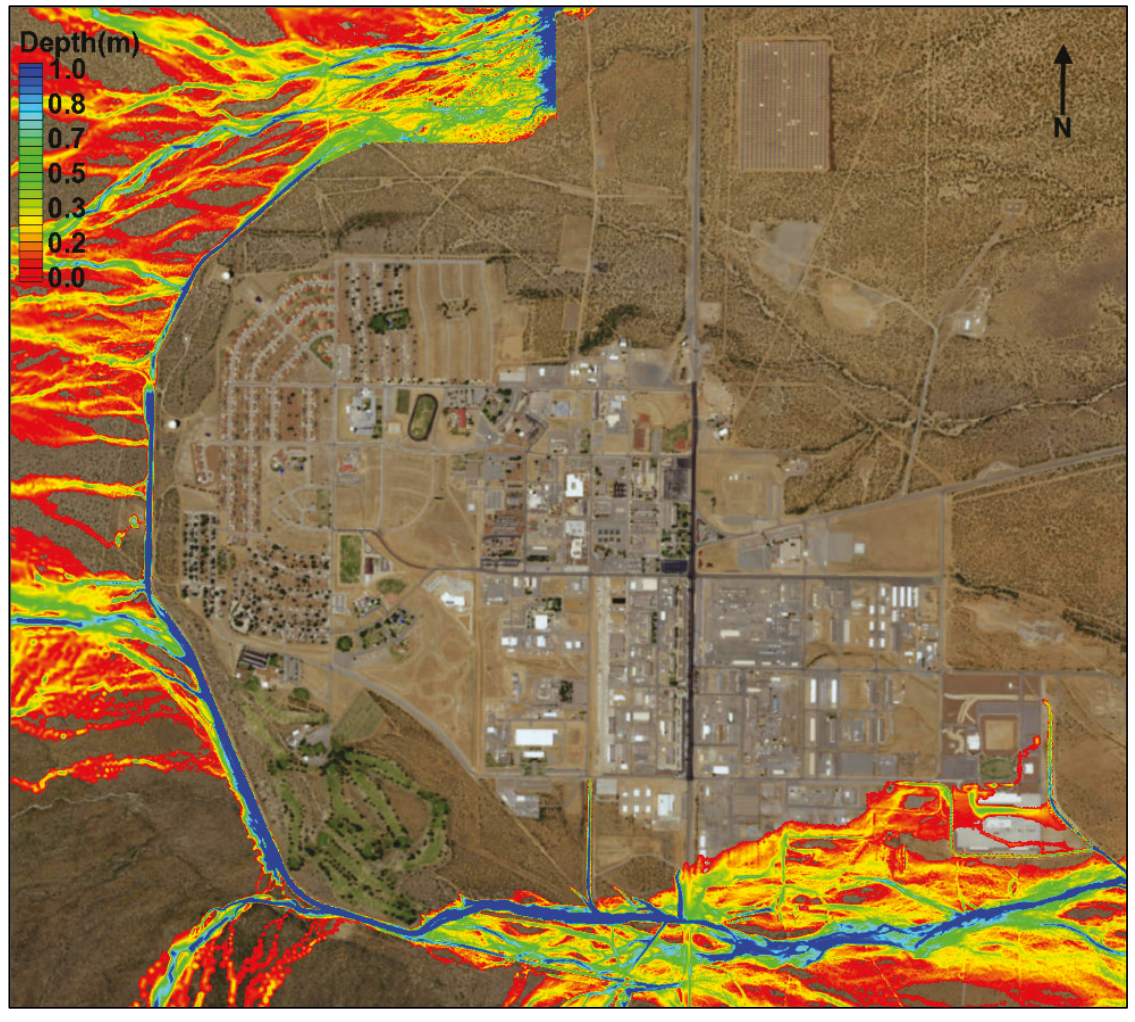


Figure 25. Alternative 2B; 500-year event.

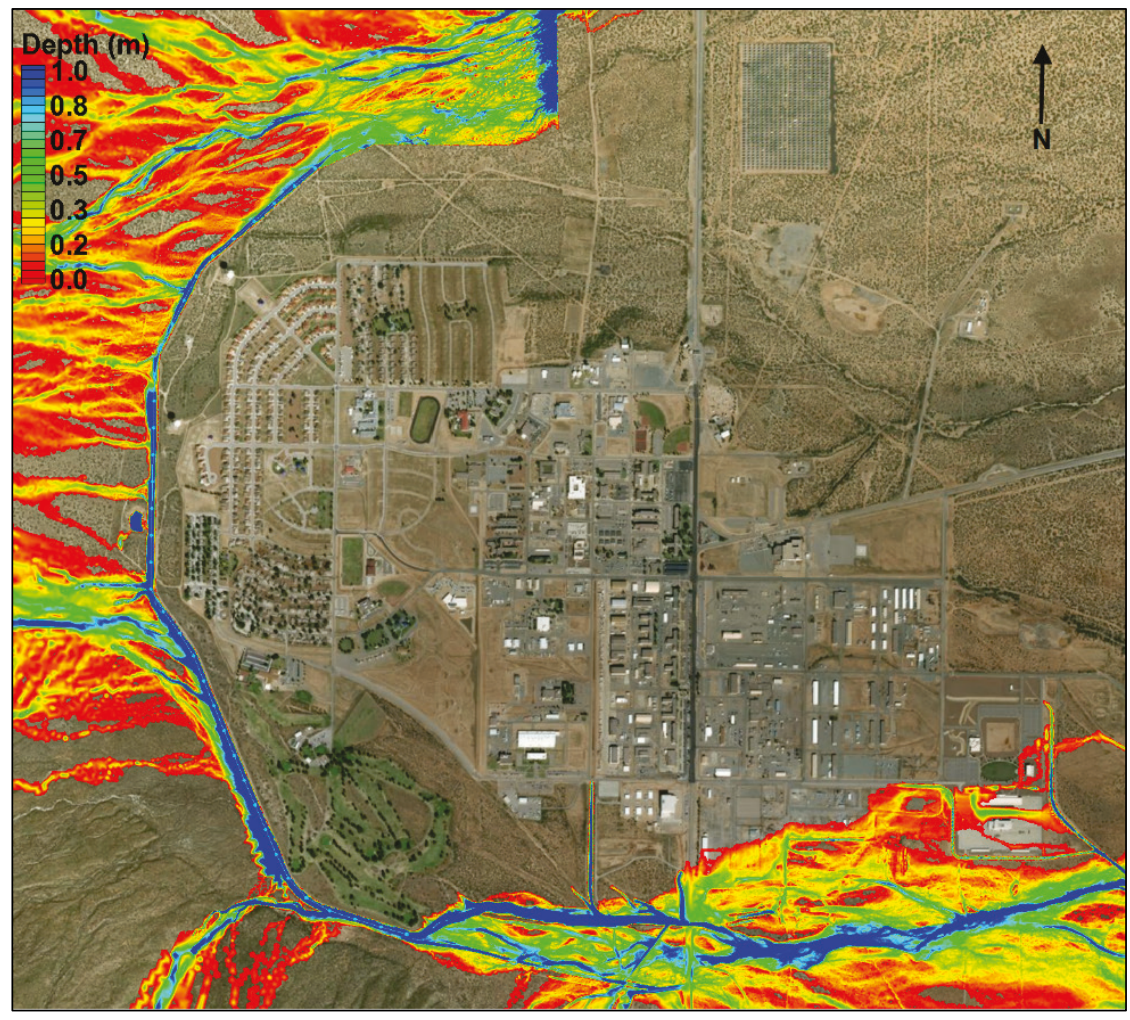

Figure 26. Alternative 2B; 1978-year event.

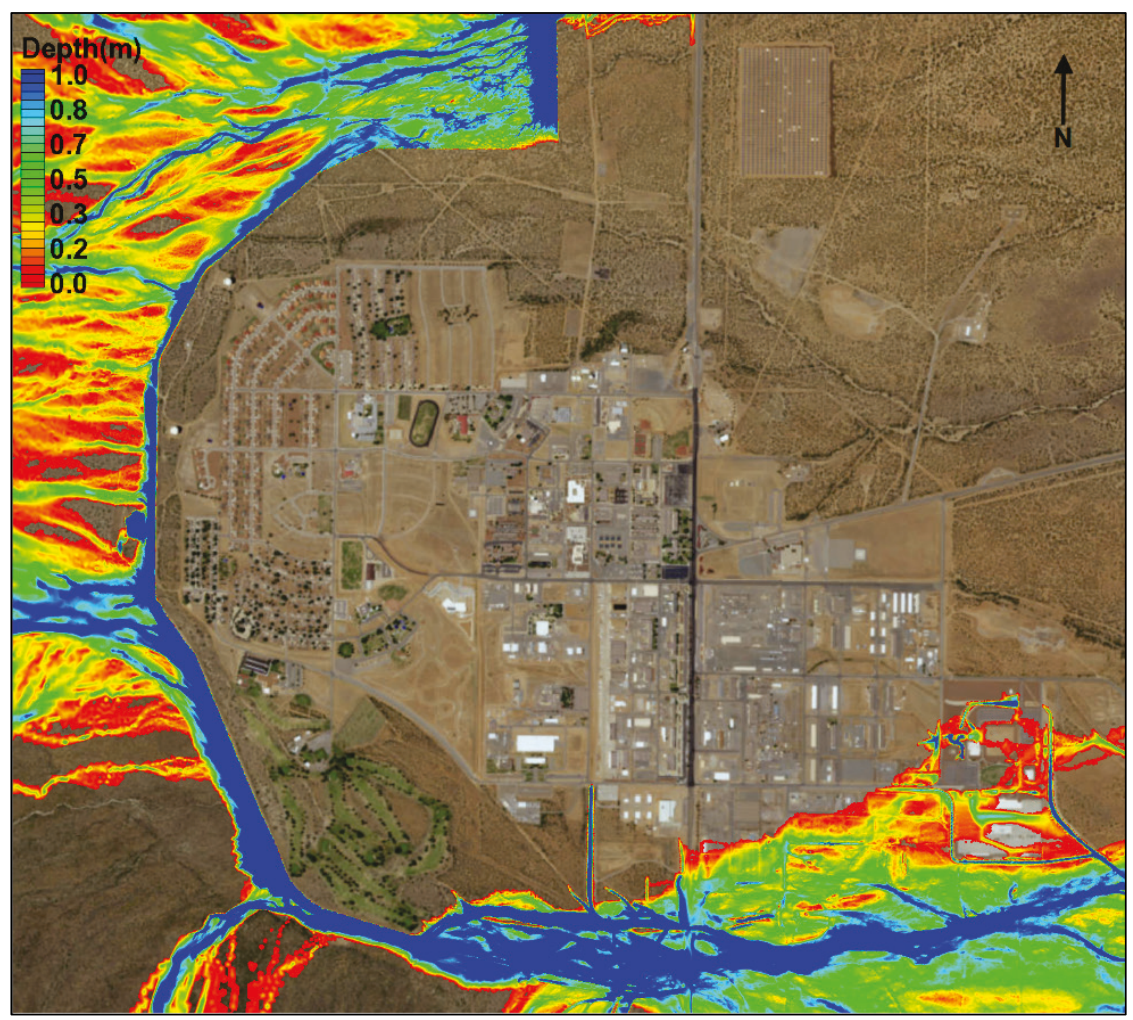


Figure 27. Alternative 2B results for the existing levee.

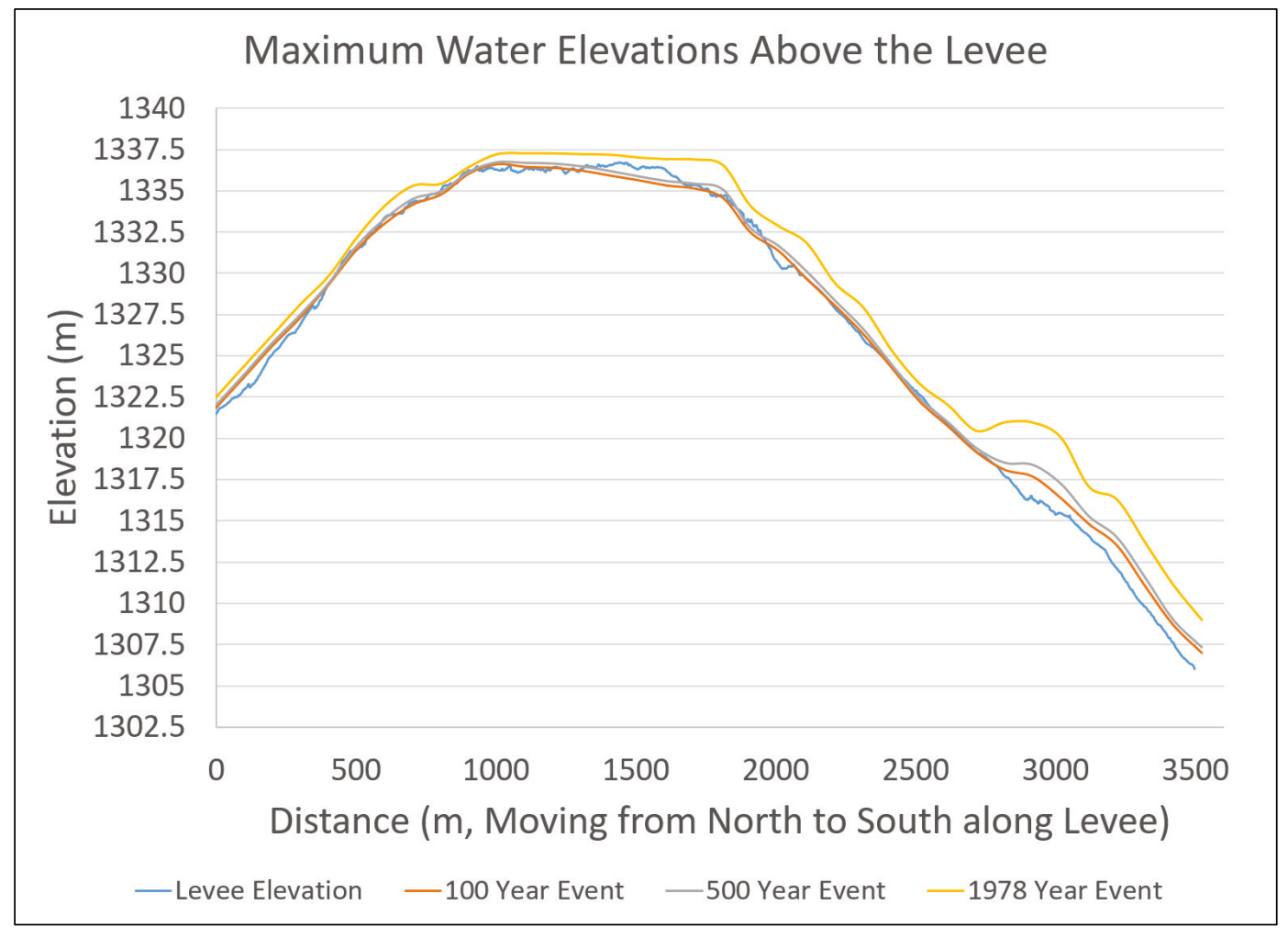

Figure 28. Alternative $2 \mathrm{~B}$ results for the new proposed north levee.

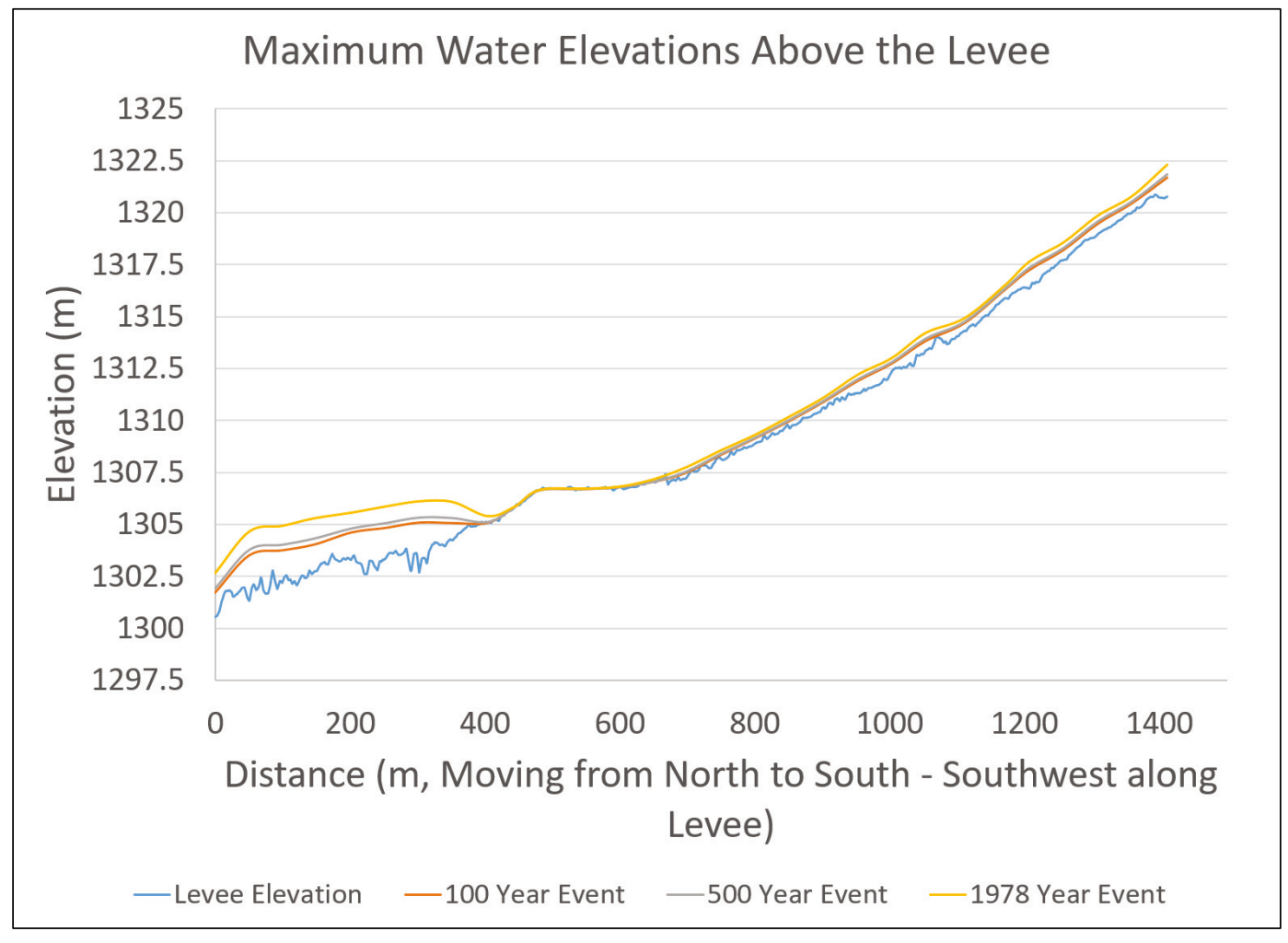


Figure 29. Alternatives 2B and 2A simulations at Owen Road.

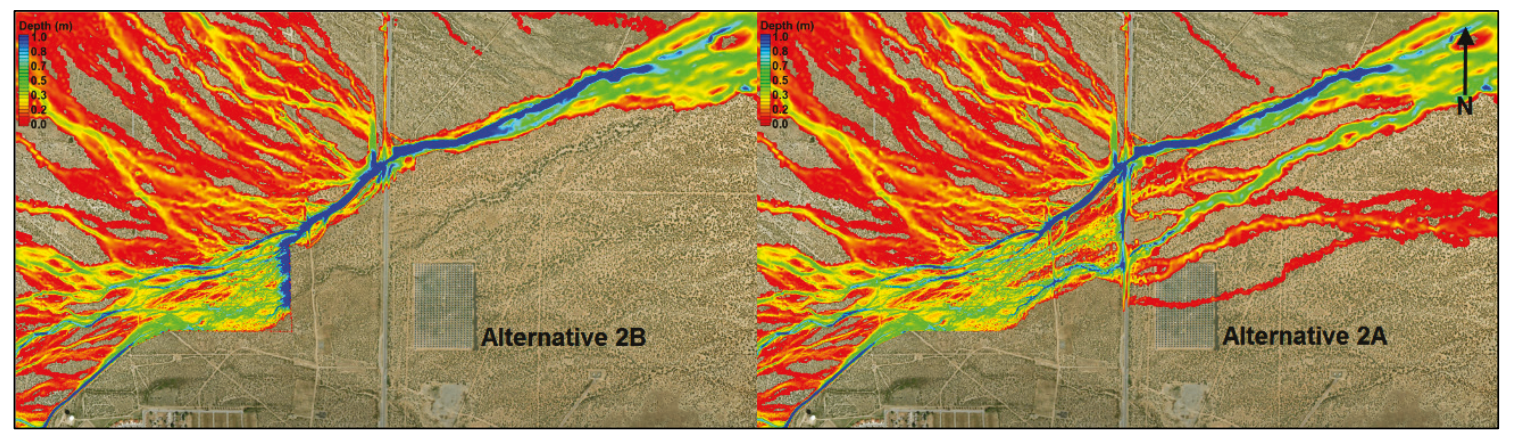

\subsection{Alternative 2C}

Additional modifications to Alternative 2B were implemented in this alternative (refer to Figure 14 for reference). The maximum water depth at each node during any point in time during the simulation was extracted and plotted (Figure 30 - Figure 32). Profile views of the maximum levee elevation and the maximum depth during the simulation for the existing levee and new proposed southern levee is plotted in Figure 33 and Figure 34, respectively.

Figure 30. Alternative 2C; 100-year event.

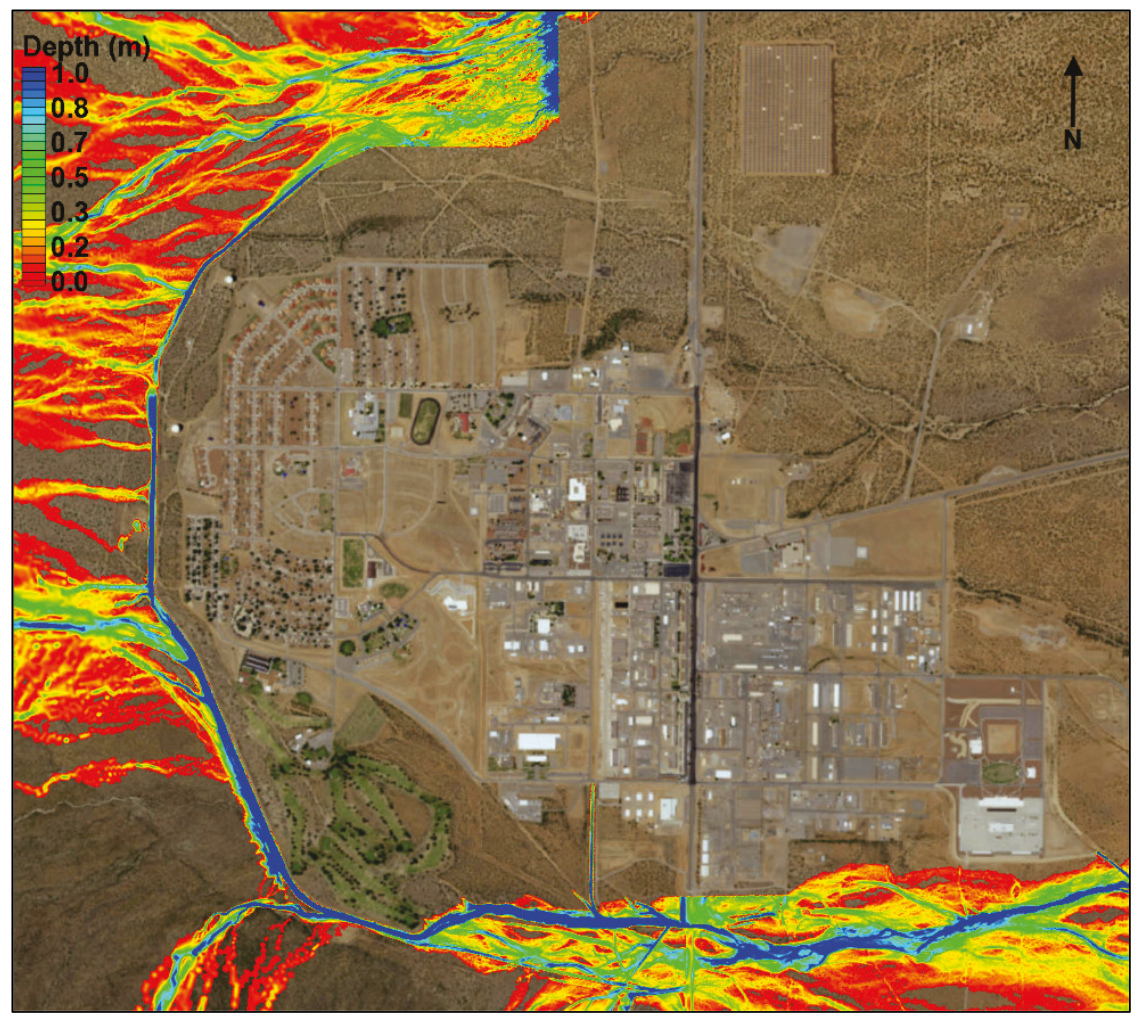


Figure 31. Alternative 2C; 500-year event.

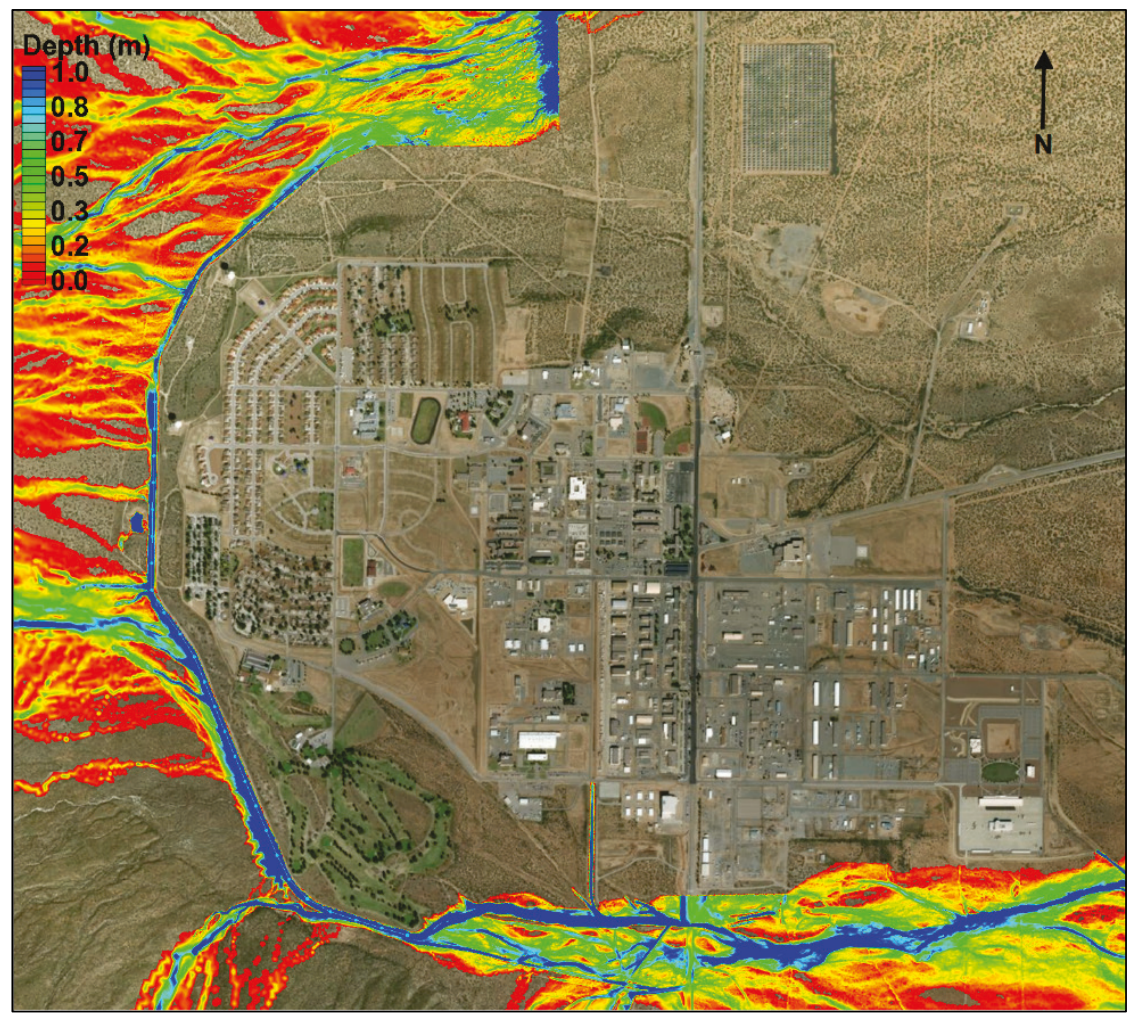

Figure 32. Alternative 2C; 1978-year event.

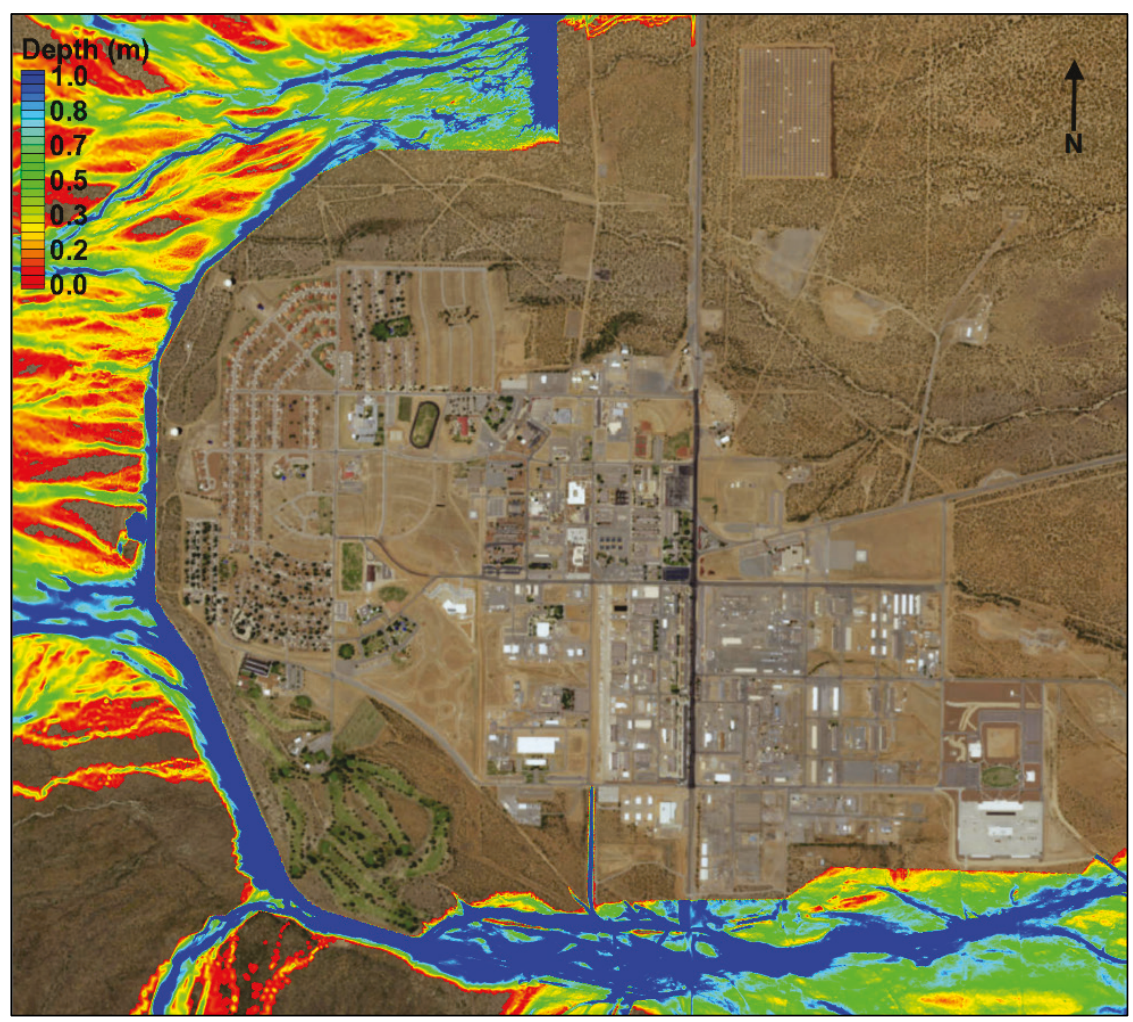


Figure 33. Alternative $2 \mathrm{C}$ results for the existing levee.

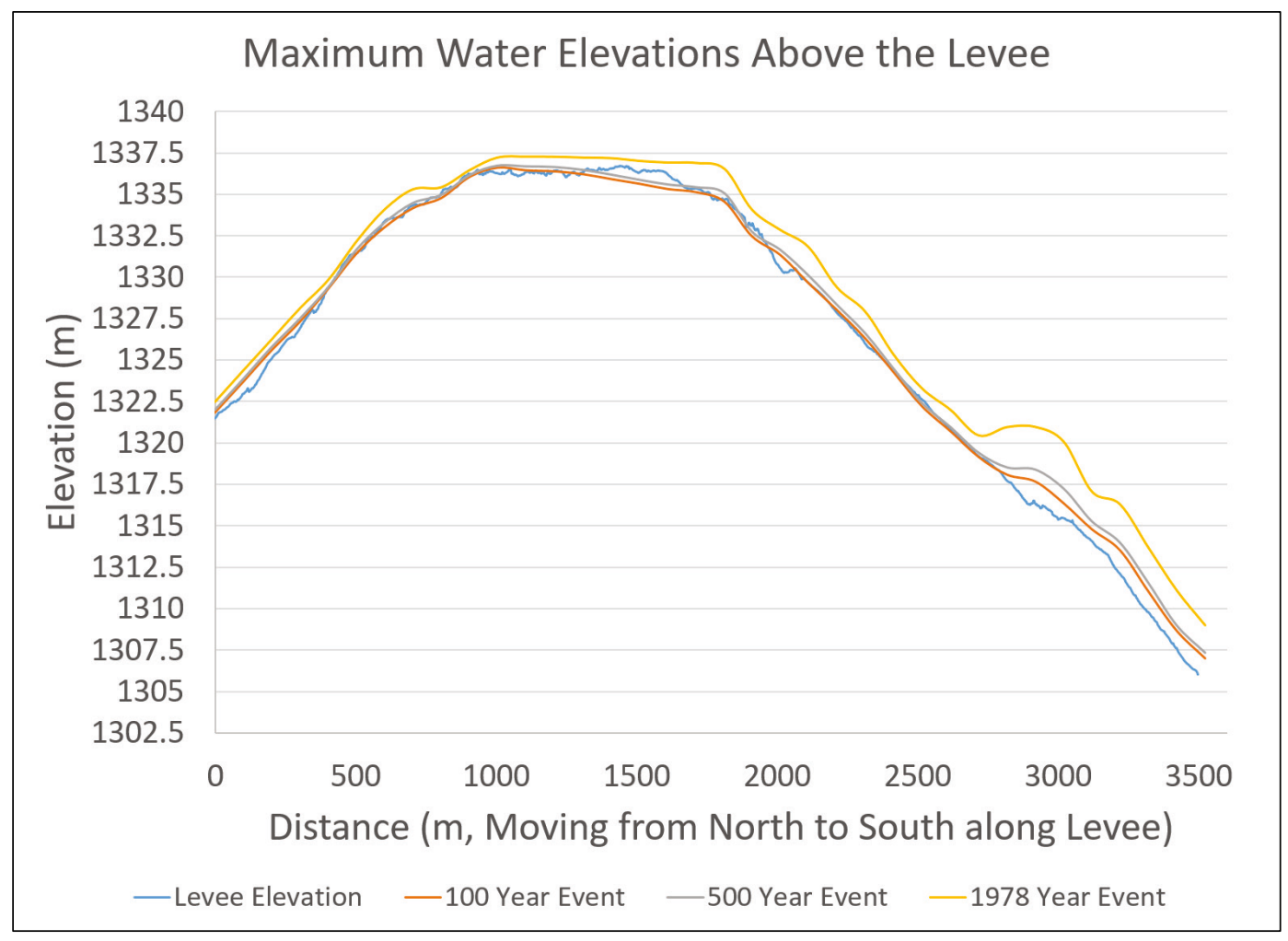

Figure 34. Alternative $2 \mathrm{C}$ results for the new proposed south levee.

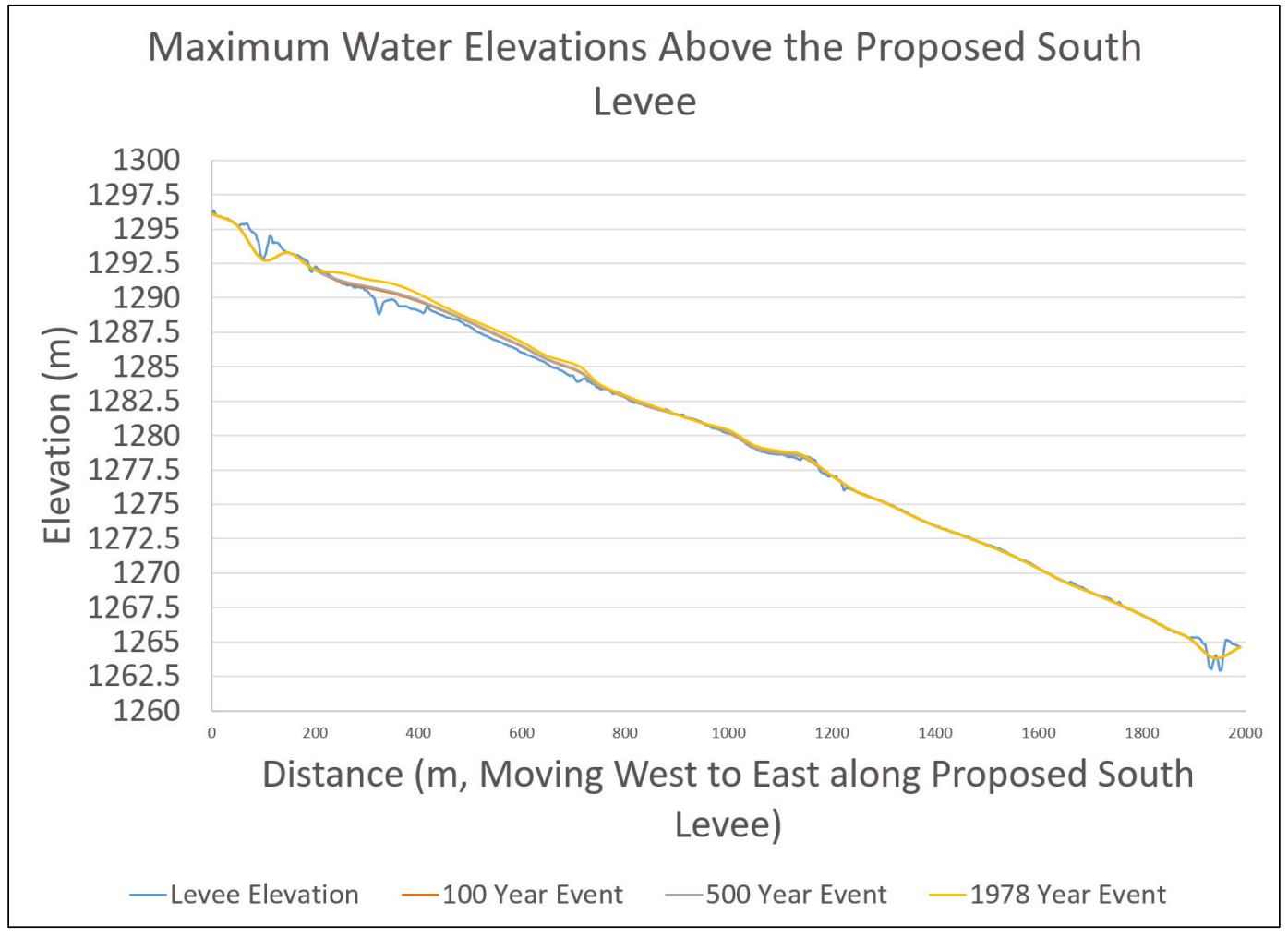


Alternative $2 \mathrm{C}$ was found to be the most successful in protecting the installation from flooding and inundation. In the following figures (Figure 35 - Figure 46), the maximum water depth can be tracked periodically (10minute increments, beginning at the 1-hour, 10-minute mark) throughout the simulation for the 100-year event.

Figure 35. Alternative 2C; 100-year event results at 1 hour, 10 minutes.

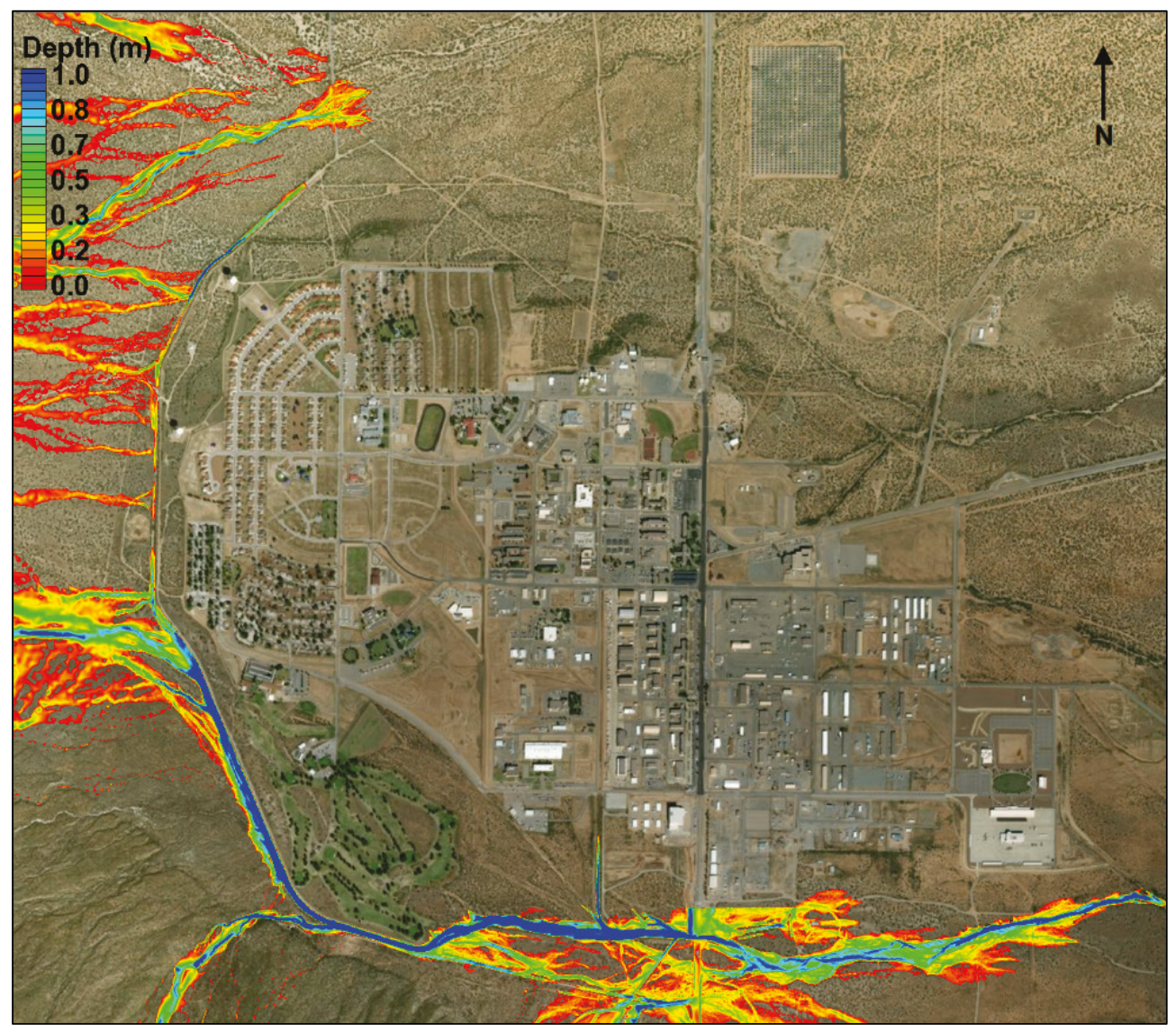


Figure 36. Alternative 2C; 100-year event results at 1 hour, 20 minutes.

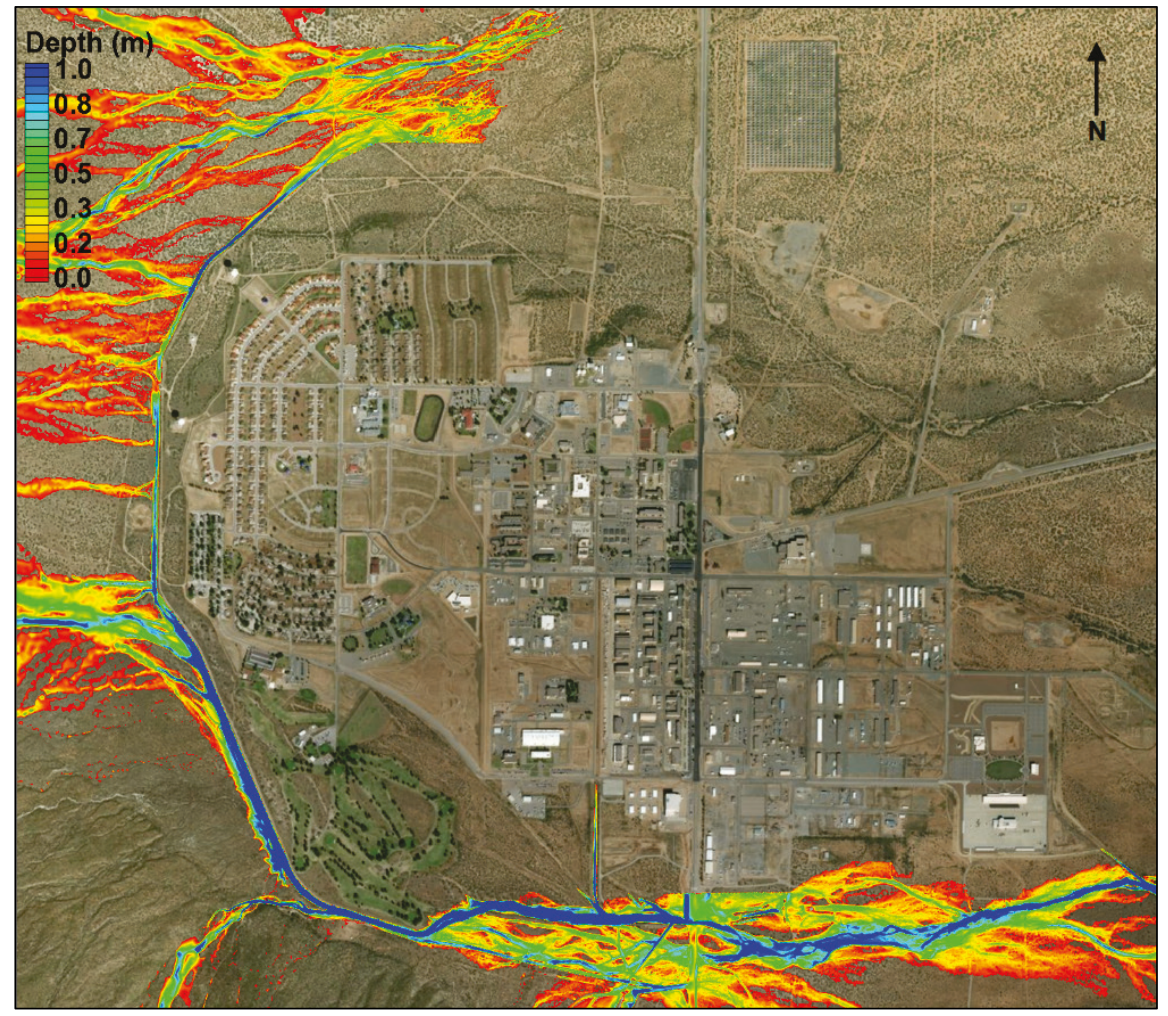

Figure 37. Alternative 2C; 100-year event results at 1 hour, 30 minutes.

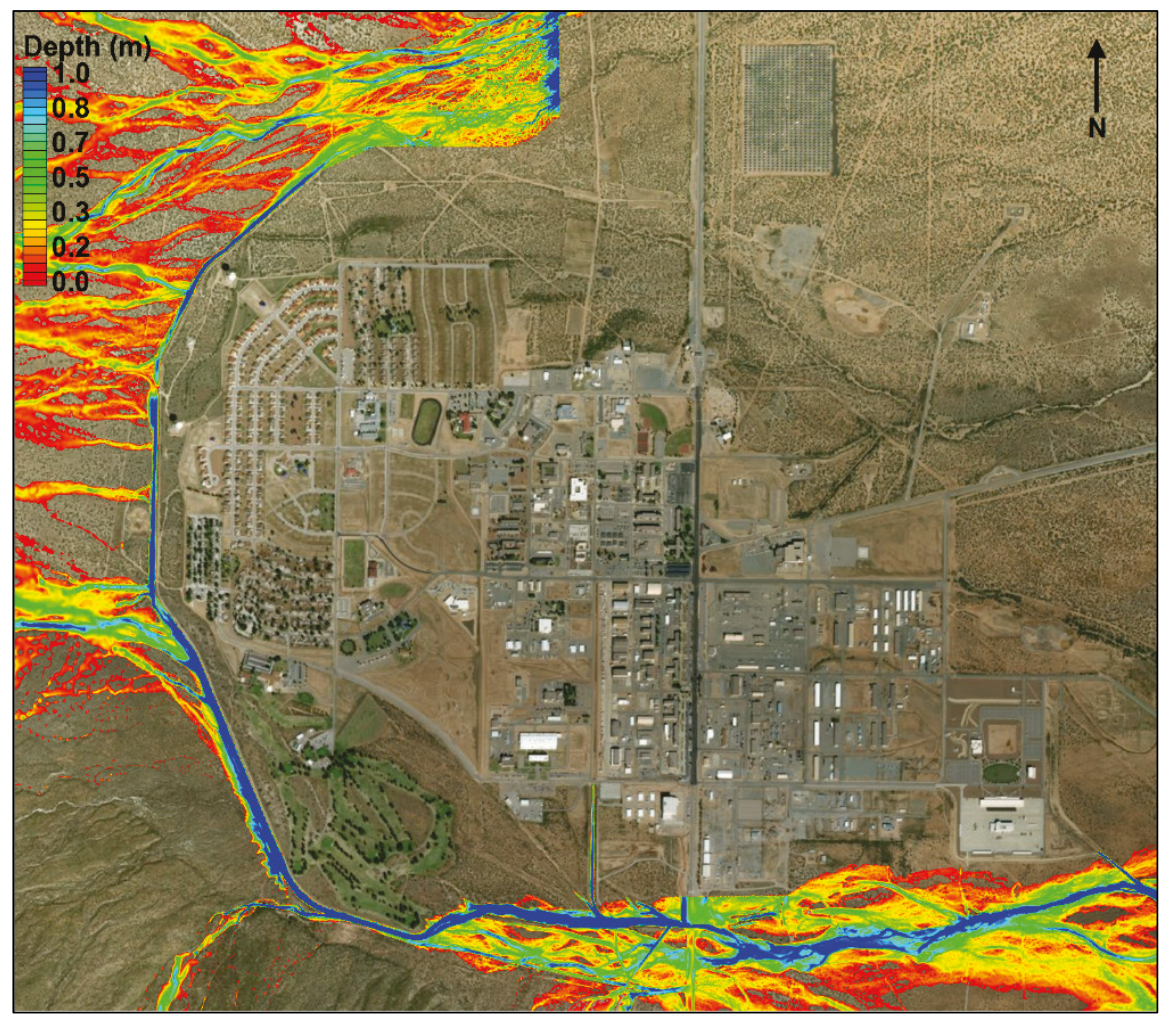


Figure 38. Alternative 2C; 100-year event results at 1 hour, 40 minutes.

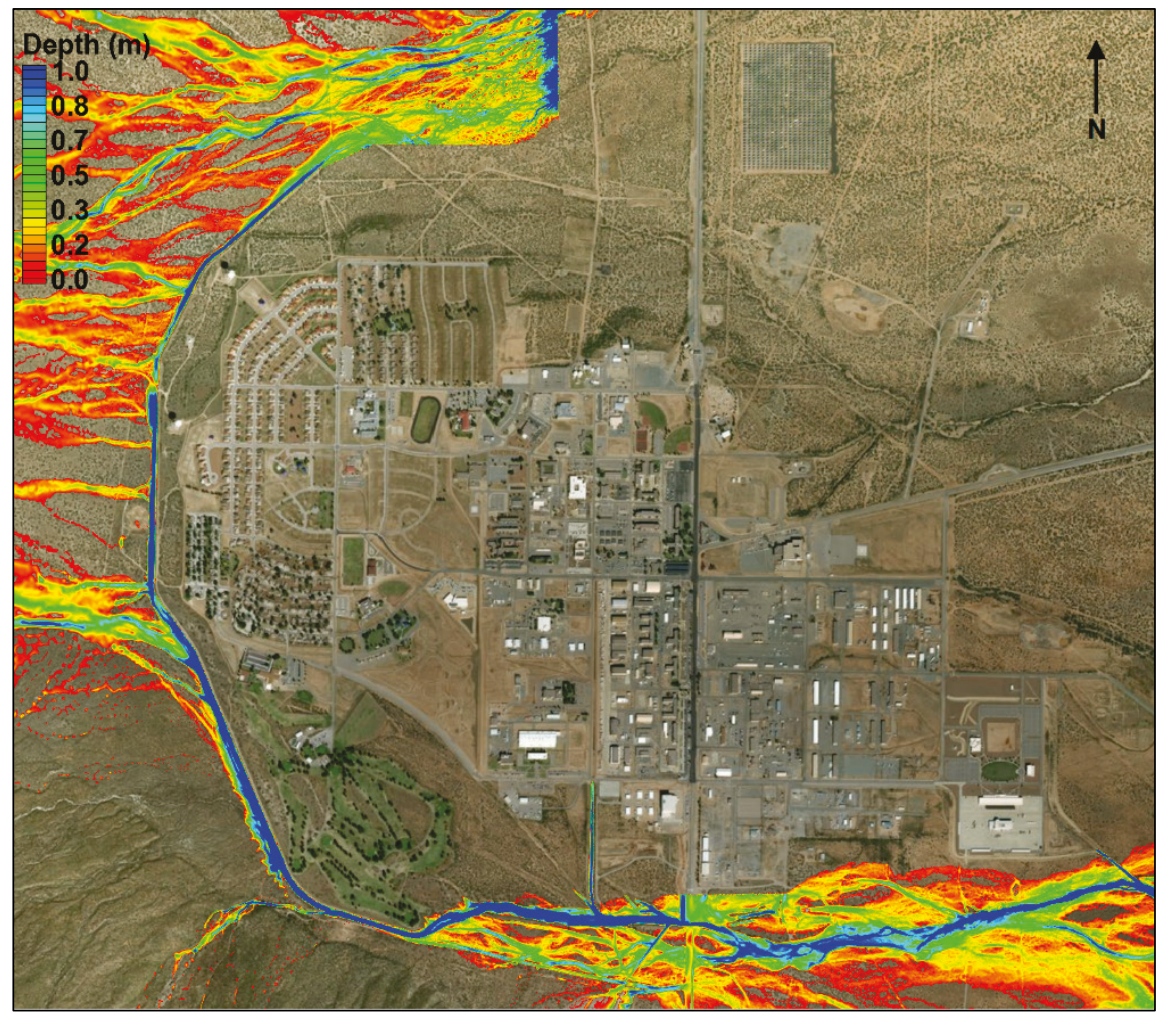

Figure 39. Alternative 2C; 100-year event results at 1 hour, 50 minutes.

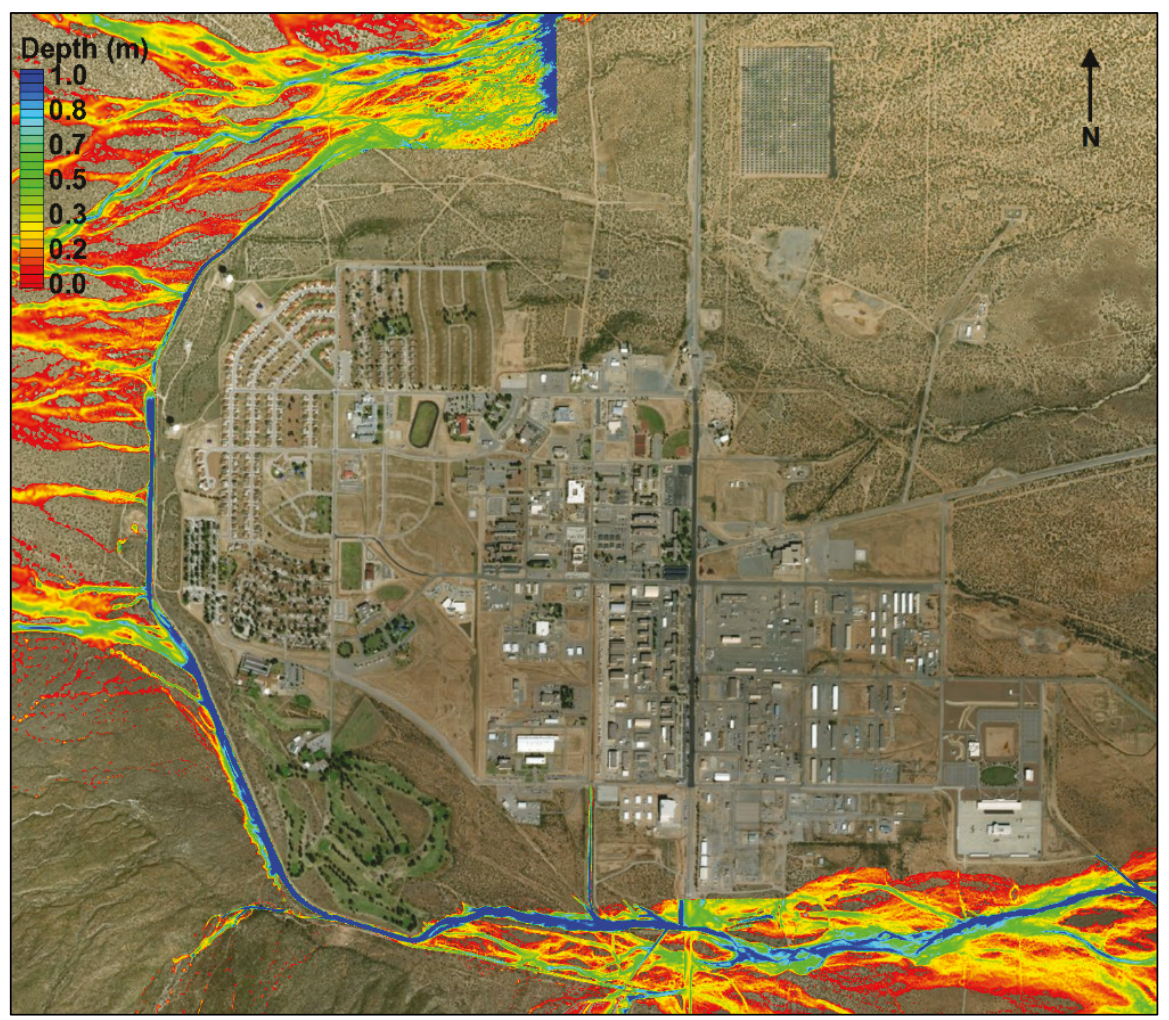


Figure 40. Alternative 2C; 100 -year event results at 2 hours.

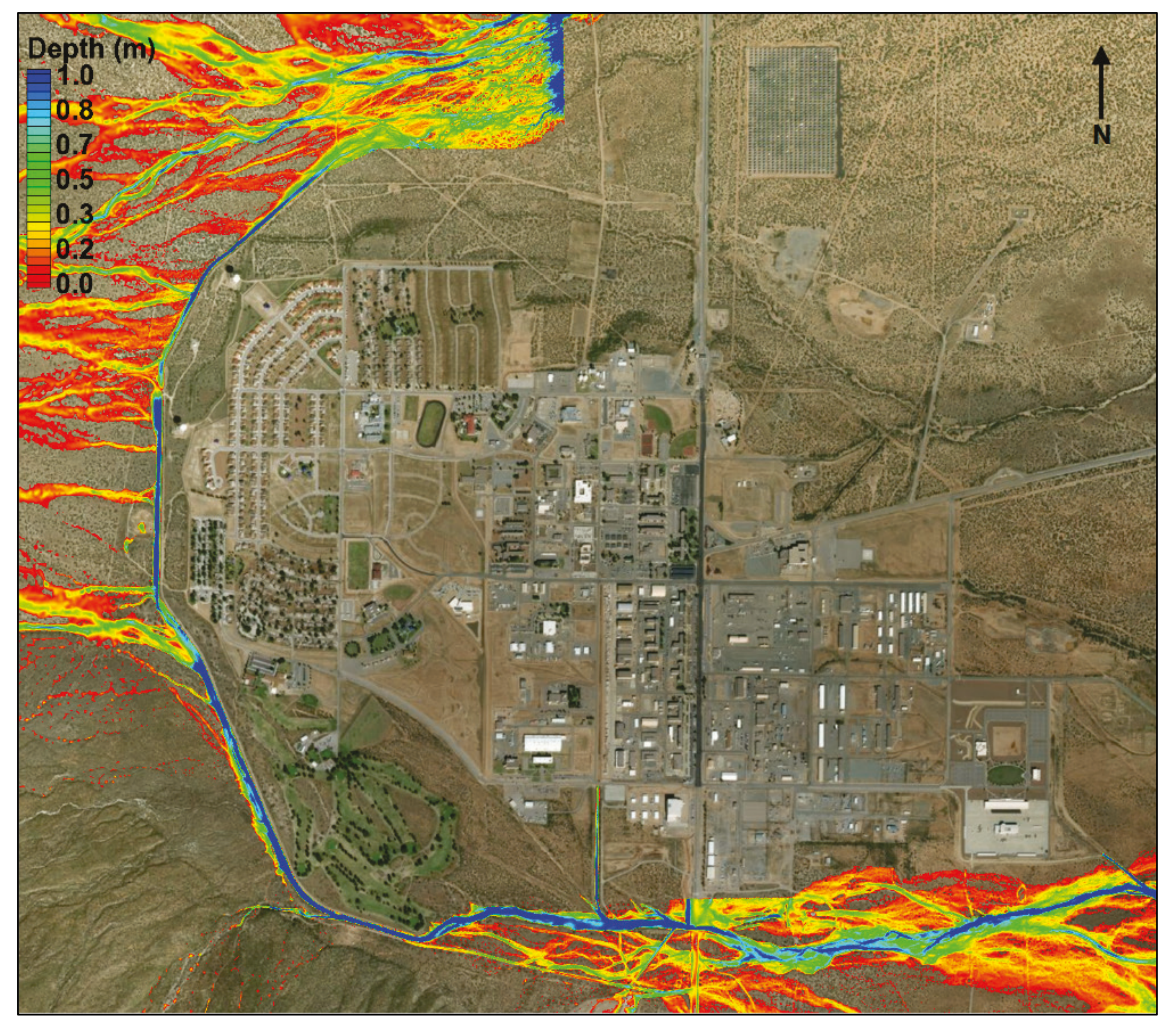

Figure 41. Alternative 2C; 100-year event results at 2 hours, 10 minutes.

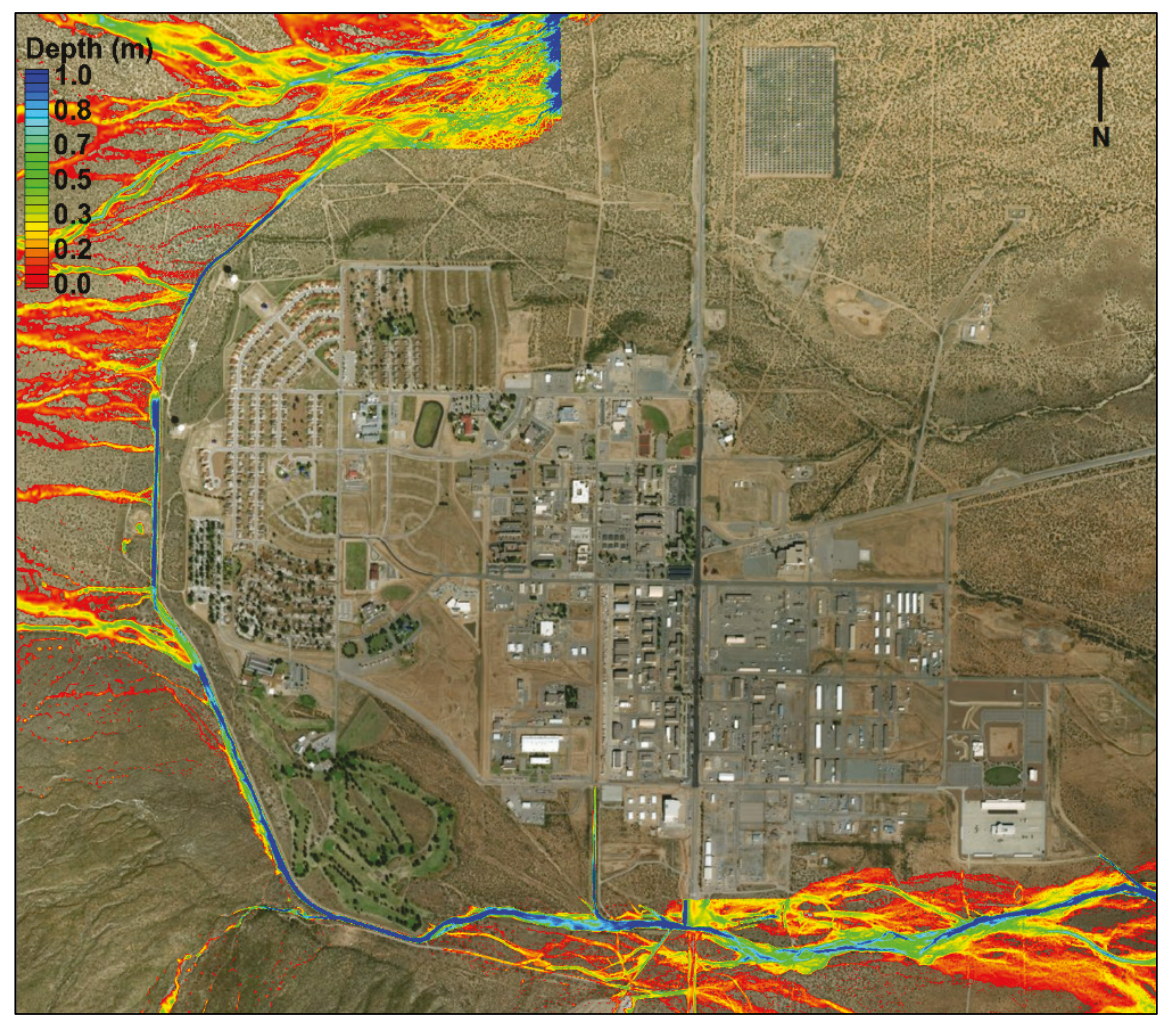


Figure 42. Alternative 2C; 100 -year event results at 2 hours, 20 minutes.

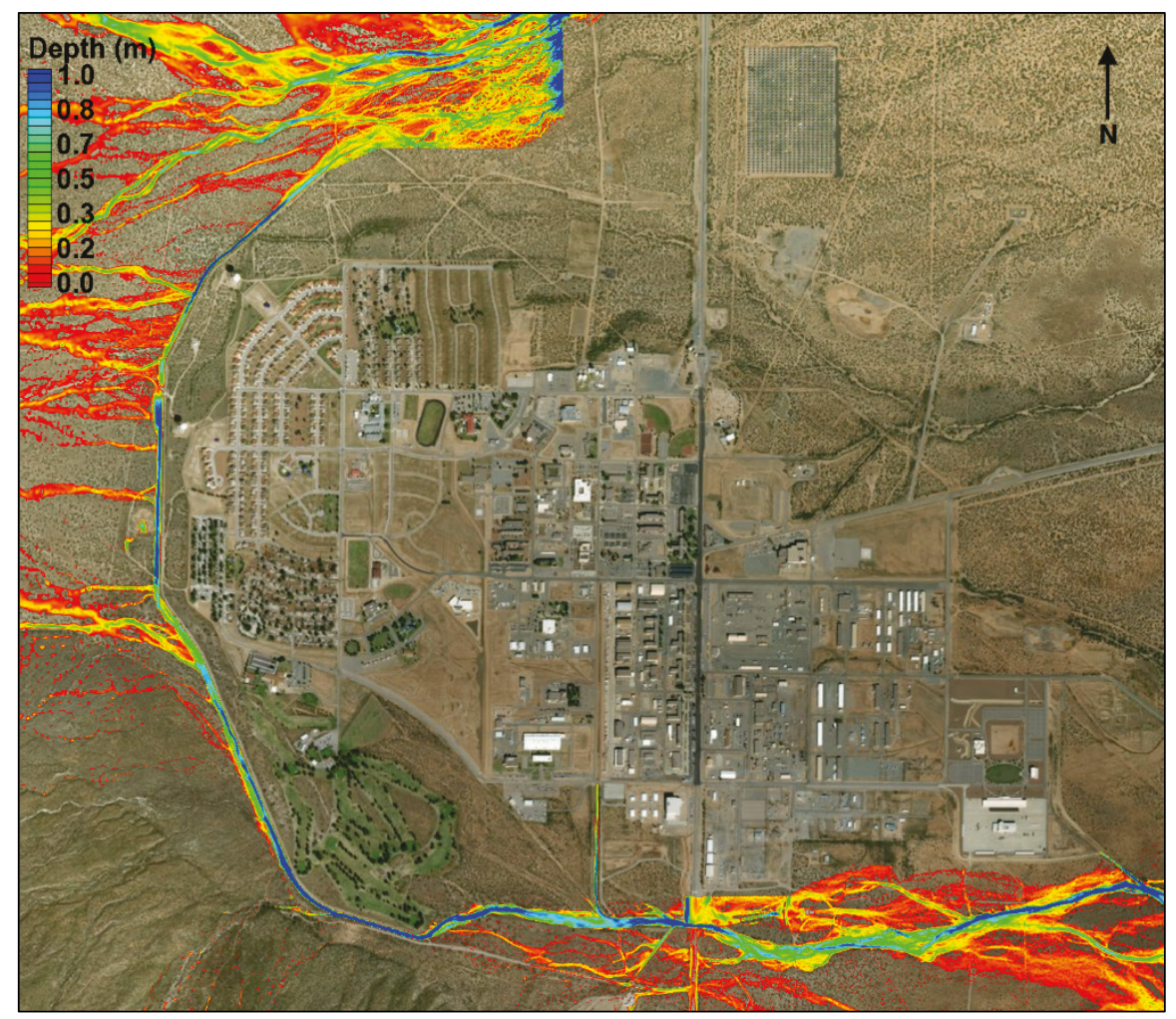

Figure 43. Alternative 2C; 100 -year event results at 2 hours, 30 minutes.

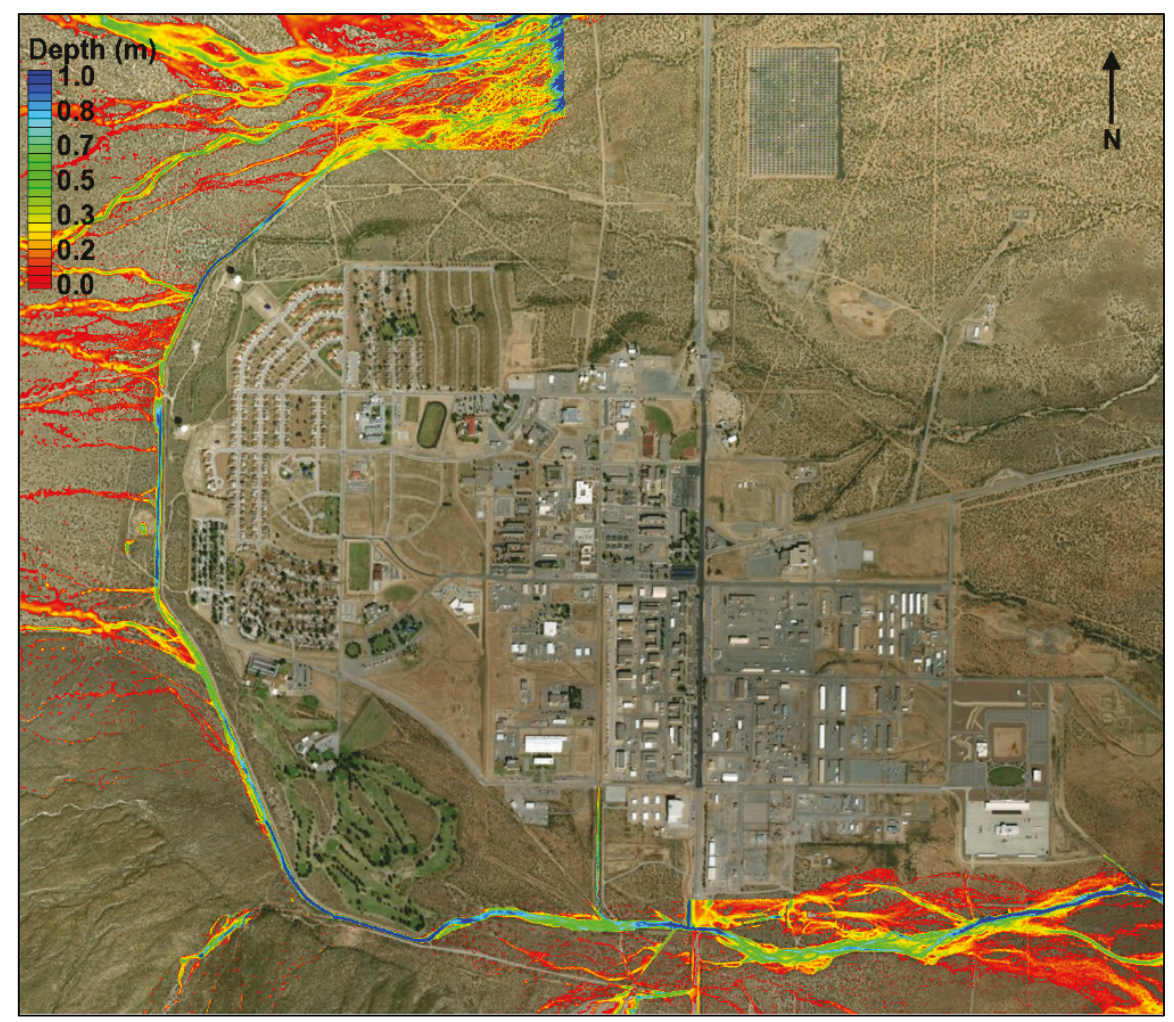


Figure 44. Alternative 2C; 100 -year event results at 2 hours, 40 minutes.

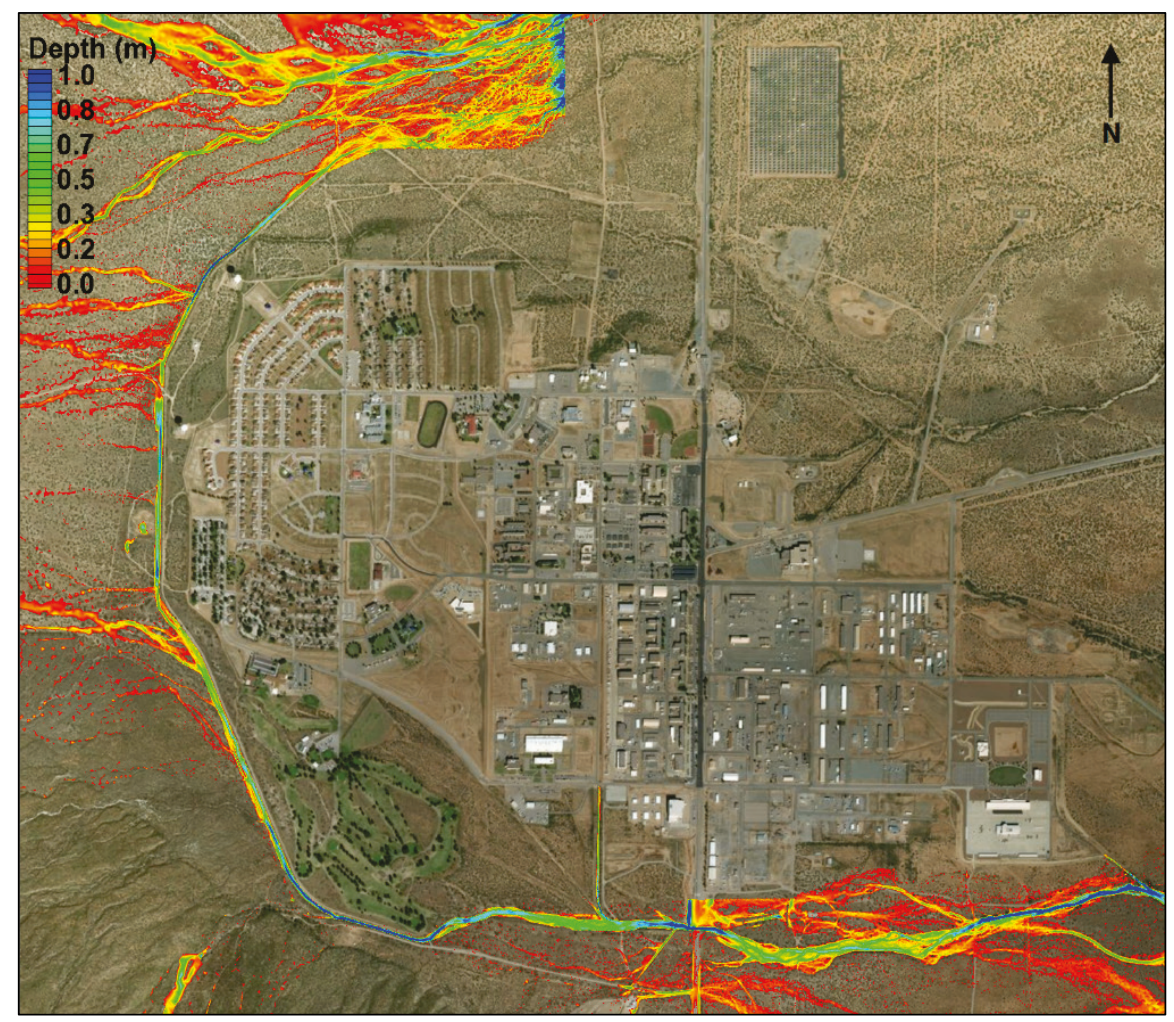

Figure 45. Alternative 2C; 100 -year event results at 2 hours, 50 minutes.

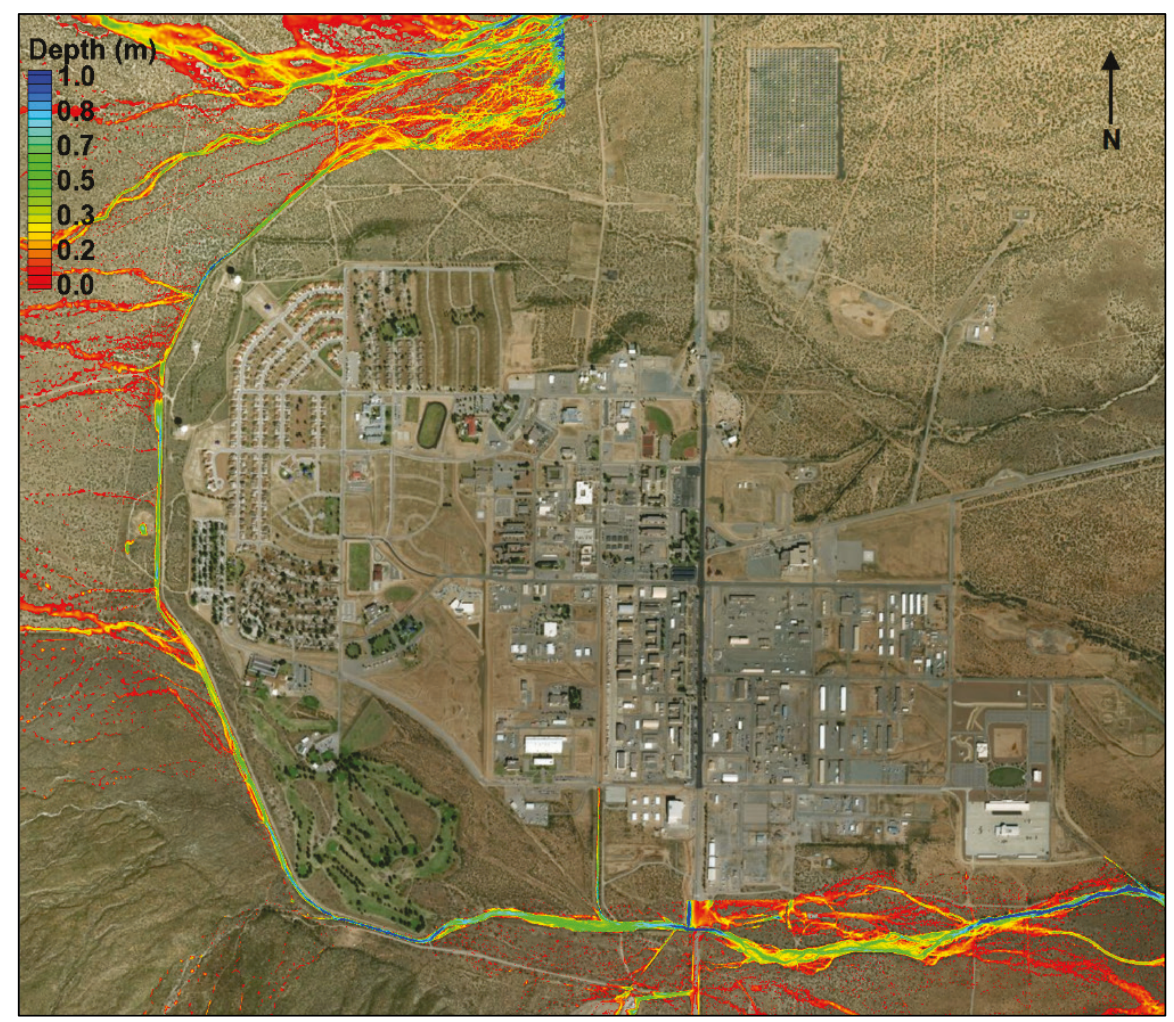


Figure 46. Alternative 2C; 100 -year event results at 3 hours.

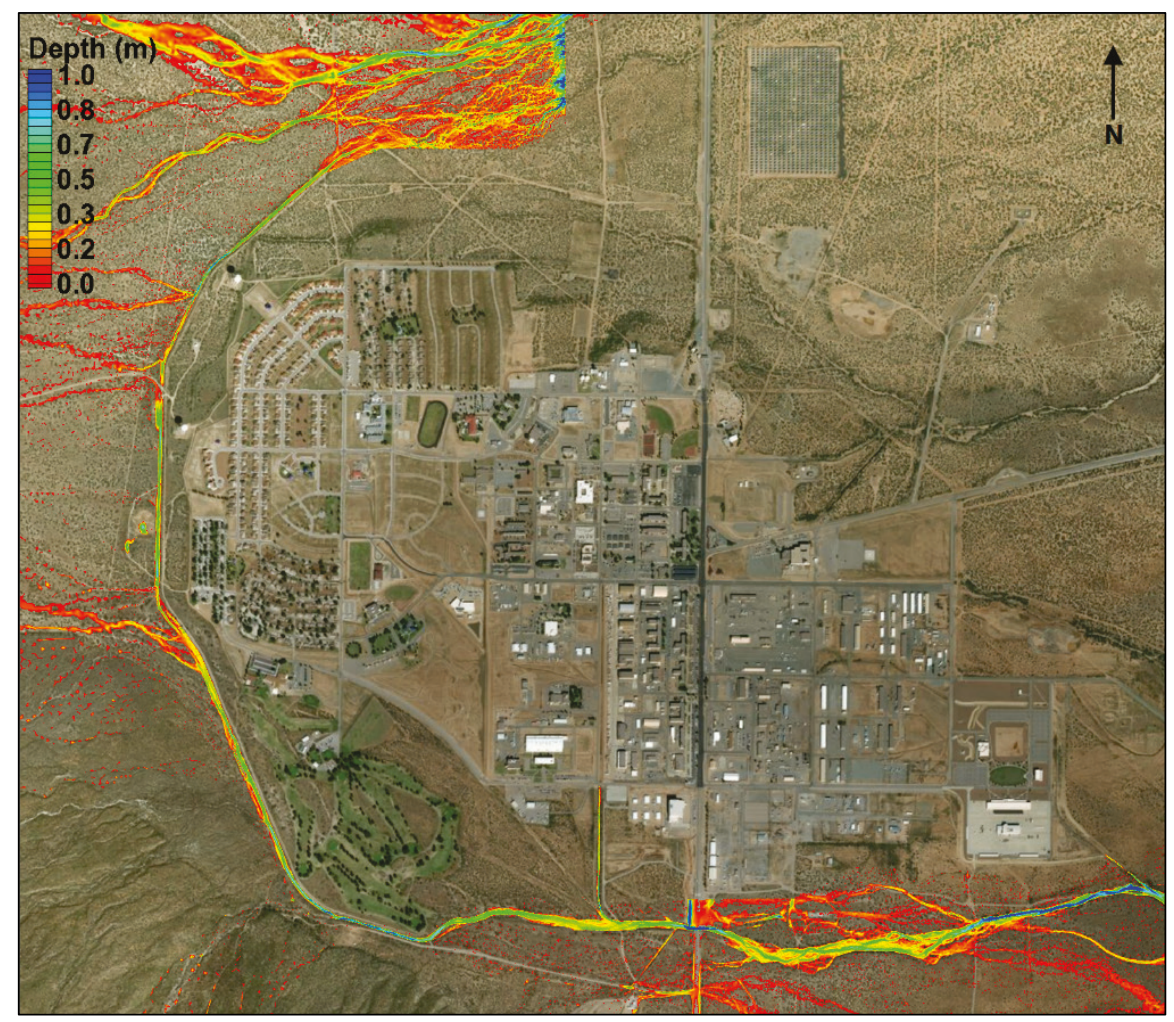

\subsection{Sensitivity analysis}

Since there were no validation data available, ERDC conducted a sensitivity analysis to determine the impact of varying model parameters. This was accomplished by varying the values for Manning's roughness. Note that the value for Manning's roughness for the existing conditions and Alternative 1 were $\mathrm{n}=0.030$ (for all material types). Sensitivity A used a value of 0.035, and Sensitivity B used 0.025 for surface roughness values for all material types. The 100-year, 500-year, and 1978-year storm events were simulated for each roughness value, totaling to nine numerical simulations. Overall, the variation of the storm frequency had the most effect on the model. The range of Manning's roughness values taken were from recommendations from Arcement et al. (1989) and Chow (1959). In general, the expectancy that the water depths would be slightly greater in locations with increased roughness proved to be true. However, the difference of adjusting the roughness value for the entire model was minimal, and the value of $n=$ 0.030 was used for all simulations. The results of these simulations can be seen in Figure $47-$ Figure 58. For reference, Alternative 1 simulation results can be seen in Figure 15 - Figure 18. 
Figure 47. Sensitivity B $(n=0.025)$ results, 100 -year event.

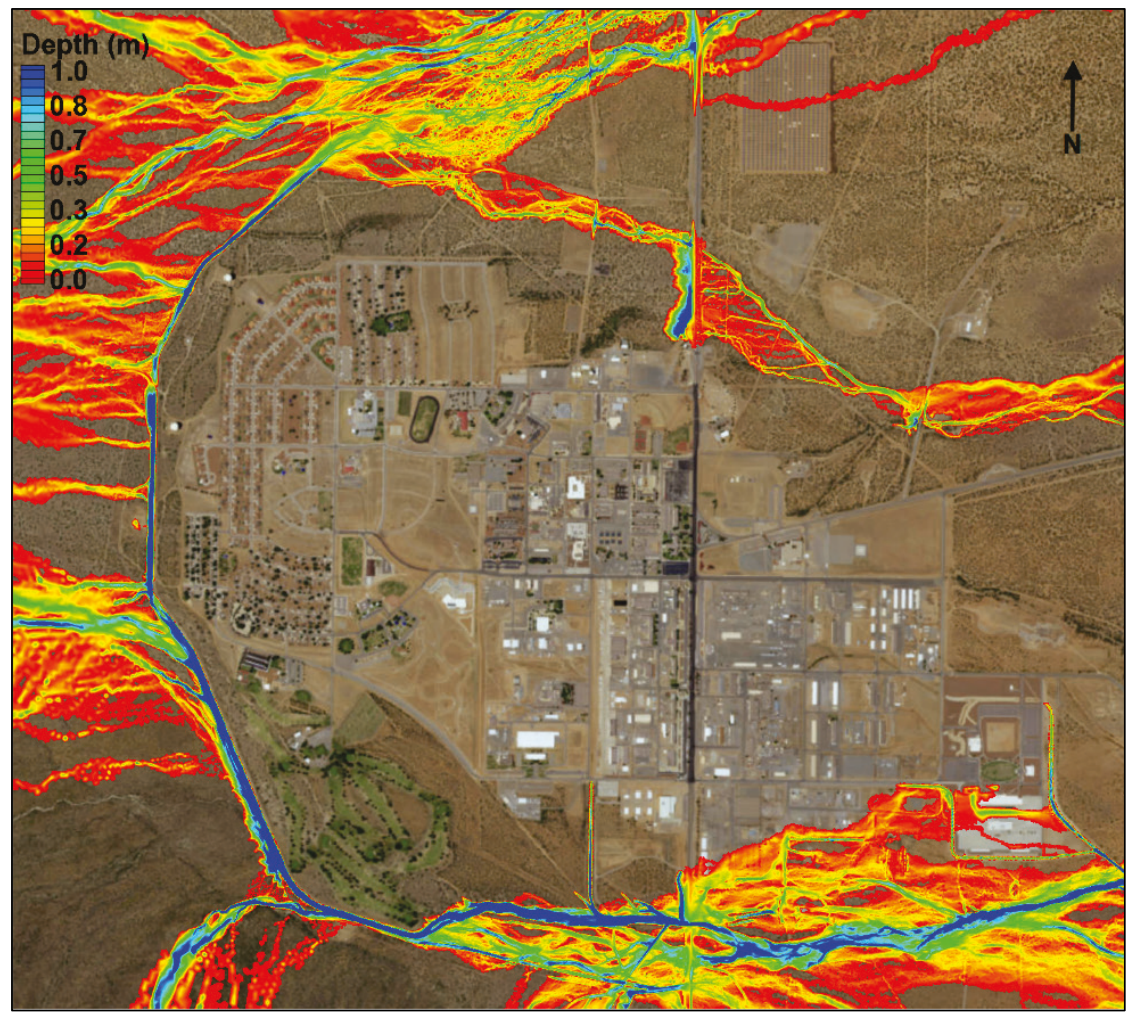

Figure 48. Sensitivity A ( $n=0.035$ ) results, 100 -year event.

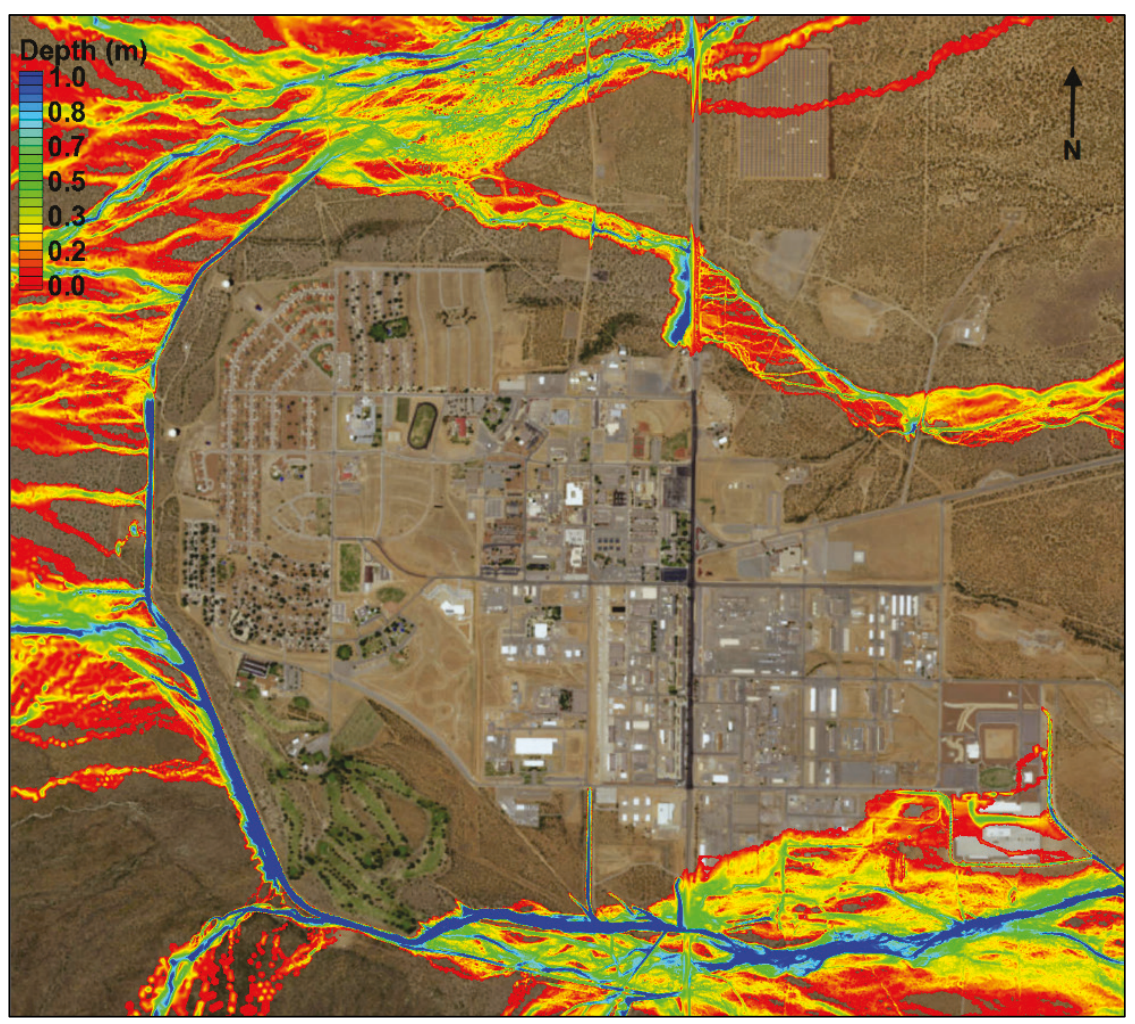


Figure 49. Alternative 1 - Sensitivity B difference plot, 100-year event.

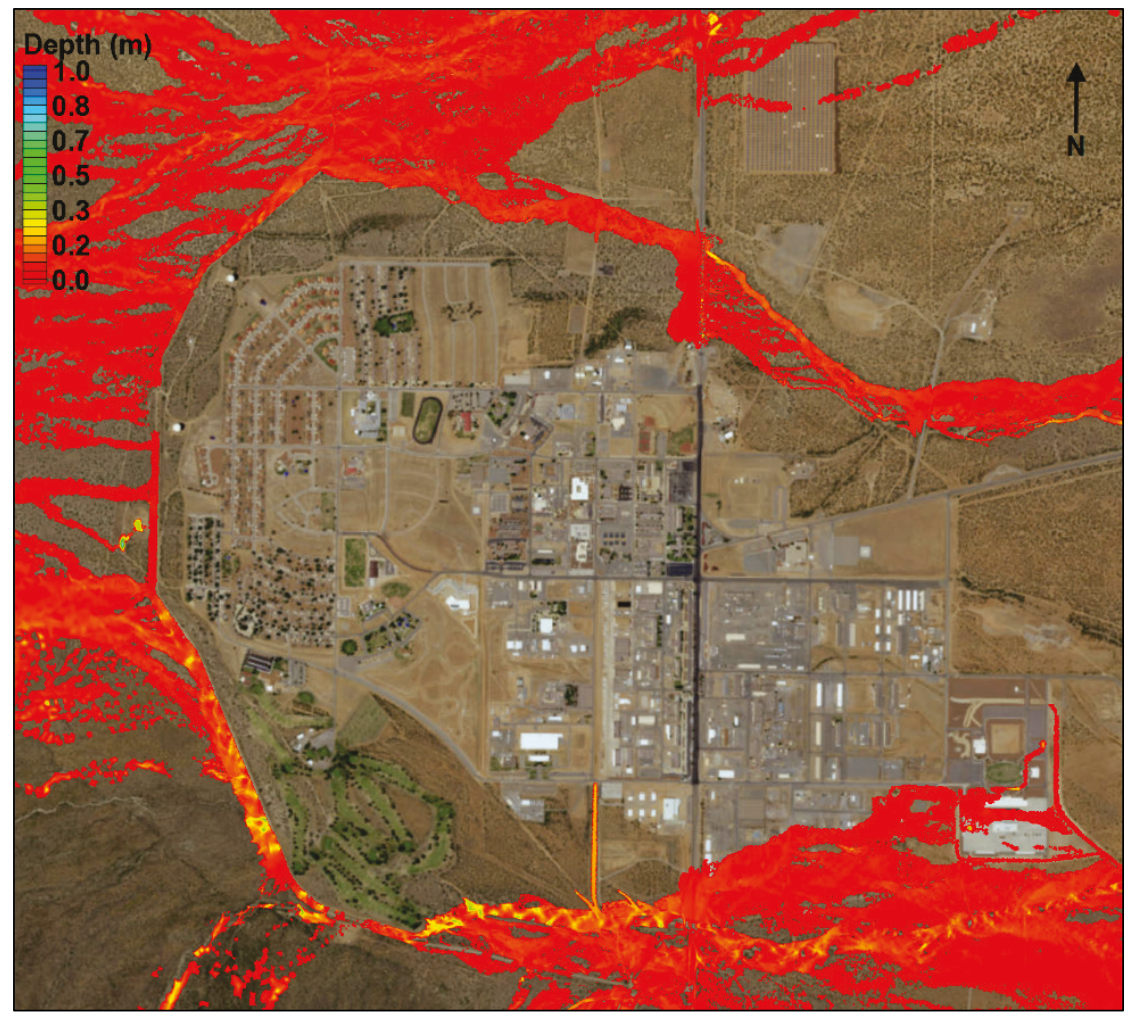

Figure 50. Sensitivity A - Alternative 1 difference plot, 100-year event.

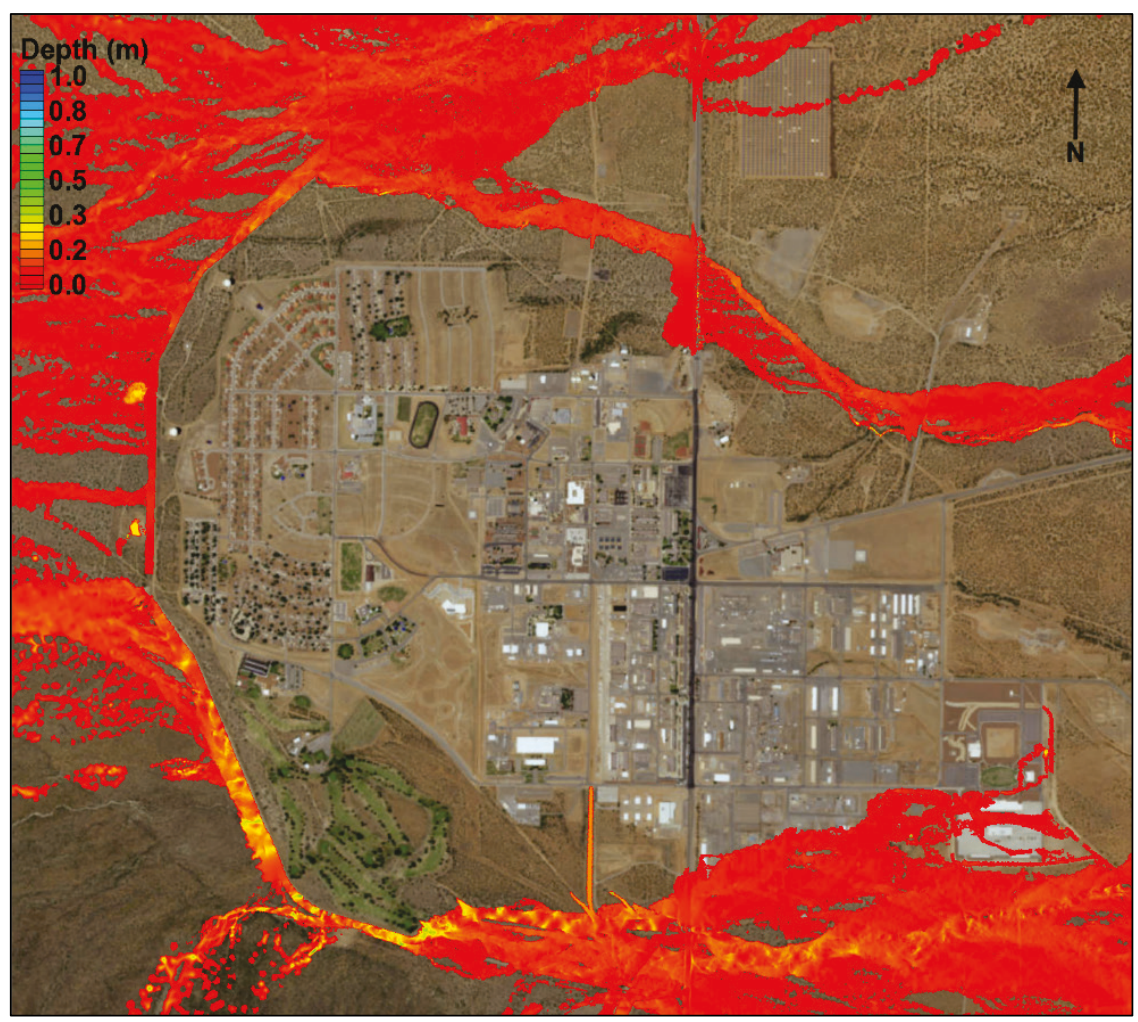


Figure 51. Sensitivity B $(n=0.025)$ results, 500-year event.

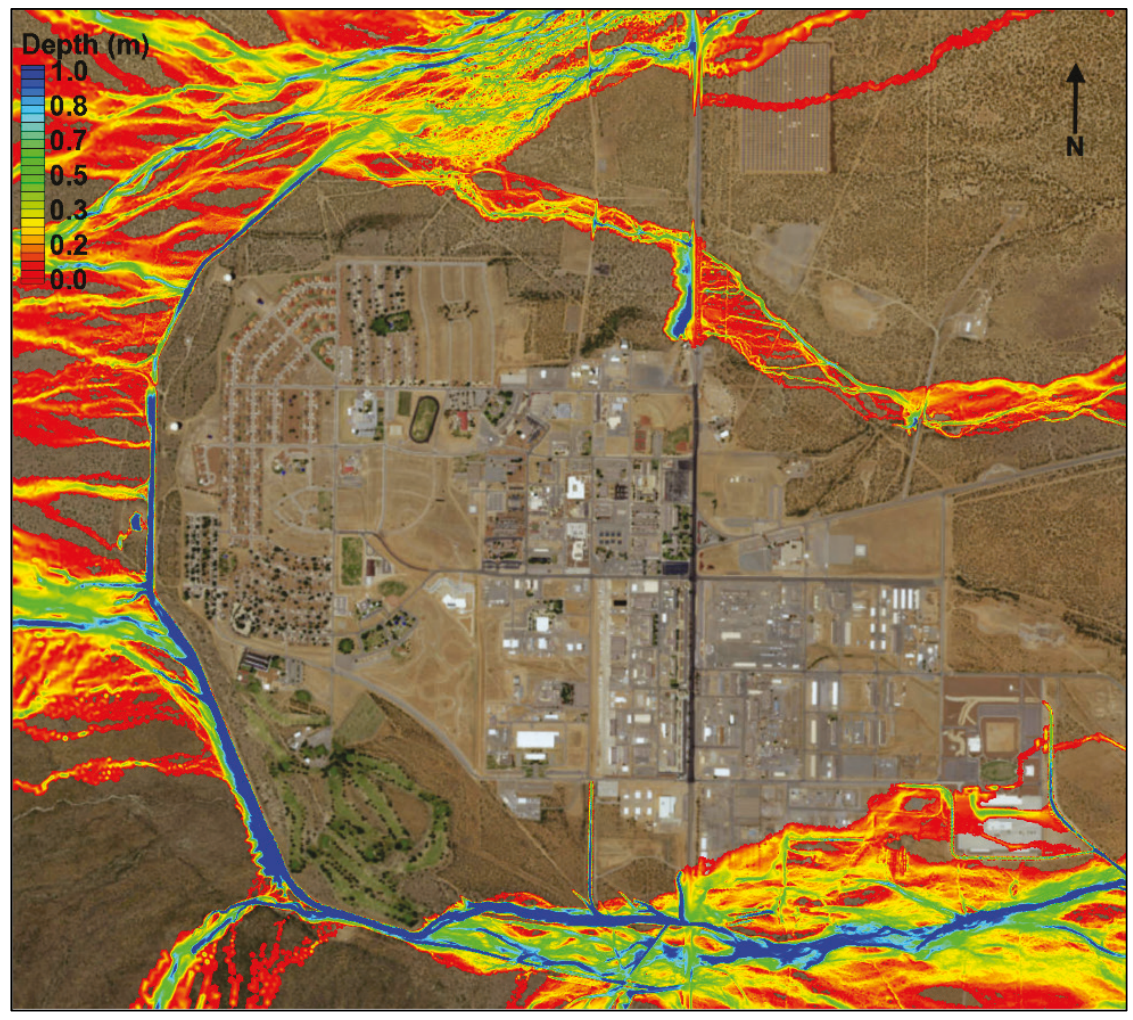

Figure 52. Sensitivity $A(n=0.035)$ results, 500-year event.

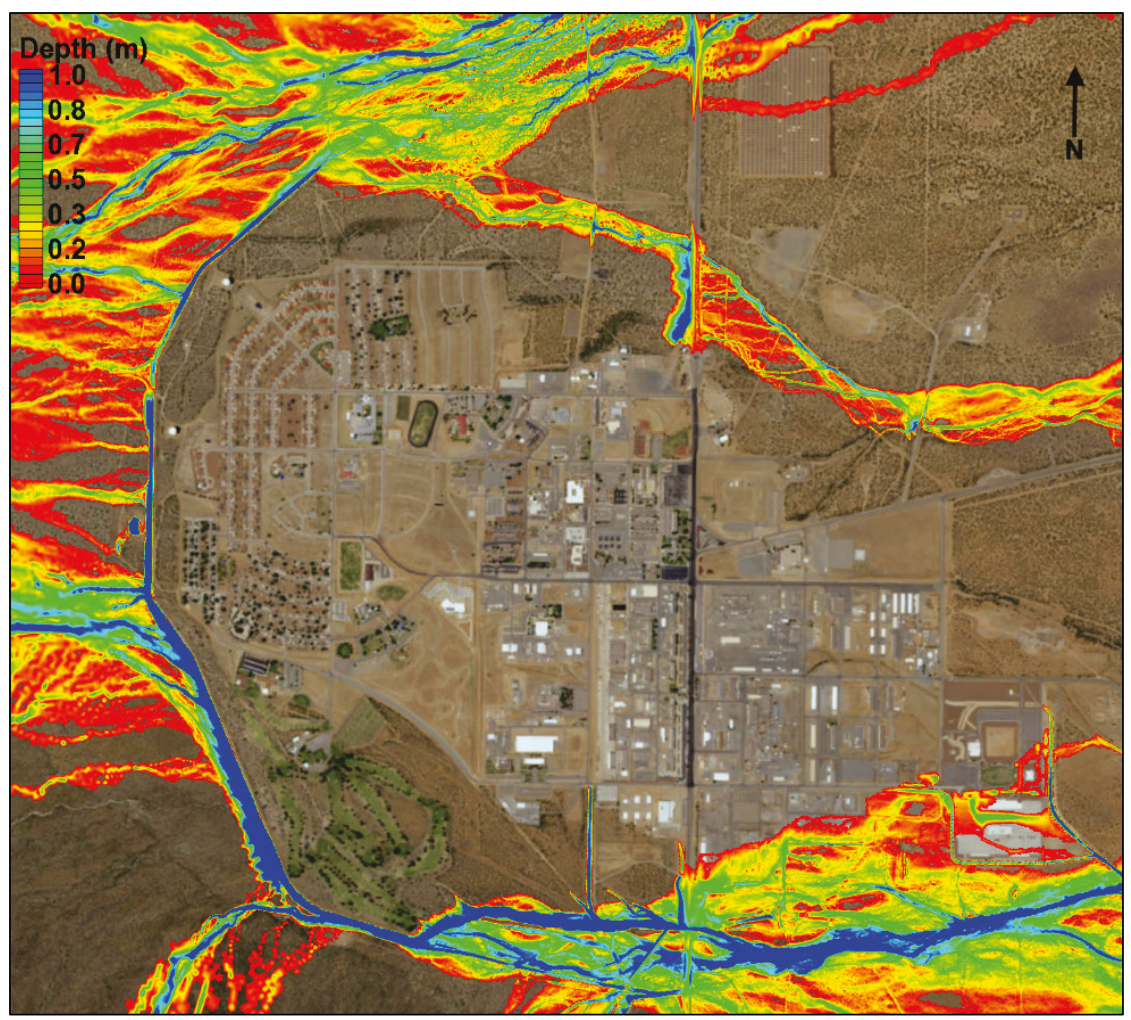


Figure 53. Alternative 1 - Sensitivity B difference plot, 500-year event.

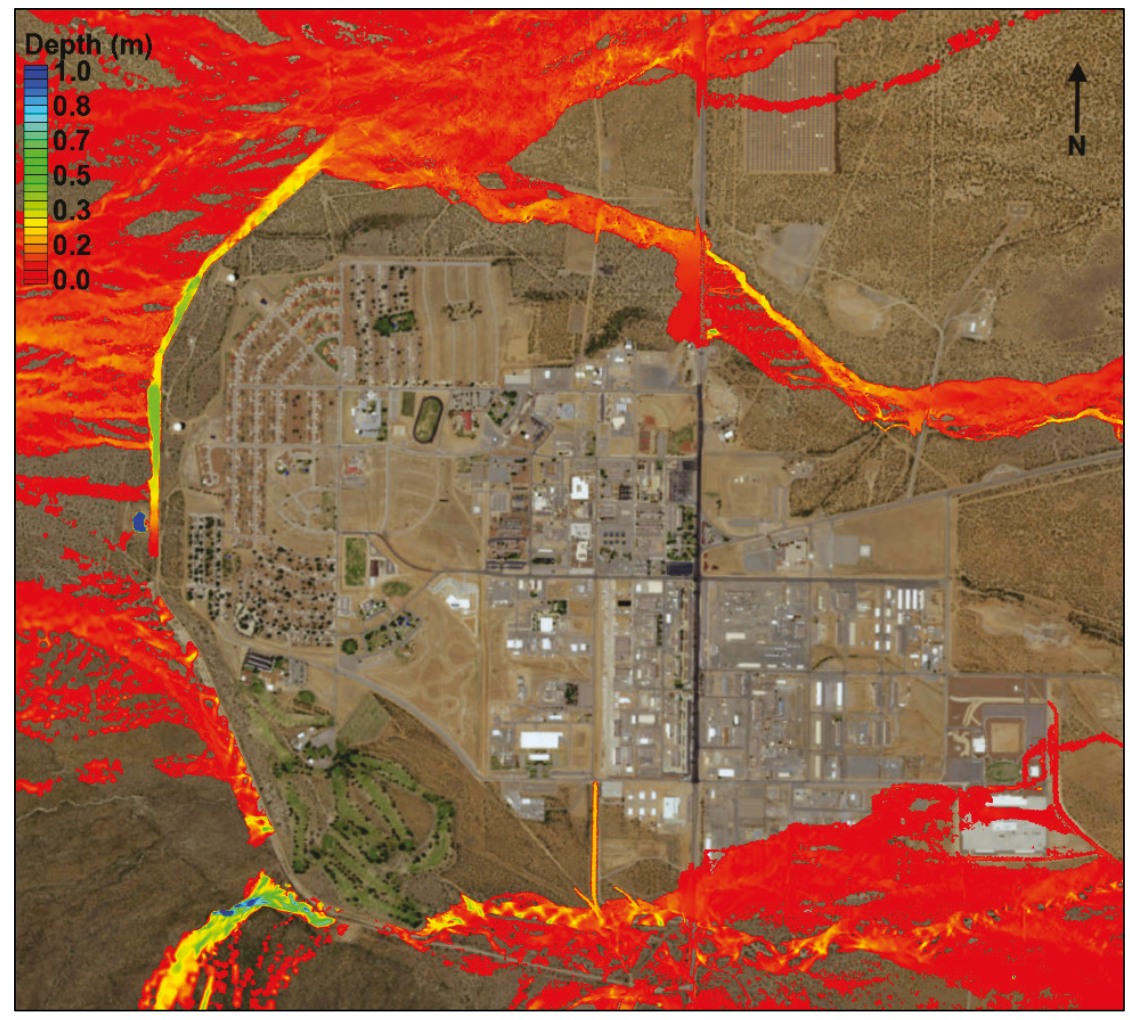

Figure 54. Sensitivity A - Alternative 1 difference plot, 500-year event.

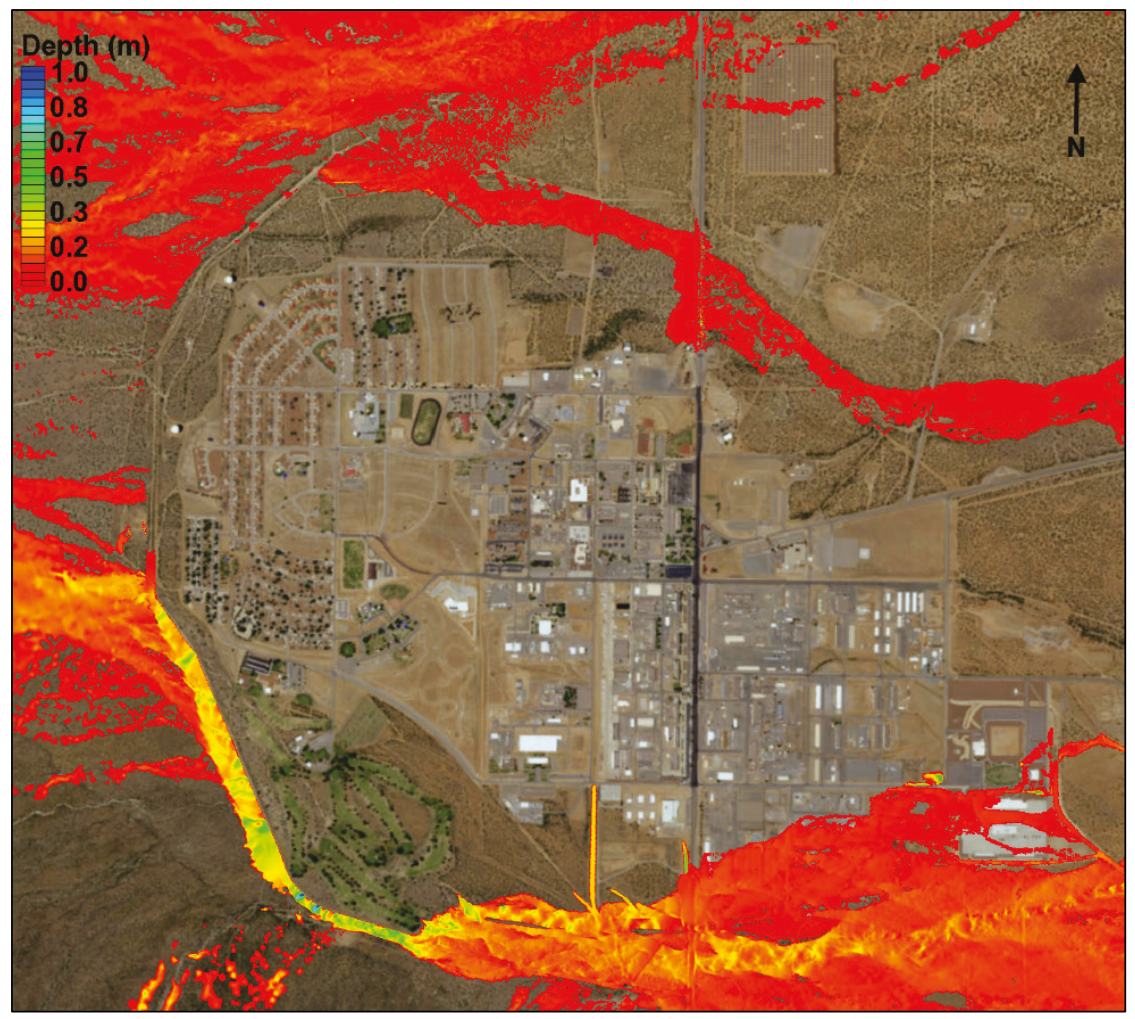


Figure 55. Sensitivity $B(n=0.025)$ results, 1978-year event.

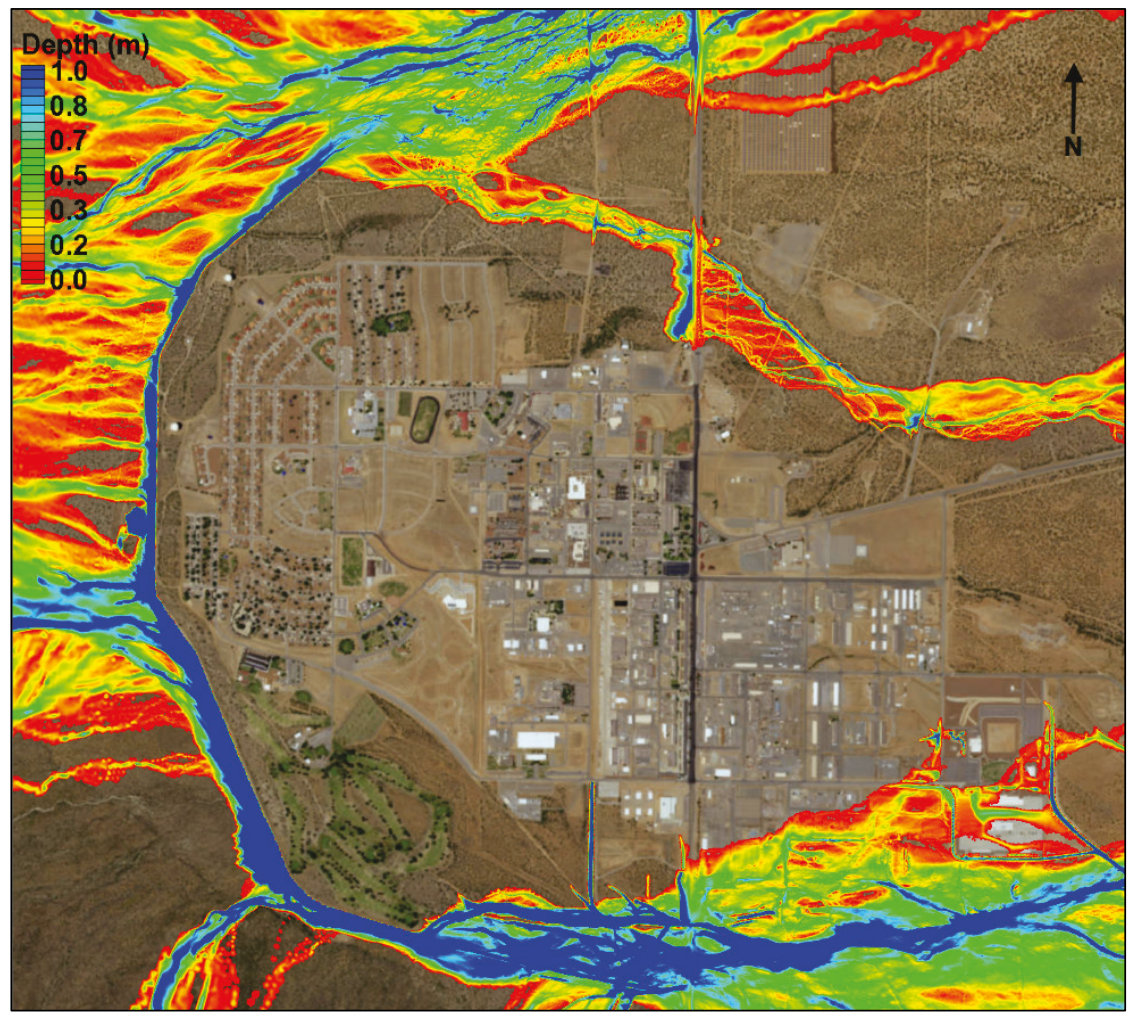

Figure 56. Sensitivity A ( $n=0.035)$ results, 1978-year event.

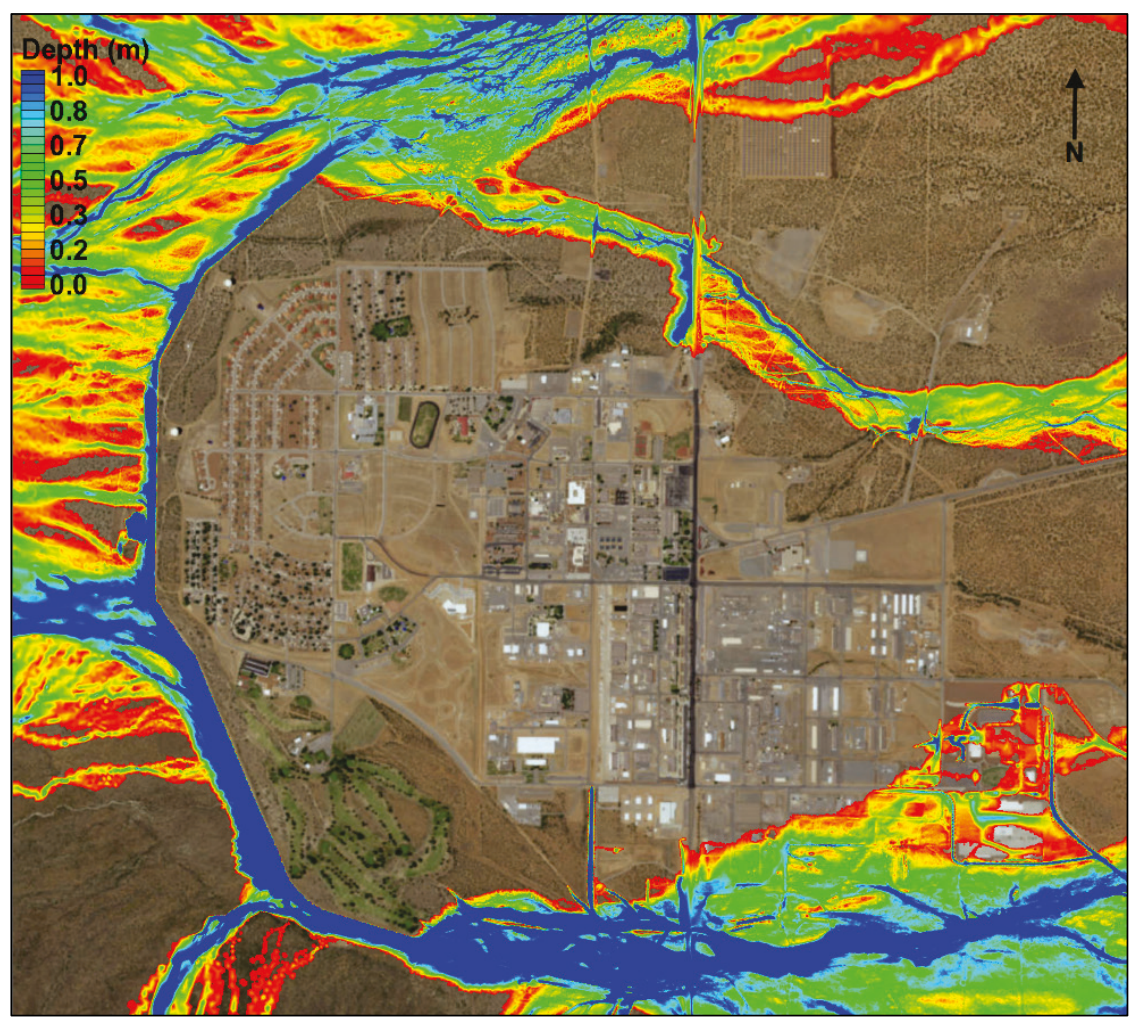


Figure 57. Alternative 1 - Sensitivity B difference plot, 1978-year event.

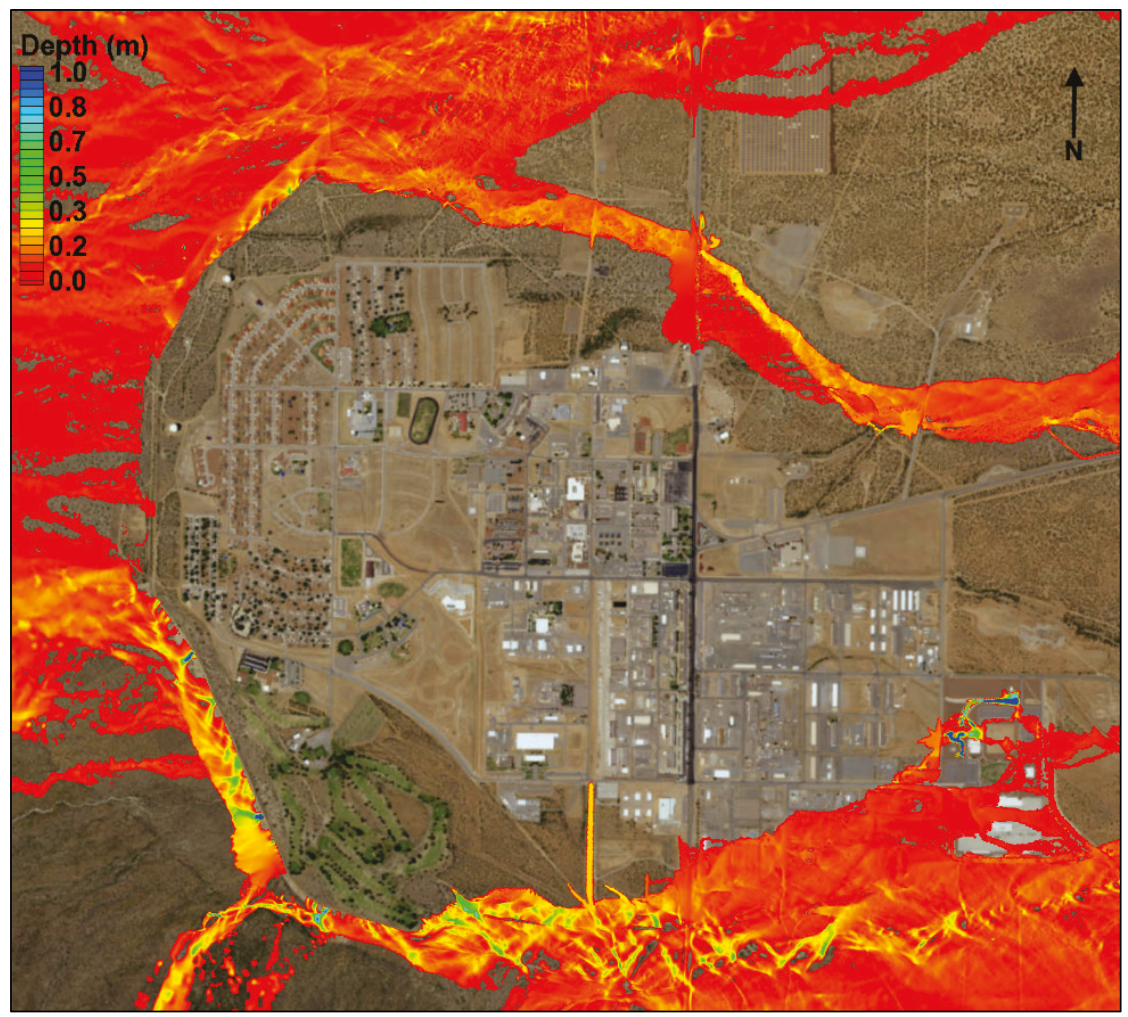

Figure 58. Sensitivity A - Alternative 1 difference plot, 1978-year event.

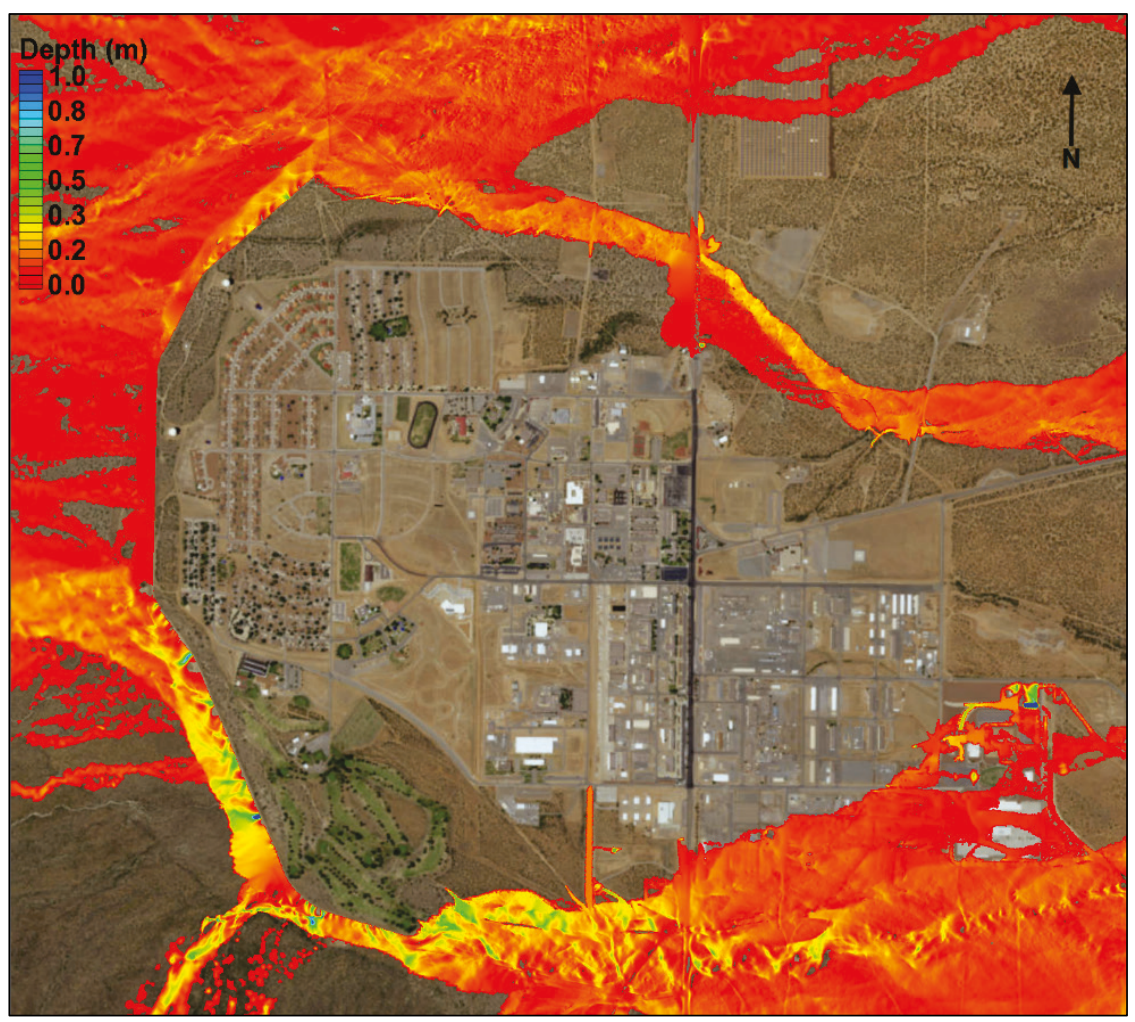




\section{Conclusions}

Table 3 details each of the alternative simulations. Refer to Table 2 for a summary of the general levee modifications (height adjustment) needed to prevent the installation from flooding.

Table 3. Specifics of each alternative.

\begin{tabular}{|l|l|}
\hline Alternative & Description \\
\hline Alternative 1 & $\begin{array}{l}\text { Existing levee (approximately } 3.55 \mathrm{~km} \text { ) was turned off in the model } \\
\text { to assess the water depth at the crest of the existing levee. }\end{array}$ \\
\hline Alternative 2A & $\begin{array}{l}\text { An extension of Alternative 1 in that the same existing levee } \\
\text { boundary was kept in position. There was an additional section of } \\
\text { levee in the North Arroyo area (approximately 1.4 km) that was also } \\
\text { turned off and did not allow water to overtop. }\end{array}$ \\
\hline Alternative 2B & $\begin{array}{l}\text { Included further levee modifications to Alternatives 1 and 2A with } \\
\text { the adjustment to the north levee addition to achieve more } \\
\text { functionality and efficiency (approximately 1.4 km; turned off to } \\
\text { prevent overtopping). }\end{array}$ \\
\hline Alternative 2C & $\begin{array}{l}\text { Incorporated Alternative 2B modifications as well as the addition of } \\
\text { a standalone southern-based levee (approximately 1.9 km; turned } \\
\text { off to prevent overtopping). }\end{array}$ \\
\hline
\end{tabular}

Three different storm event hydrographs were simulated with the existingconditions model and each proposed alternative model. The existingconditions model simulation and the proposed model alternative simulations provided insight to several issues:

- The existing conditions show flooding within the installation will occur for a 100-year, or greater, rainfall event. The 100-year event runoff from the Organ Mountains overtops the levee surrounding the installation on its western face. The amount of flooding that will inundate the WSMR increases with the amount of precipitation that the drainage basin receives.

- The sensitivity analysis helped to confirm the model's accurate representation of the domain and the hydraulic behavior of the model. Consistent results with changes to the surface roughness in the model reinforces this conclusion. More flooding occurred with higher values of Manning's roughness coefficients.

- The existing-conditions levee is sufficient in most locations to protect against the 100-year storm event.

- Alternative 1 allowed no water to enter the WSMR. This alternative represents raising the existing levee elevations sufficiently higher than 
the flood water surfaces. This simulation demonstrated where the existing levee would be overtopped for the three storm events.

- Alternative 2A helped protect the northern area of White Sands from inundation past the levee. The southern portion of the installation was still susceptible to flooding.

- Alternative 2B also protected White Sands from flooding in the northern portion of the installation. An addition was added to the proposed Alternative $2 \mathrm{~A}$ in this simulation in which water was being held much like a detention pond area. The southern part of the WSMR was again susceptible to flooding.

- Alternative $2 \mathrm{C}$ showed the least amount of flooding as an added levee at the southern portion of the installation completely protected WSMR from inundation.

Based on the alternative simulations, Alternative $2 \mathrm{C}$ provided the most comprehensive protection. This alternative will potentially mitigate flooding on the WSMR installation. 


\section{References}

Arcement, G. J., and V. R. Schneider. 1989. Guide for Selecting Manning's Roughness Coefficients for Natural Channels and Flood Plains. Water Supply Paper. Washington, DC: U.S. Dept. of Interior, U.S. Geological Survey. https://pubs.er.usgs.gov/publication/wsp2339

Chow, V. T. 1959. Open Channel Hydraulics. New York: McGraw-Hill.

Jacobs/Huitt-Zollars. 2009. 2009 Infrastructure Report: Storm Water Drainage Study for BCT (Heavy). PN 71258, FY 2010. White Sands Missile Range.

Sharp, J. A., S. Scott, M. Jourdan, and G. Savant. 2012. Camp Marmal Flood Study. ERDC/CHL TR-12-5. Vicksburg, MS: U.S. Army Engineer Research and Development Center.

U.S. Army Corps of Engineers (USACE). 2015. Adaptive Hydraulics (AdH) Version 4.5 Hydrodynamic User Manual. Vicksburg, MS: U.S. Army Engineer Research and Development Center. https://chl.erdc.dren.mil/adh/main/index.html

White, E. 1978. Saturday night's storm broke rainfall records, caused damage worth 'several million dollars.' The Missile Ranger, August 25, 1978. http://www.wsmrhistoric.com/files/1978\%20Missile\%20Ranger\%20V30\%20lssue\%2015.pdf

White, E. 1979. Road to be renamed for Owen who died in last year's flood. The Missile Ranger, June 8, 1979. http://wsmrhistoric.com/files/1979\%20Missile\%20Ranger\%20V30\%20lssue\%2022.pdf 


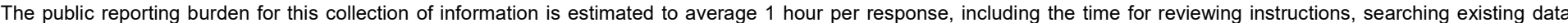

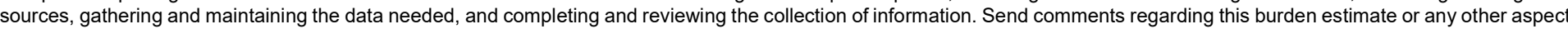

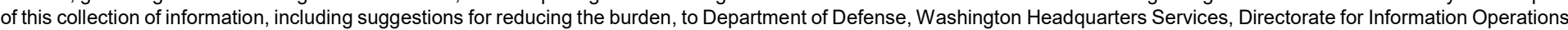

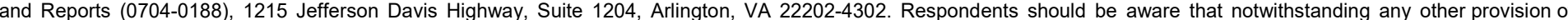
law, no person shall be subject to any penalty for failing to comply with a collection of information if it does not display a currently valid OMB control number. PLEASE DO NOT RETURN YOUR FORM TO THE ABOVE ADDRESS.

\begin{tabular}{l|l|l}
$\begin{array}{l}\text { 1. REPORT DATE } \\
\text { December } 2018\end{array}$ & $\begin{array}{l}\text { 2. REPORT TYPE } \\
\text { Final Report }\end{array}$ & 3. DATES COVERED (FrOm - To)
\end{tabular}

\section{TITLE AND SUBTITLE}

Hydraulic Modeling of Extreme Flows for the White Sands Missile Range Using Adaptive Hydraulics $(\mathrm{AdH})$

\section{5a. CONTRACT NUMBER}

5b. GRANT NUMBER

5c. PROGRAM ELEMENT NUMBER

5d. PROJECT NUMBER 10754978

5e. TASK NUMBER

5f. WORK UNIT NUMBER

8. PERFORMING ORGANIZATION REPORT NUMBER

Coastal and Hydraulics Laboratory

U.S. Army Engineer Research and Development Center

3909 Halls Ferry Road

Vicksburg MS, 39180-6199

ERDC/CHL TR-18-17

10. SPONSOR/MONITOR'S ACRONYM(S)

9. SPONSORING/MONITORING AGENCY NAME(S) AND ADDRESS(ES)

U.S. Army, White Sands Missile Range

White Sands, NM 88002-5070

11. SPONSOR/MONITOR'S REPORT NUMBER(S)

12. DISTRIBUTION/AVAILABILITY STATEMENT

Approved for public release; distribution is unlimited.

\section{SUPPLEMENTARY NOTES}

\section{ABSTRACT}

The River Engineering Branch of the U.S. Army Engineer Research and Development Center, Coastal and Hydraulics Laboratory, conducted a two-dimensional numerical model investigation of the White Sands Missile Range located approximately 24.1 kilometers east of Las Cruces, NM. The range has experienced flooding within the installation during past large rainstorm events. The floodwater flowing easterly from the Organ Mountains overtops the levee that protects the installation for extreme events in some locations. The installation becomes more flooded with increasing values of storm return period (e.g., 100-year, 500-year). Plans consist of raising the levee elevation in critical locations as well as extending the levee in other areas. Numerical calculations indicated that raising the existing levee by approximately 0.5 meter and adding an extension on the northern portion of the installation as well as a standalone levee south of the installation eliminated flooding from 100-year events.

\section{SUBJECT TERMS}

Flood control, Hydraulic models, Rain and rainfall, Rainstorms, White Sands Missile Range (N.M.)--Hydrology

16. SECURITY CLASSIFICATION OF:

\begin{tabular}{l|l|l|}
\hline a. REPORT & b. ABSTRACT & c. THIS PAGE \\
Unclassified & Unclassified & Unclassified
\end{tabular}

17. LIMITATION OF ABSTRACT

SAR
18. NUMBER OF 19a. NAME OF RESPONSIBLE PERSON PAGES Gary Bell

54 19b. TELEPHONE NUMBER (Include area code) 601-634-4621 